\title{
Etiology and Pharmacology of Neuropathic Pain
}

\author{
Sascha R. A. Alles ${ }^{1}$ and Peter A. Smith \\ Michael Smith Laboratories and Djavad Mowafaghian Centre for Brain Health, University of British Columbia, Vancouver, British \\ Columbia, Canada (S.R.A.A.); and Neuroscience and Mental Health Institute and Department of Pharmacology, University of Alberta, \\ Edmonton, Alberta, Canada (P.A.S.)
}

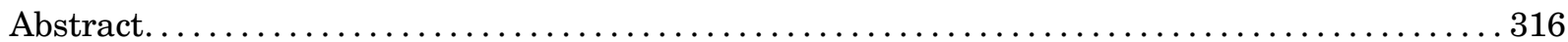

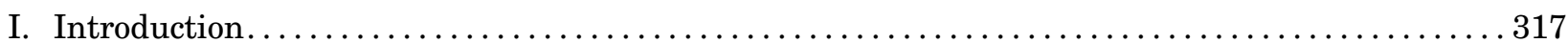

A. Clinical Presentation and Pharmacotherapy of Neuropathic Pain . . . . . . . . . . . . . . 317

B. Organization of the Spinal Dorsal Horn . . . . . . . . . . . . . . . . . . . . . . . . . 318

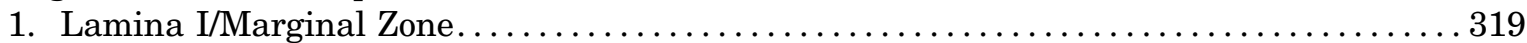

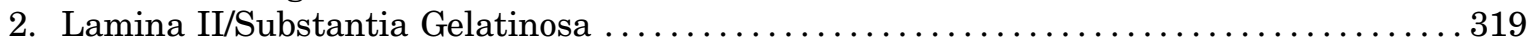

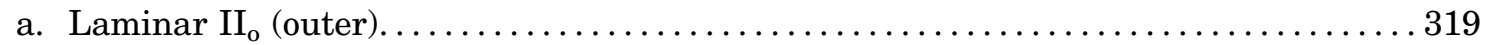

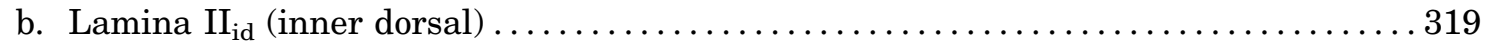

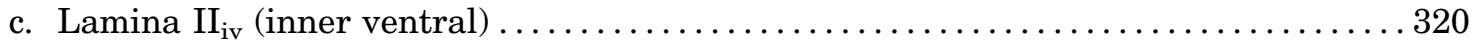

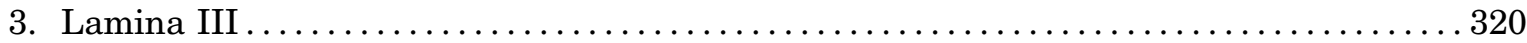

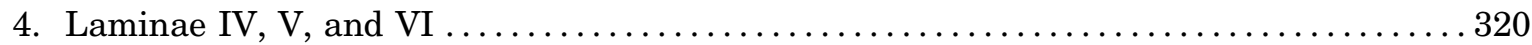

II. Mechanisms of Neuropathic Pain and Potential Therapeutic Targets . . . . . . . . . . . . . 320

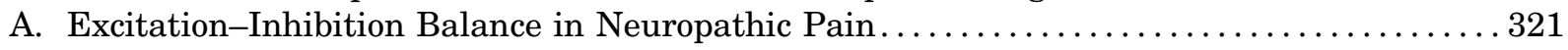

B. The Colony-Stimulating Factor 1, Microglia, Purinergic Ionotropic 2X4, ATP, Brain-

Derived Neurotrophic Factor, GABA-Chloride Cascade ........................ 322

1. Brain-Derived Neurotrophic Factor and a Shift in Neuronal Chloride Gradient ....... 322

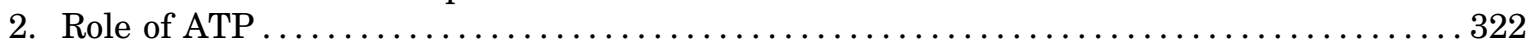

3. Signaling between Injured Peripheral Nerve and Spinal Microglia............... 322

4. Source of ATP in Central Sensitization ................................ 323

C. Increased Excitatory Drive to Excitatory Neurons and Decreased Excitatory Drive to

Inhibitory Neurons . . . . . . . . . . . . . . . . . . . . . . . . . . . . . . . . . 323

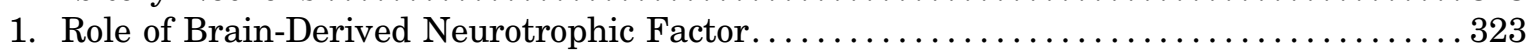

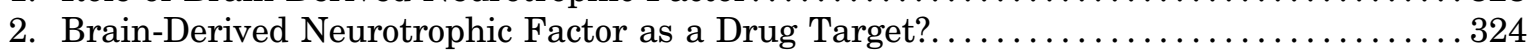

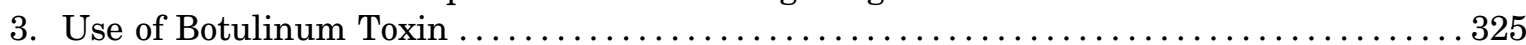

D. Altered Sensory Processing and Generation of Allodynia....................... 325

1. Mechanosensitive Ion Channels as Therapeutic Targets ....................... 325

2. Potentiation of GABA or Glycine as Therapeutic Targets . . . . . . . . . . . . . . 326

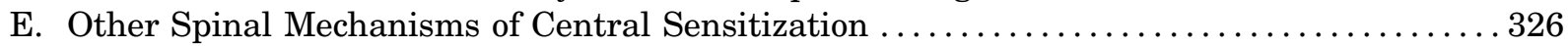

1. Long-Term Potentiation and Memory Processes......................... 326

2. Role of Astrocytic Glutamate Transporter (Excitatory Amino Acid Transporter 2) . . . 326

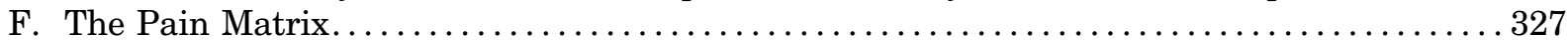

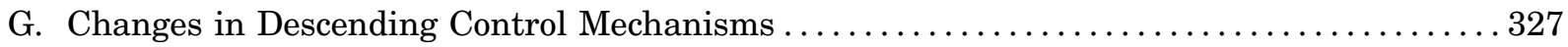

H. Role of Mesolimbic Reward Circuitry.................................... 327

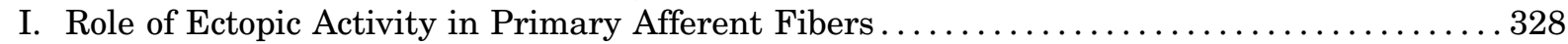

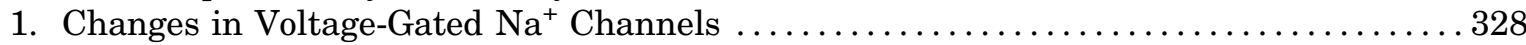

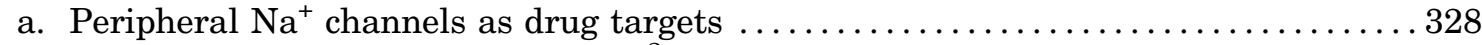

2. Changes in High Voltage-Activated $\mathrm{Ca}^{2+}$ Channels $\left(\mathrm{Ca}_{\mathrm{v}} 1\right.$ and $\left.\mathrm{Ca}_{\mathrm{v}} 2\right) \ldots \ldots \ldots \ldots \ldots . \ldots 328$

Address correspondence to: Dr. Peter A. Smith, Department of Pharmacology and Neuroscience and Mental Health Institute, 9.75 Medical Sciences Building, University of Alberta, Edmonton, AB T6G 2H7, Canada. E-mail: pas3@ualberta.ca

This work was supported by grants from Pfizer Canada (Neuropathic Pain Research Awards), Paralyzed Veterans of America, and Natural Sciences and Engineering Research Council.

${ }^{1}$ Current affiliation: Molecular Nociception Group, Wolfson Institute for Biomedical Research, University College London, London, United Kingdom.

https://doi.org/10.1124/pr.117.014399. 


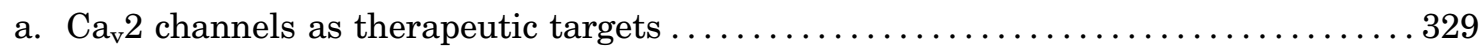

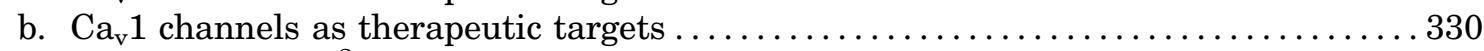

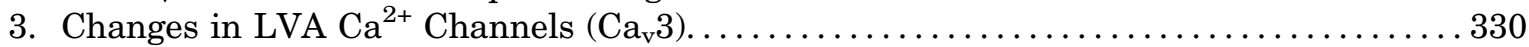

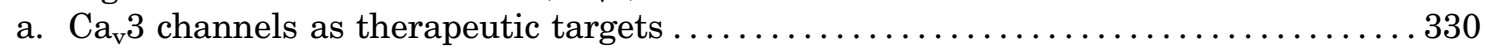

4. Changes in Hyperpolarization-Activated Cyclic Nucleotide-Gated Channels ......... 330

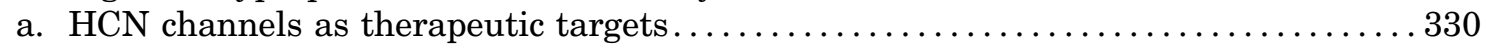

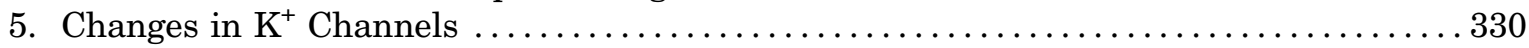

6. Changes in Transient Receptor Potential Channels ......................... 331

a. Transient receptor potential type V1 channels as therapeutic targets-capsaicin and transient receptor potential channel type $\mathrm{V} 1$ antagonists ................ 331

b. Transient receptor potential type V1 channels as therapeutic targetsangiotensin receptor type 2 receptor antagonists ......................... 331

J. Neuroimmune Interactions in Neuropathic Pain. . . . . . . . . . . . . . . . . . . . . . 331

K. Adenosine A3 Receptors as a Therapeutic Target............................ 332

III. Current Therapeutic Management of Neuropathic Pain: Focus on Gabapentinoids ............ 332

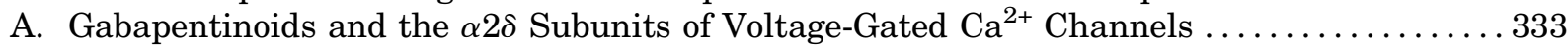

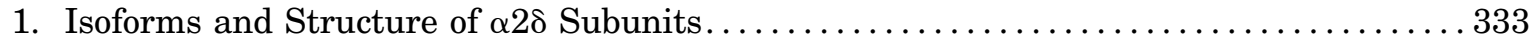

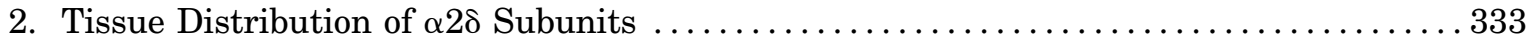

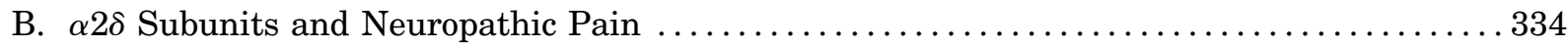

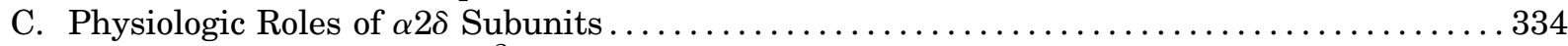

1. Rapid Trafficking of $\mathrm{Ca}^{2+}$ Channel $\alpha$ Subunits to the Plasma Membrane ........... 334

2. Slower Trafficking of $\mathrm{Ca}^{2+}$ Channel $\alpha$ Subunits to Primary Afferent Terminals ....... 334

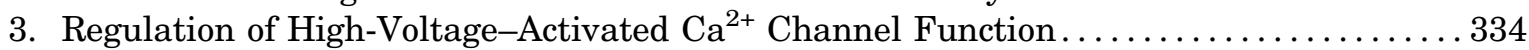

4. Setting Neurotransmitter Release Probability ............................ 336

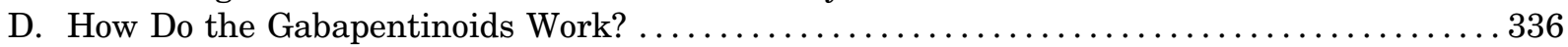

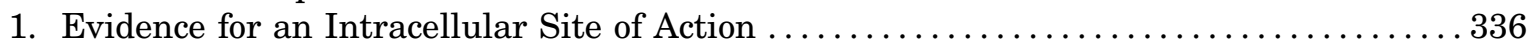

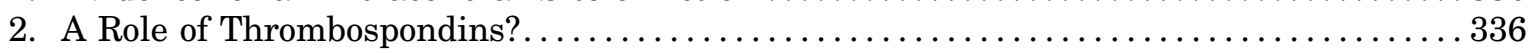

3. Rapid and Slow Actions in the Spinal Dorsal Horn ....................... 336

4. Differential Effects of Gabapentinoids on Excitatory and Inhibitory Processes in the

Substantia Gelatinosa ................................................ 337

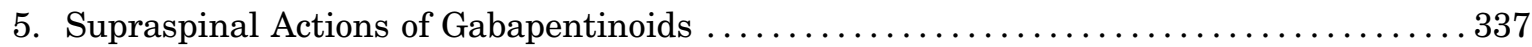

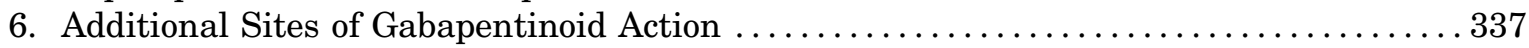

E. Doses of Gabapentinoids Used in Animal Studies and Relationship to Clinical Studies .... 338

IV. Basic Science of Gabapentinoid Action and Observations in the Clinic ................. 338

A. Inconsistency of Gabapentinoid Effectiveness............................... 338

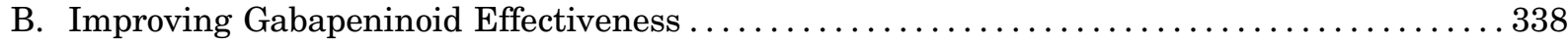

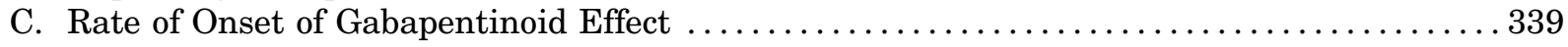

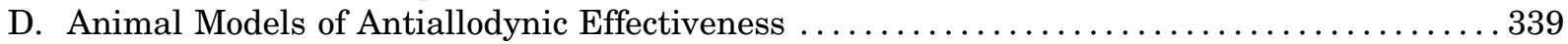

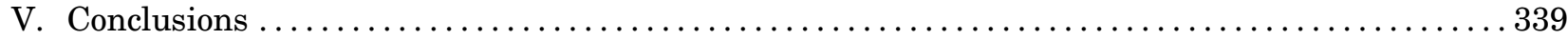

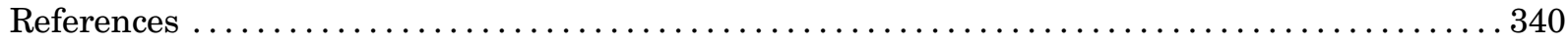

Abstract-Injury to or disease of the nervous system can invoke chronic and sometimes intractable neuropathic pain. Many parallel, interdependent, and time-dependent processes, including neuroimmune interactions at the peripheral, supraspinal, and spinal levels, contribute to the etiology of this “disease of pain." Recent work emphasizes the roles of colony-stimulating factor 1 , ATP, and brain-derived neurotrophic factor. Excitatory processes are enhanced, and inhibitory processes are attenuated in the spinal dorsal horn and throughout the

\footnotetext{
ABBREVIATIONS: AMPA, $\alpha$-amino-3-hydroxy-5-methyl-4-isoxazolepropionic acid; AT2, angiotensin receptor type 2; BCH, 2-(-)-endoamino-bicycloheptene-2-carboxylic acid; BDNF, brain-derived neurotrophic factor; $\mathrm{Ca}_{\mathrm{v}} 1, \mathrm{Ca}_{\mathrm{v}} 2, \mathrm{Ca}_{\mathrm{v}} 3$, voltagae gated $\mathrm{Ca}^{+}$channels types 1, 2 and 3; CB2, cannabinoid receptor 2; CCI, chronic constriction injury; CCL, chemokine (C-C motif) ligand; CNS, central nervous system; CSF-1, colony-stimulating factor 1; DRG, dorsal root ganglion; EAAT2, excitatory amino acid transporter 2; GBP, gabapentin; GLT-1, glutamate-transporter-1; HCN, hyperpolarization-activated cyclic nucleotide gated; HVA, high voltage activated; IB4, isolectin B4; $\mathrm{I}_{\mathrm{Ca}}$, calcium channel current; IL, interluekin; KCC2, potassium-chloride exporter 2; LTP, long-term potentiation; LVA, low voltage activated; mEPSC, miniature excitatory postsynaptic current; MIDAS, metal ion-dependent adhesion site; $\mathrm{Na}_{\mathrm{v}} 1.7, \mathrm{Na}_{\mathrm{v}} 1.8, \mathrm{Na}_{\mathrm{v}} 1.9$, voltage gated sodium channels types 1.7, 1.8 and 1.9; NMDA, N-methyl D-aspartate; NPY, neuropeptide Y; P2X4R, purinergic ionotropic receptor 2X4; PGB, pregabalin; sEPSC, spontaneous excitatory postsynaptic current; STOML-3, stomatin-like protein 3; TLR5, Toll-like receptor 5; TNF, tumor necrosis factor; TrkB, tropomyosin receptor kinase B; TRP, transient receptor potential; TRPM8, TRP channel type M8; TRPV1, TRP channel type V1; TSP, thrombospondin; VGCC, voltage-gated calcium channel; VNUT, vesicular nucleotide transporter; VWA, Von Willebrand Factor A.
} 
somatosensory system. This leads to central sensitization and aberrant processing such that tactile and innocuous thermal information is perceived as pain (allodynia). Processes involved in the onset of neuropathic pain differ from those involved in its long-term maintenance. Opioids display limited effectiveness, and less than 35\% of patients derive meaningful benefit from other therapeutic approaches. We thus review promising therapeutic targets that have emerged over the last 20 years, including $\mathrm{Na}^{+}, \mathrm{K}^{+}$, $\mathrm{Ca}^{2+}$, hyperpolarization-activated cyclic nucleotide-gated channels, transient receptor potential channel type V1 channels, and adenosine A3 receptors. Despite this

\section{Introduction}

\section{A. Clinical Presentation and Pharmacotherapy of Neuropathic Pain}

Pain is the most common reason for people to seek medical attention (Salter, 2014). Despite this, nociceptive pain is a vital physiologic process that signals actual or potential tissue damage (Iadarola and Caudle, 1997). By so doing, it protects the individual from injury and secures the survival of the species. By contrast, direct injury to neural tissue can produce nerve or neuropathic pain that lasts for months or years after any injury has healed (Costigan et al., 2009b; Moulin et al., 2014). Exact prevalence of neuropathic pain within the global population is unknown, but most studies put estimates at between $1.5 \%$ and $8 \%$, equating to between 100 million and 560 million people worldwide (Gilron et al., 2006; Torrance et al., 2006, 2013; Salter, 2014; Bouhassira and Attal, 2016).

Neuropathic pain is defined formally as "pain caused by a lesion or disease of the somatosensory system" (Jensen et al., 2011). It can be caused by traumatic nerve, spinal cord, or brain injury (including stroke) or can be associated with diabetic, human immunodeficiency virus/AIDS, and postherpetic neuropathies, or with multiple sclerosis (Treede et al., 2008) or cancer, and/or the toxic effects of chemotherapeutic agents (Xiao et al., 2007; Schmidt et al., 2010).

Clinical diagnosis of neuropathic pain depends on evaluation of the following criteria: 1) pain with a distinct neuroanatomical distribution, 2) a medical history that suggests a lesion or disease of the nervous system, 3) a confirmatory test to demonstrate neuroanatomical distribution, and 4) a confirmatory test to demonstrate a lesion or disease of the nervous system (Treede et al., 2008). Definite neuropathic pain is categorized as fulfilling all of these criteria, whereas probable neuropathic pain is categorized as fulfilling criteria 1 and 2 without evidence from 3 to 4 . There has been an increasing awareness of neuropathic pain in the scientific literature over the past 40 years, suggesting that it is more commonplace than previously thought. The prevalence of the phrase neuropathic pain in books as measured using Google "Ngram" Viewer has increased more than fourfold between 1992 and 2008. progress, the gabapentinoids retain their status as first-line treatments, yet their mechanism of action is poorly understood. We outline recent progress in understanding the etiology of neuropathic pain and show how this has provided insights into the cellular actions of pregabalin and gabapentin. Interactions of gabapentinoids with the $\alpha 2 \delta$-1 subunit of voltage-gated $\mathrm{Ca}^{2+}$ channels produce multiple and neuron typespecific actions in spinal cord and higher centers. We suggest that drugs that affect multiple processes, rather than a single specific target, show the greatest promise for future therapeutic development.
The various manifestations of neuropathic pain are notoriously resistant to the actions of nonsteroidal antiinflammatory drugs and opioids (Yekkirala et al., 2017). In stark contrast to the profound effectiveness of opioids in nociceptive pain, there is no similar panacea for the treatment of neuropathic pain. Any pain that is opioid resistant is likely neuropathic. A recent meta-analysis of clinical trial data (Finnerup et al., 2015) supported the use of tricyclic antidepressants, serotonin-noradrenaline uptake inhibitors such as duloxetine and the gabapentinoids, pregabalin (PGB), and gabapentin (GBP) as first-line treatments. Tramadol and controlled-release opioids are recommended as second-line treatments and cannabinoids as third-line treatments. Fourthline treatments include methadone, lamotrigine, lacosamide, tapentadol, and botulinum toxin (Moulin et al., 2014). Other drugs in current clinical use include carbemazepine, lidocaine patch, capsaicin patch, and ziconotide (Table 1).

Barriers to the development of effective new treatments include the diversity of pathophysiological situations, different pain etiologies, genetic predispositions (Mogil, 2012a; Zorina-Lichtenwalter et al., 2016; Sexton et al., 2017), and different ethnicities (Hastie et al., 2012) encountered in the clinic. This is compounded by epigenetic modifications in humans (Stone and Szyf, 2013) and by the limited ability of rodent models to predict clinical efficacy (Mogil, 2017; Patel et al., 2017; Sexton et al., 2017; Yekkirala et al., 2017). Despite the realization that pain processing in males differs from that in females (Mogil, 2012b; Mifflin and Kerr, 2013; Sorge et al., 2015; Dodds et al., 2016; Melchior et al., 2016; Dickie et al., 2017; Sorge and Totsch, 2017), many preclinical studies have been done on male rodents to avoid possible complications imposed by the estrous cycle. It is also established that neonatal injury can affect manifestation of pain in adults (Beggs et al., 2012a). Lastly, ongoing and/or paroxysmal stimulusindependent pain is a major issue with patients, but this is difficult to assess in animal models (Calvo et al., 2012).

Despite these issues, recent advances in understanding the etiology of neuropathic pain have paved the way for development of new therapeutic approaches. At present, however, none of these rationally developed 
TABLE 1

Drugs currently used in the clinical management of neuropathic pain

\begin{tabular}{|c|c|c|}
\hline Drug & Target & Status \\
\hline $\begin{array}{l}\text { Gabapentinoids (pregabalin, } \\
\text { gabapentin) }\end{array}$ & $\begin{array}{l}\alpha 2 \delta-1 \text { auxiliary subunit of voltage-gated } \mathrm{Ca}^{2+} \\
\text { channels }\end{array}$ & First-line treatment (Finnerup et al., 2015) \\
\hline $\begin{array}{l}\text { Tricyclic antidepressants } \\
\text { (amitriptyline) }\end{array}$ & Noradrenaline/Serotonin uptake systems & First-line treatment (Finnerup et al., 2015) \\
\hline $\begin{array}{l}\text { Noradrenaline/Serotonin uptake } \\
\text { inhibitors (duloxetine) }\end{array}$ & Noradrenaline/Serotonin uptake systems & First-line treatment (Finnerup et al., 2015) \\
\hline Tramadol & $\begin{array}{l}\text { Opioid receptors and noradrenaline/serotonin } \\
\text { uptake systems }\end{array}$ & Second-line treatment (Moulin et al., 2014) \\
\hline Controlled release opioids & Opioid receptors & Second-line treatment (Moulin et al., 2014) \\
\hline Cannabinoids & $\mathrm{CB} 1$ and $\mathrm{CB} 2$ receptors & Third-line treatment (Moulin et al., 2014) \\
\hline Botulinum toxin & Neurotransmitter release & Fourth-line treatment (Moulin et al., 2014) \\
\hline Methadone & Opioid and NMDA receptors & Fourth-line treatment (Moulin et al., 2014) \\
\hline Lamotrigine & $\begin{array}{l}\text { Voltage-gated } \mathrm{Na}^{+} \text {channels; L-, P-, and N-type } \mathrm{Ca}^{2+} \\
\text { channels }\end{array}$ & Fourth-line treatment (Moulin et al., 2014) \\
\hline Lacosamide & Slow inactivation of voltage-gated $\mathrm{Na}^{+}$channels & Fourth-line treatment (Moulin et al., 2014) \\
\hline Tapentadol & $\begin{array}{l}\mu \text {-Opioid receptors and noradrenaline uptake } \\
\text { system }\end{array}$ & Fourth-line treatment (Moulin et al., 2014) \\
\hline Carbemazepine & Voltage-gated $\mathrm{Na}^{+}$channels and $\mathrm{GABA}_{\mathrm{A}}$ receptors & $\begin{array}{l}\text { Use primarily restricted to trigeminal neuralgia } \\
\text { (Demant et al., 2014) }\end{array}$ \\
\hline $\begin{array}{l}\text { Ziconotide (synthetic } \omega \text {-conotoxin } \\
\text { MVIIA) }\end{array}$ & N-type voltage-gated $\mathrm{Ca}^{2+}$ channels & $\begin{array}{l}\text { Administered intrathecally when other treatments } \\
\text { fail (McGivern, 2007) }\end{array}$ \\
\hline Ketamine & NMDA receptors & $\begin{array}{l}\text { Sometimes used clinically (Niesters et al., 2014; } \\
\quad \text { Maher et al., 2017) }\end{array}$ \\
\hline Lidocaine patch & Voltage-gated $\mathrm{Na}^{+}$channels & In clinical use (Finnerup et al., 2015) \\
\hline Capsaicin patch & TRPV1 channels & In clinical use (Dworkin et al., 2007) \\
\hline
\end{tabular}

compounds have attained the status of monoamine uptake inhibitors and gabapentinoids as first-line treatments. Several reviews of the pharmacotherapy of neuropathic pain have appeared in the last few years; some are broadly based (Kremer et al., 2016; Yekkirala et al., 2017), whereas others discuss the use of specific agents such as cannabinoids (Luongo et al., 2017), amitriptyline (Moore et al., 2015), $\mathrm{Ca}^{2+}$ and/or $\mathrm{Na}^{+}$ channel blockers (Waxman and Zamponi, 2014; Zamponi et al., 2015; Patel et al., 2017), and agents that potentiate GABAergic inhibition (Zeilhofer et al., 2012a).

Because gabapentinoids were originally developed as anticonvulsant agents (Offord and Isom, 2015), much is still to be learned about the mechanism of their antiallodynic effect (Bannister et al., 2017b). This means that the drugs that are used most frequently are the least well understood. In the following sections, we will overview recent advances in understanding the etiology of pain and how it has led to rational drug development and to a further, yet incomplete, understanding of gabapentinoid action.

\section{B. Organization of the Spinal Dorsal Horn}

Although a full description of the organization of the dorsal horn is beyond the scope of the present review, the following paragraphs provide background to recent advances in the understanding of spinal mechanisms that initiate neuropathic pain. We will show how these insights have led to the identification of therapeutic targets and to improved understanding of gabapentinoid action. For additional information on dorsal horn organization and nociceptive processing, the reader is referred to recent reviews (Braz et al., 2014; Peirs et al.,
2015; Cordero-Erausquin et al., 2016; Peirs and Seal, 2016; Abraira et al., 2017; Todd, 2017) and original papers (Lu and Perl, 2003, 2005; Santos et al., 2007; Yasaka et al., 2010).

Tissue damage or perturbation capable of causing pain is detected by free nerve endings in peripheral and visceral structures and relayed by first-order sensory neurons (primary afferents) to second-order sensory neurons in the dorsal horn of the spinal cord. Glutamate and neuropeptides such as substance $\mathrm{P}$ and calcitonin gene-related peptide mediate neurotransmission between primary afferent and second-order sensory neurons. Glutamate interacts with $\mathrm{Ca}^{2+}$-permeable and $\mathrm{Ca}^{2+}$-impermeable $\alpha$-amino-3-hydroxy-5-methyl-4-isoxazolepropionic acid (AMPA) and with N-methyl D-aspartate (NMDA) receptors, but not with kainate receptors (Tong and MacDermott, 2006). The cell bodies of first-order sensory neurons reside in the dorsal root ganglia (DRG).

Although all primary afferent neurons are widely believed to be glutamatergic (West et al., 2015), it has been suggested that GABA-mediated inhibitory interactions may play a role in nociceptive processing at the level of the DRG (Du et al., 2017). If these findings are verified, they will provoke considerable debate and reassessment of current ideas of sensory and nociceptive processing. It is possible that primary afferent neurons release GABA from their cell bodies in DRG, yet release glutamate from their terminals in the spinal cord.

The gray matter of the spinal cord is divided into the 10 laminae of Rexed (Fig. 1A) (Rexed, 1952). Nociceptive information is received in lamina I, lamina II (substantia gelatinosa; Fig. 1, A and B), and, to a lesser extent, 
A

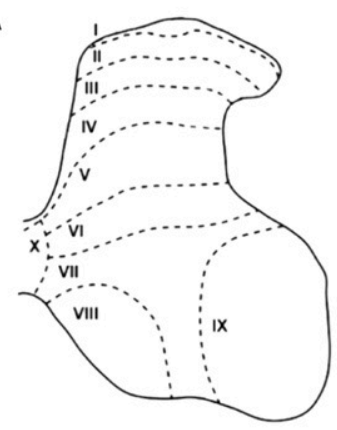

B Rat spinal cord in vitro

C

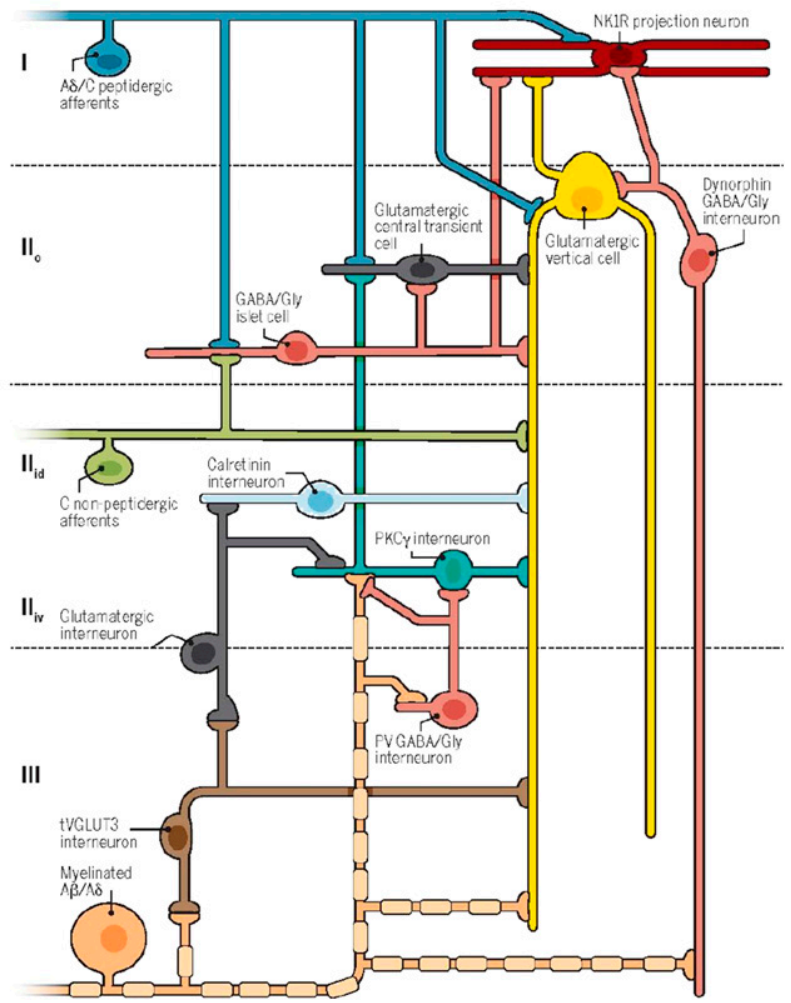

Fig. 1. (A) Rexed laminae of the spinal cord. Laminae I and II form the marginal zone and substantia gelatinosa, respectively, and together these make up the superficial dorsal horn. Within the dorsal horn, $\mathrm{A} \beta$ tactile and hair afferents end mainly in laminae III-VI with some extension into lamina IIi with distribution dependent on function. A $\delta$ hair-follicle afferents extend across the lamina II/III border. A $\delta$ nociceptors end mainly in lamina I, occasionally branching to laminae $\mathrm{V}$ and $\mathrm{X}$. Peptidergic, nociceptive $\mathrm{C}$ fiber afferents synapse mainly in lamina I and IIo. Nonpeptidergic C fibers occupy the inner part of lamina II. (B) Acutely isolated spinal cord slice from a 30-day-old rat. The substantia gelatinosa is clearly visible as a translucent band under infrared differential interference contrast optics. (C) Diagram to illustrate the principal synaptic connections in the superficial dorsal horn. From Peirs and Seal (2016). Reprinted with permission from American Association for the Advancement of Science.

lamina V (Todd, 2010; Zeilhofer et al., 2012b; West et al., 2015; Peirs and Seal, 2016). Although lamina I contains interneurons for modulation and projection neurons for transmission of nociceptive information, lamina II contains mainly interneurons that project to lamina I. In spite of its importance, there is still very much that is unknown about dorsal horn circuitry and how it relates to the pathophysiology of chronic pain (Sandkuhler,
2009; Todd, 2010; Prescott et al., 2014; Peirs and Seal, 2016). Aspects of dorsal horn physiology and organization that are salient to pain etiology, drug development, and gabapentinoid action are described below.

1. Lamina I/Marginal Zone. This contains both interneurons and projection neurons and receives inputs from $\mathrm{A} \delta$ - and C-peptidergic primary afferents fibers (Torsney, 2011; Cordero-Erausquin et al., 2016) (Fig. 1C). A $\delta$ fibers convey the immediate first pain evoked by tissue injury. Peptidergic afferent fibers, which contain substance $\mathrm{P}$ and calcitonin gene-related peptide, are involved in transmitting the second pain that results from injury-induced inflammation. Unlike non-nociceptive $\mathrm{C}$ fibers, they do not bind the plant isolectin B4 (IB4) (Stucky and Lewin, 1999; Fang et al., 2006) and instead express transient receptor potential (TRP) channel type V1 (TRPV1) channels, tropomyosin receptor kinase A neutrophin receptors, and voltage-gated sodium channel type 1.9 (Nav1.9) tetrodotoxin-resistant $\mathrm{Na}^{+}$channels (Fang et al., 2002). Lamina I also receives input from excitatory vertical cells in lamina II. Output neurons to higher centers express neurokinin NK1 receptors (Yu et al., 2005) that are activated by substance $\mathrm{P}$ (Fig. 1C)

2. Lamina II/Substantia Gelatinosa. Unlike lamina I, lamina II does not contain neurons that project directly to higher centers (Fig. 1C). It is divided into three sublaminae.

a. Laminar $I_{o}$ (outer). Laminar $\mathrm{II}_{\mathrm{o}}$ (outer) receives glutamatergic nociceptive input from lamina I as well as polysynaptic input from deeper laminae. It contains glutamatergic stalked or vertical cells (Fig. 1C), which project back to lamina I and typically display a delayed firing pattern in response to a depolarizing current command (Yasaka et al., 2010). Their dendrites penetrate deeper regions of lamina II and lamina III (Todd, 2010; Peirs and Seal, 2016). Another population of excitatory neurons known as central cells expresses short $(<400 \mu \mathrm{m})$ rostrocaudal projections (Todd, 2010, 2017) (Fig. 1C).

Inhibitory interneurons in lamina $\mathrm{II}_{\mathrm{o}}$ typically display a tonic discharge pattern and islet cell morphology and project rostrocaudally for $400 \mu \mathrm{m}$ or more (Grudt and Perl, 2002; Todd, 2010). They receive some of their excitatory synaptic input from non-nociceptive, rapidly conducting $\mathrm{A} \beta$ fibers (Daniele and MacDermott, 2009), and this may provide a cellular basis for the attenuation of pain by activation of innocuous sensory pathways (Zeilhofer et al., 2012b). It is likely that islet cell terminals release both glycine and GABA and that both neurotransmitters may be packaged in the same vesicles (Keller et al., 2001).

b. Lamina $I I_{i d}$ (inner dorsal). Neurons in lamina $\mathrm{II}_{\mathrm{id}}$ receive direct input from $\mathrm{C}$ nonpeptidergic afferents $(\mathrm{Lu}$ and Perl, 2003; Cordero-Erausquin et al., 2016) (Fig. 1C). These afferents generally do not convey nociceptive information and bind the plant isolectin 
IB4. They express P2X3 receptors for ATP and the RET-tyrosine kinase-GFR $\alpha$ receptor complex for glial cell line-derived neurotrophic factor (Molliver et al., 1997).

c. Lamina $I I_{i v}$ (inner ventral). Lamina $\mathrm{II}_{\mathrm{iv}}$ (inner ventral) contains excitatory interneurons that express calretinin or protein kinase $\mathrm{C} \gamma$ (Peirs and Seal, 2016). Immunohistochemical staining for this layer of protein kinase $\mathrm{C} \gamma$-expressing neurons has been used to define the boundary between lamina II and III (Hughes et al., 2003; Stebbing et al., 2016; Boyle et al., 2017).

3. Lamina III. This receives peripheral input from $\mathrm{A} \beta / \mathrm{A} \delta$ myelinated or lightly myelinated primary afferents (Fig. 1C). Inputs project to parvalbumin-containing inhibitory GABA/glycinergic neurons and to excitatory interneurons. NR1-expressing projection neurons also reside in lamina III (Todd, 2010).

4. Laminae $I V, V$, and VI. These laminae contain wide dynamic range (projection) neurons that receive direct $\mathrm{A} \beta$ fiber input from primary afferents as well as polysynaptic inputs that convey nociceptive information from superficial laminae (Peirs and Seal, 2016). Their rate of discharge is thus correlated to the type of input, with painful sensation eliciting high frequency discharge and innocuous stimuli generating more modest discharge (Dalal et al., 1999). These laminae are involved in the complex processing of tactile information such as object size, shape, texture as well as vibration, and direction of stimulus movement. This encoded information is relayed to higher centers (Abraira et al., 2017).

\section{Mechanisms of Neuropathic Pain and Potential Therapeutic Targets}

Neuropathic pain is a maladaptive response of the nervous system to damage. The signs and symptoms include allodynia (pain in response to an innocuous stimulus), hyperalgesia (increased pain response to a noxious stimulus), spontaneous pain (electric-shocklike or shooting pain), and, occasionally, causalgia or incessant burning pain (Costigan et al., 2009b). Some patients experience anesthesia dolorosa or loss of sensation, but persistence of pain from the site of injury (Wall et al., 1979). Neuropathic pain is also seen in complex regional pain syndromes I and II as a result of neurogenic inflammation and/or pathologic cross talk between sensory and sympathetic nerves (Abdulla and Smith, 1997; McLachlan and Hu, 1998; Yen et al., 2006; Calvo et al., 2012; Magnussen et al., 2015). For these reasons, neuropathic pain is often referred to as the "disease of pain." Neuropathic pain is marked by changes in normal sensory signaling at the level of the periphery, spinal cord, and brain (thalamus and cortex) that occur over the course of weeks or months. These lead to alterations in genomic expression and differences in cortical structures (Costigan et al., 2009b;
Sandkuhler, 2009; Alvarado et al., 2013; Tajerian et al., 2013, 2014; Luo et al., 2014). Thus, the pathophysiological changes responsible for the onset of neuropathic pain are distinct from those responsible for its chronic presentation. This distinction between the onset phase and the maintenance phase of neuropathic pain becomes particularly relevant when attempting to relate findings in animal models with the presentation of pain in the clinic. Many animal studies relate to pain onset and do not address the longterm persistence of pain, which is more relevant to the clinical situation.

This review concentrates on neuropathic pain as generated by peripheral nerve injury, as this is the focus of most experimental studies (Kim et al., 1997; Decosterd and Woolf, 2000; Calvo et al., 2012; Stemkowski and Smith, 2013). It has been suggested, however, that injury to the spinal cord per se may engage peripheral mechanisms to generate chronic pain (Yang et al., 2014b). In the clinic, peripheral nerve injury can reflect traumatic injury but is more frequently a consequence of diabetic-, postherpetic-, or human immunodeficiency virus-related neuropathies or complex regional pain syndromes I or II. In all situations, release of inflammatory mediators at the site of injury triggers alterations in the properties of primary afferent neurons (Watkins and Maier, 2002; Scholz and Woolf, 2007). Their excitability is increased, and this leads to the appearance of ectoptic, stimulusindependent activity (Wall and Devor, 1983). This altered activity results from changes in the properties and/or expression of various types of voltage-gated $\mathrm{Na}^{+}$, $\mathrm{K}^{+}$, and $\mathrm{Ca}^{2+}$ channels (Waxman et al., 1999; Abdulla and Smith, 2001b, 2002; Cummins et al., 2001; Stemkowski and Smith, 2012b; Bourinet et al., 2014; Waxman and Zamponi, 2014; Daou et al., 2016). There are also changes in the function of $\mathrm{Na}^{+}-\mathrm{K}^{+}$ATPases (Venteo et al., 2016), intracellular $\mathrm{Ca}^{2+}$ handling (Hogan et al., 2014; D'Arco et al., 2015; Yilmaz and Gold, 2016; Yilmaz et al., 2017), TRP channels (Basso and Altier, 2017), and hyperpolarization-activated cyclic nucleotide-gated (HCN) channels (Hogan and Poroli, 2008; Emery et al., 2011; Noh et al., 2014; Young et al., 2014).

It has been known for 40 years that injury to sensory axons can bring about changes in the organization of the spinal cord sensory map (Devor and Wall, 1978), and that sensory disturbances relating to neuropathic pain can be attributed to changes in excitability of the injured neuron and abnormal ongoing and evoked discharge from ectopic neural pacemaker sites (Govrin-Lippmann and Devor, 1978; Wall and Devor, 1983). These ideas were confirmed by showing that ectopic discharge from the neuroma induced by nerve injury or from dorsal root ganglia could be silenced by lidocaine (Devor et al., 1992). The idea of central sensitization was first put forward by Clifford Woolf in 
the early 1980s to describe the cascade of events that are attributed to the maladaptive changes in plasticity of sensory processing that occur in neuropathic pain (Woolf, 1983; Woolf and Thompson, 1991; Woolf and Mannion, 1999; Latremoliere and Woolf, 2009).

\section{A. Excitation-Inhibition Balance in Neuropathic Pain}

Following peripheral nerve injury or neuropathy, central sensitization within the spinal cord results from changes in synaptic transmission; excitatory synaptic processes are enhanced, and inhibitory processes are attenuated (Kuner, 2010; Prescott et al., 2014; West et al., 2015). The intrinsic properties of dorsal horn neurons such as rheobase, threshold, excitability, and/or input resistance are little changed by peripheral nerve injury (Balasubramanyan et al., 2006). This finding is consistent with the likelihood that ongoing ectopic activity in peripheral nerves is required to drive and maintain central sensitization (Devor, 2006; Pitcher and Henry, 2008; Gold and Gebhart, 2010; Vaso et al., 2014; Daou et al., 2016; Sexton et al., 2017).

Numerous parallel and interdependent pathophysiological processes in the periphery, spinal cord, and higher centers contribute to the onset of neuropathic pain. This very much complicates the search for effective therapeutic targets. Although gabapentinoids may only bind to one specific target, the $\alpha 2 \delta$-1 subunit of voltage-gated $\mathrm{Ca}^{2+}$ channels (Gee et al., 1996; Field et al., 2006; Offord and Isom, 2015), this interaction has multiple consequences for synaptic transmission, neuron-selective actions, and network excitability at the spinal level (Biggs et al., 2014; Alles and Smith, 2016; Alles et al., 2017) and within higher brain centers (Suzuki et al., 2005; Eroglu et al., 2009; Suto et al., 2014; Crosby et al., 2015; Patel and Dickenson, 2016a; Bannister et al., 2017b); this multiplicity of effect may explain their therapeutic effectiveness. The appreciation of this concept has led to the evidence-based development of drugs that will affect multiple targets (Gadotti et al., 2015; Zamponi et al., 2015).

Details of pathophysiological processes that contribute to the development of neuropathic pain are outlined in the following sections. In addition, and where relevant, we identify experimental drugs that target these changes. Some of these substances have not yet been tested in the clinic, whereas others have yielded

TABLE 2

Examples of drugs in development that remain viable candidates for future therapeutic interventions

\begin{tabular}{|c|c|c|}
\hline Drug & Target & Comments \\
\hline $\mathrm{Mg}^{2+}$ & NMDA receptors & $\begin{array}{l}\text { Some positive results reported in the clinic } \\
\text { (Pickering et al., 2011) }\end{array}$ \\
\hline Cobazam & $\alpha 2$ subunit of $\mathrm{GABA}_{\mathrm{A}}$ receptor & $\begin{array}{l}\text { Encouraging results in preliminary clinical } \\
\text { trials (Besson et al., 2015) }\end{array}$ \\
\hline N-desmethyl clobazam & $\alpha 2$ subunit of $\mathrm{GABA}_{\mathrm{A}}$ receptor & $\begin{array}{l}\text { Parent compound for development of new drugs } \\
\text { (Ralvenius et al., 2016) }\end{array}$ \\
\hline$\mu$-TRTX-Hhn1b & $\mathrm{Na}_{\mathrm{v}} 1.7$ & Liu et al., 2014 \\
\hline$\mu$-SLPTX-Ssm6a & $\mathrm{Na}_{\mathrm{v}} 1.7$ & Yang et al., 2013 \\
\hline Monoclonal antibody & Voltage sensor paddle domain of Nav1.7 & Lee et al., 2014 \\
\hline $\mathrm{OB}-1$ & $\begin{array}{l}\text { STOML-3 and Piezo2 mechanoreceptor } \\
\text { channels }\end{array}$ & Wetzel et al., 2017 \\
\hline CLP-257 & $\mathrm{KCC} 2\left(\mathrm{~K}^{+} / \mathrm{Cl}^{-}\right.$cotransporter $)$ & Gagnon et al., 2013 \\
\hline KYS05090S or ABT-639. . & Small-molecule T-channel blockers & $\begin{array}{l}\text { Jarvis et al., 2014; Zhang et al., 2015a; } \\
\text { M'Dahoma et al., } 2016\end{array}$ \\
\hline $\begin{array}{l}\text { N-((1-(2-(tertbutylamino)-2-oxoethyl)piperidin- } \\
\text { 4-yl)methyl)-9-pentyl-9Hcarbazole-3- } \\
\text { carboxamide }\end{array}$ & $\begin{array}{l}\text { CB2 agonist that targets } \mathrm{Ca}_{\mathrm{v}} 3.2 \mathrm{~T} \text {-type } \\
\text { channels }\end{array}$ & $\begin{array}{l}\text { Berger et al., 2014; Bladen et al., 2015; Snutch } \\
\text { and Zamponi, } 2017\end{array}$ \\
\hline A-1264087 & \multirow[t]{3}{*}{ State-dependent $\mathrm{Ca}_{\mathrm{v}} 2$ blockers } & \multirow{4}{*}{$\begin{array}{l}\text { Oral administration of all of these drugs } \\
\text { displays antiallodynic efficacy in rodent } \\
\text { models (Patel et al., 2017) } \\
\text { (Besson et al., 2013) Encouraging results in } \\
\text { preliminary trials (Besson et al., 2015) }\end{array}$} \\
\hline TROX-1 & & \\
\hline ZC88. & & \\
\hline Clobezam & $\alpha 2$ subunit of $\mathrm{GABA}_{\mathrm{A}}$ & \\
\hline GCD-0276 & \multirow[t]{3}{*}{$\mathrm{Na}_{\mathrm{v}} 1.7$} & \multirow{3}{*}{$\begin{array}{l}\text { Under development (Bagal et al., 2014, 2015; } \\
\text { Yekkirala et al., 2017) }\end{array}$} \\
\hline GCD-0310 & & \\
\hline PF-05089771 & & \\
\hline BIIB074 & $\mathrm{Na}_{\mathrm{v}} 1.7$ & $\begin{array}{l}\text { In phase } 2 \text { a clinical trials (Zakrzewska et al., } \\
\text { 2017) }\end{array}$ \\
\hline M4 & $\begin{array}{l}\text { Broad-spectrum dihydropyridine-related } \mathrm{Ca}^{2+} \\
\text { channel blocker blocks } \mathrm{Ca}_{\mathrm{v}} 1.2 \text { (L-type), } \mathrm{Ca}_{\mathrm{v}} \\
2.2\left(\mathrm{~N} \text {-type), and } \mathrm{Ca}_{\mathrm{v}} 3.2 \text { and } 3.3 \text { (T-type }\right. \\
\text { channels) }\end{array}$ & $\begin{array}{l}\text { Under development (Gadotti et al., 2015; } \\
\text { Zamponi et al., 2015). }\end{array}$ \\
\hline EMA401 & AT2 (angiotensin) receptor antagonist & $\begin{array}{l}\text { Produces antinociception in mouse neuropathic } \\
\text { pain models and inhibits capsaicin-induced } \\
\text { calcium fluxes in human and DRGs }\end{array}$ \\
\hline IB-MECA & \multirow[t]{2}{*}{ Adenosine A3 receptor } & Efficacy of A3 receptor agonists in relief of \\
\hline MRS5698 & & $\begin{array}{l}\text { allodynia in rodent models has been } \\
\text { convincingly demonstrated (Ford et al., 2015; } \\
\text { Little et al., 2015) }\end{array}$ \\
\hline ICA-27243 & $\mathrm{KCNQ} / \mathrm{K}_{\mathrm{v}} 7.2 / 7.3$ channel opener & $\begin{array}{l}\text { Effective in animal models of inflammatory } \\
\text { pain (Hayashi et al., 2014) }\end{array}$ \\
\hline
\end{tabular}

KCNQ, M-type potassium channel comprising $\mathrm{K}_{\mathrm{v}} 7.2$ and $\mathrm{K}_{\mathrm{v}} 7.3$ subunits. 
disappointing results in phase I or phase II trials. Table 2 lists substances that remain as viable entities for use as future therapeutic development.

\section{B. The Colony-Stimulating Factor 1, Microglia,} Purinergic Ionotropic 2X4, ATP, Brain-Derived Neurotrophic Factor, GABA-Chloride Cascade

1. Brain-Derived Neurotrophic Factor and a Shift in Neuronal Chloride Gradient. Coull et al. (2003) showed that a decrease in transmembrane chloride gradient occurred in rat dorsal horn lamina I neurons following peripheral nerve injury as a result of a reduction in expression of the potassium-chloride exporter, potassium-chloride exporter 2 (KCC2). The resulting accumulation of intracellular $\mathrm{Cl}^{-}$can cause normally inhibitory GABAergic, anionic, outward synaptic currents to become inward excitatory currents (Coull et al., 2003; Prescott et al., 2006).

It was corroborated that this change was due to a reduction in KCC2 expression as a knockdown of spinal KCC2 in noninjured rats reduced pain thresholds and resulted in neuropathic pain behaviors (Coull et al., 2003, 2005). Hence, an injury that causes neuropathic pain results in a marked change in dorsal horn function such that the net excitability of nociceptive lamina I neurons is increased. It was also shown more recently that alterations in KCC2 expression in deep dorsal horn neurons are confined to nociceptive neurons that project via the spinothalamic tract, whereas wide dynamic range neurons that are activated by a variety of sensory modalities (Dalal et al., 1999) were unaffected (Lavertu et al., 2014).

The Salter and de Koninck (Coull et al., 2005) groups have also shown that brain-derived neurotrophic factor (BDNF) release from activated spinal microglia is responsible for the aforementioned depolarizing shift in anion gradient observed in lamina I neurons in neuropathic pain. In this study, administration of activated microglia or application of BDNF produced the shift in anion gradient seen after nerve injury. Also, blocking signaling between BDNF and its cognate receptor [tropomyosin receptor kinase B (TrkB)] reversed pain behaviors (allodynia) and the shift in anion gradient. Lastly, allodynia and the shift in anion gradient were shown to be prevented by blocking release of BDNF from microglia by treatment with interfering RNA against BDNF.

It was shown recently that BDNF potentiates excitatory NMDA receptor-mediated currents through activation of TrkB and phosphorylation of the GluN2B subunit by the Src-family kinase Fyn (Hildebrand et al., 2016). Interestingly, this potentiation appears to require the coincident BDNF-mediated $\mathrm{Cl}^{-}$disinhibition. The exact molecular mechanism of this interaction remains to be elucidated as it does not appear to reflect increased NMDA receptor availability as a result of GABA-induced depolarization (Hildebrand et al., 2016).
2. Role of ATP. It is also known that, following peripheral nerve injury, there is an increase in the expression of the ATP-gated ionotropic purinoceptor, 2X4 (P2X4R), and in the metabotropic purinoceptor, 2Y12 (P2Y12R), in microglia. This increase in expression parallels the increase in pain hypersensitivity (Tozaki-Saitoh et al., 2008; Trang et al., 2011, 2012). The mechanism by which P2X4R upregulation leads to BDNF release from microglia is attributed to influx of $\mathrm{Ca}^{2+}$ through P2X4Rs, activation of p38 mitogenactivated kinase, and a consequent increase in synthesis and SNARE-mediated exocytosis of BDNF (Trang et al., 2009). Interestingly, this mechanism is specific to male mice as microglia are not required for mechanical sensitivity to pain in female mice in which adaptive immune cells are involved (Sorge et al., 2015; Sorge and Totsch, 2017). Sex differences in pain processing are currently a very active area of investigation with obvious clinical implications (Mogil, 2012b; Mifflin and Kerr, 2013; Dodds et al., 2016; Mifflin et al., 2017).

3. Signaling between Injured Peripheral Nerve and Spinal Microglia. The transformation of resting microglia into a phenotype that expresses P2X4R has been ascribed to the release of chemical mediators from injured primary afferent fibers. These include the chemokines, fractalkine (Milligan et al., 2004; Grace et al., 2014), chemokine (C-C motif) ligand (CCL)2, and CCL21 (Biber et al., 2011; Toyomitsu et al., 2012). Recent work, however, discounts these mediators and instead favors colony-stimulating factor 1 (CSF-1) as the primary effector of microglial transformation in neuropathic pain (Guan et al., 2016; Okubo et al., 2016). It has been suggested that the injury-induced release of inflammatory mediators such as interleukin (IL)- $1 \beta$ from satellite glial cells in DRG promotes induction of Csf1 in the cell bodies of primary afferent neurons (Lim et al., 2017). As will be discussed below, fractalkine and CCL2 are involved in other aspects of the etiology of neuropathic pain. CSF-1 is released from primary afferents and acts on microglia to induce various genes, including that for the ATP receptor, P2X4R, as well as microglial proliferation and self-renewal (Guan et al., 2016). The membrane adaptor protein DAP12 is required for nerve injury-induced upregulation of P2X4R, but not for microglial proliferation. The relationship between CSF-1, P2X4R, ATP, and BDNF is illustrated schematically in Fig. 2A. It remains to be determined whether the release of CSF-1 from primary afferents is vesicular and depends on neuronal activity. This is important to know as it may help to explain how injury-induced ectopic activity in primary afferents leads to central sensitization.

BDNF is also released from sensory neurons in an activity-dependent fashion (Balkowiec and Katz, 2000), but it remains to be determined whether this process contributes to the onset of neuropathic pain or whether it is associated with more physiologic and reversible 


\section{A Mediators Effecting Central Sensitization}

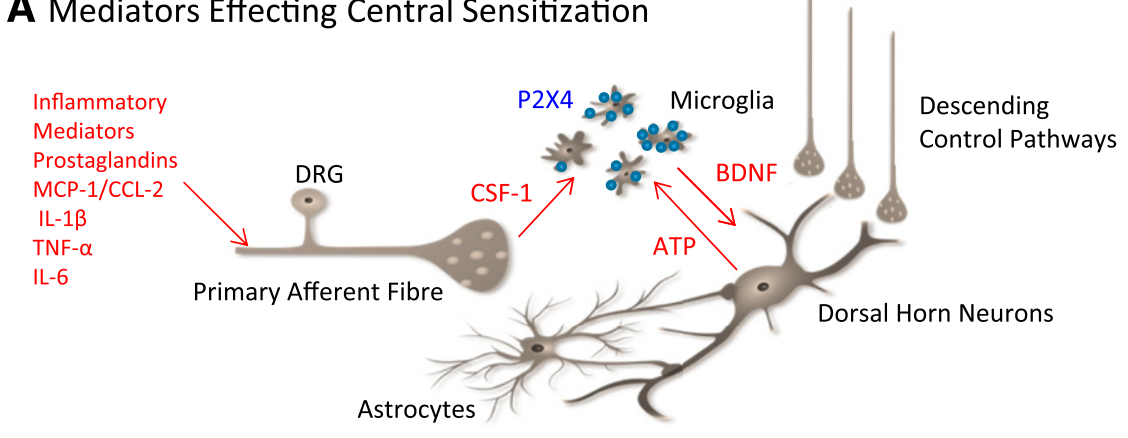

B Uninjured

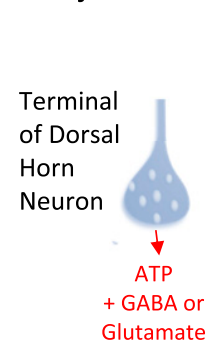

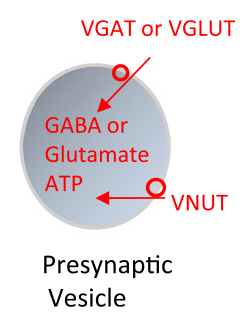

Vesicle
C Following Peripheral Nerve Injury

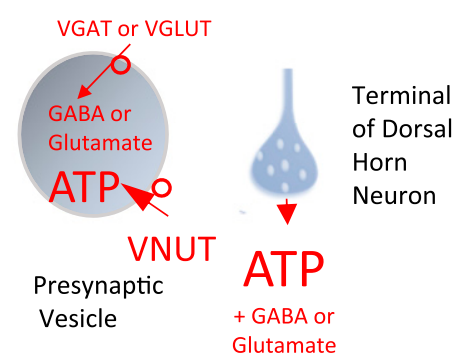

Fig. 2. (A) Diagram to illustrate some of the processes leading to central sensitization. Classic inflammatory mediators released at the site of injury alter the properties of primary afferent fibers such that they become hyperexcitable and/or spontaneously active. CSF-1 released from primary afferents changes the phenotype of microglia that they start to express new receptors, including purinergic ionotropic 2X4. ATP released from dorsal horn neurons interacts with P2X4Rs on microglia to promote release of BDNF, which interacts with neurons to increase dorsal horn excitability. (B and C) Diagrams to show how peripheral nerve injury increases ATP release from dorsal horn neurons by upregulating the vesicular nucleotide transporter VNUT.

central sensitization as is seen in some types of inflammatory pain.

4. Source of ATP in Central Sensitization. After peripheral nerve injury, increased spinal levels of ATP reflect release from the dorsal horn neurons themselves and not from primary afferents, astrocytes, or microglia. This increased release is brought about by upregulation of the vesicular nucleoside transporter (VNUT; Fig. 2, B and C) (Masuda et al., 2016). Neurotransmitters are transported from the cytoplasm into synaptic vesicles via specific transporter proteins: vesicular GABA transporter in inhibitory neurons and various isoforms of the vesicular glutamate transporter in excitatory neurons. Synaptic vesicles in most, if not all, neurons contain ATP that is released along with the primary neurotransmitter. VNUT serves to transport cytosolic ATP into synaptic vesicles. When it is upregulated after nerve injury, vesicles contain a high level of ATP, which is released and stimulates P2X4R on microglia. As mentioned above, this promotes release of BDNF (Trang et al., 2009). The mechanism whereby peripheral nerve injury produces a trans-synaptic upregulation of VNUT in dorsal horn neurons remains to be elucidated.

\section{Increased Excitatory Drive to Excitatory Neurons and Decreased Excitatory Drive to Inhibitory Neurons}

Chronic constriction injury (CCI) or axotomy of the sciatic nerve produces an electrophysiological footprint of neuropathic pain in the substantia gelatinosa (Biggs et al., 2010; Smith, 2014) (Fig. 3A). In this footprint, neurons have been classified according to their firing pattern as tonic, delay, irregular, phasic, or transient (Balasubramanyan et al., 2006), and the effects of CCI noted as increases or decreases in the amplitude and frequency of spontaneous excitatory postsynaptic current (sEPSC) or miniature excitatory postsynaptic current (mEPSC). Given the established relationship between neuronal firing pattern and its neurotransmitter phenotype (Yasaka et al., 2010; Punnakkal et al., 2014), the footprint reflects an increased excitatory drive to putative excitatory delay-firing and transientfiring neurons (Fig. 4A) and a decreased excitatory drive to putative inhibitory tonic-firing neurons (Fig. 4B) (Bailey and Ribeiro-da-Silva, 2006; Balasubramanyan et al., 2006; Chen et al., 2009; Lu et al., 2009). Both of these changes would be expected to produce an overall increase in dorsal horn excitability. Decreased excitatory drive to inhibitory neurons involves both pre- and postsynaptic changes, including a decreased contribution of $\mathrm{Ca}^{2+}$-permeable AMPA receptor to sEPSCs (Chen et al., 2016). Increased excitatory drive to excitatory neurons also involves presynaptic effects and a possible increased contribution of $\mathrm{Ca}^{2+}$-permeable AMPA receptor to postsynaptic events (Chen et al., 2013).

1. Role of Brain-Derived Neurotrophic Factor. Treatment of substantia gelatinosa neurons in organotypic culture with BDNF for 5 to 6 days produces an 
A Footprint of pain produced by peripheral nerve injury

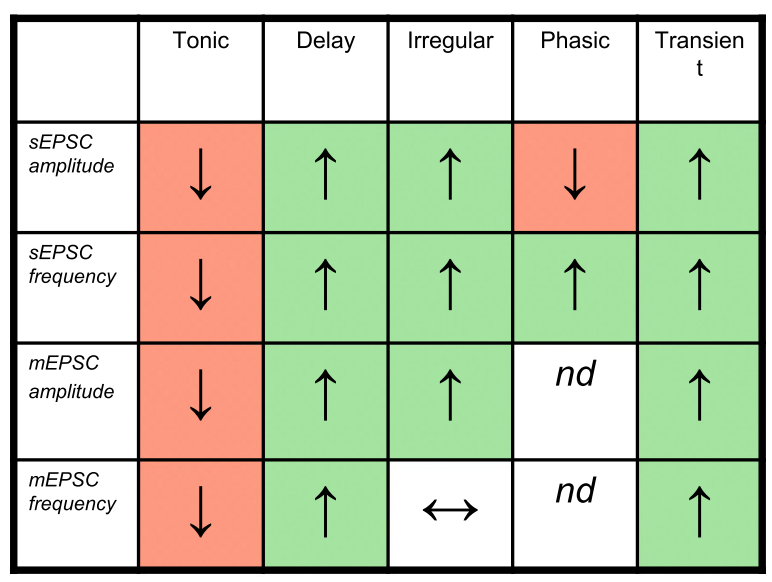

B Pattern of neuron type specific actions of gabapentin

\begin{tabular}{|l|c|c|c|c|c|}
\hline & Tonic & Delay & Irregular & Phasic & Transient \\
\hline $\begin{array}{l}\text { sEPSC } \\
\text { amplitude }\end{array}$ & $\leftrightarrow$ & $\downarrow$ & $n d$ & $\uparrow$ & $\downarrow$ \\
\hline $\begin{array}{l}s E P S C \\
\text { frequency }\end{array}$ & $\uparrow$ & $\downarrow$ & $n d$ & $\leftrightarrow$ & $\downarrow$ \\
\hline $\begin{array}{l}\text { mEPSC } \\
\text { amplitude }\end{array}$ & $\uparrow$ & $\downarrow$ & $n d$ & $n d$ & $n d$ \\
\hline $\begin{array}{l}\text { mEPSC } \\
\text { frequency }\end{array}$ & $\leftrightarrow$ & $\downarrow$ & $n d$ & $n d$ & $n d$ \\
\hline
\end{tabular}

C Overlay of pain footprint and pattern of gabapentin action

\begin{tabular}{|l|l|l|l|l|l|}
\hline & Tonic & Delay & Irregular & Phasic & Transient \\
\hline $\begin{array}{l}s E P S C \\
\text { amplitude }\end{array}$ & & & $n d$ & & \\
\hline $\begin{array}{l}s E P S C \\
\text { frequency }\end{array}$ & & & $n d$ & & \\
\hline $\begin{array}{l}\text { mEPSC } \\
\text { amplitude }\end{array}$ & & & $n d$ & $n d$ & $n d$ \\
\hline $\begin{array}{l}m E \text { ESSC } \\
\text { frequency }\end{array}$ & & & $n d$ & $n d$ & $n d$ \\
\hline
\end{tabular}

Fig. 3. (A) Diagram to illustrate the electrophysiological footprint of neuropathic pain seen in substantia gelatinosa following peripheral nerve injury (Biggs et al., 2010). Five cell types characterized by their firing pattern, tonic, delay, irregular, phasic, or transient (Balasubramanyan et al., 2006), are listed at the top of the scheme, and the frequencies and amplitudes of sEPSCs electrophysiological footprint (Lu et al., 2006; Biggs et al., 2012) that is very similar to that produced by CCI in vivo (Biggs et al., 2010; Smith, 2014). Both BDNF and CCI increase sEPSC and mEPSC amplitude and frequency in putative excitatory delay-firing neurons, and a more detailed analysis shows that both manipulations also unveil a new population of large mEPSC events, which are absent in neurons from sham-operated rats and control organotypic cultures (Biggs et al., 2010; Smith, 2014). CCI-induced attenuation of excitatory synaptic drive to inhibitory neurons is associated with functional loss of $\mathrm{Ca}^{2+}$-permeable AMPA receptors in the postsynaptic membrane (Chen et al., 2016). BDNF has also been reported to activate presynaptic NMDA receptors via a TrkB-dependent mechanism (Chen et al., 2014). Somewhat counterintuitively, this has been proposed to decrease neurotransmitter release (Bardoni et al., 2004), which may contribute to attenuation of synaptic events in inhibitory neurons of the substantia gelatinosa.

As would be expected, spinal cord slices obtained from animals subject to CCI and those in organotypic cultures exposed to BDNF for 5 to 6 days displayed an overall increase in excitability. This was observed as an increase in the amplitude of $\mathrm{Ca}^{2+}$ responses evoked by $35 \mathrm{mM} \mathrm{K}^{+}$(Lu et al., 2007; Alles et al., 2017). In addition, activated microglia-conditioned medium increased overall organotypic slice excitability, and preincubation of slices with a TrkBd5 (recombinant receptor, which sequesters $\mathrm{BDNF}$ ) inhibited this effect (Lu et al., 2009). This provides further evidence for the role of microglia-derived $\mathrm{BDNF}$ as a major driver of central sensitization (Coull et al., 2005; Biggs et al., 2010; Trang et al., 2011; Smith, 2014).

2. Brain-Derived Neurotrophic Factor as a Drug Target? Given the seminal role of BDNF in the onset of neuropathic pain and findings that suggest its involvement in pain maintenance (Wang et al., 2009), one may posit that BDNF antagonists would be an effective treatment (Sah et al., 2003). Because BDNF is involved in so many other essential processes, such as neuronal growth, survival, and synaptogenesis (Reichardt, 2006), and in processes related to memory (Malcangio and Lessmann, 2003; Montalbano et al., 2013), systemic blockade of BDNF function in pain patients would doubtless cause undesirable side effects, including

and mEPSCs are listed at the right of the scheme. Upward arrows in greencolored squares indicate a nerve injury-induced increase in each type of synaptic event in each neuron type. Downward arrows in red-colored squares indicate a nerve injury-induced decrease. $n d=$ not determined; horizontal double-headed arrow indicates no change. (B) Similar presentation to show cell-type-specific effects of gabapentin in substantia gelatinosa of nerve-injured animals. (C) Superimposition of patterns from (A) and (B). Yellow shading represents phenomena that were affected in one way by nerve injury and the opposite direction by gabapentin. 
A

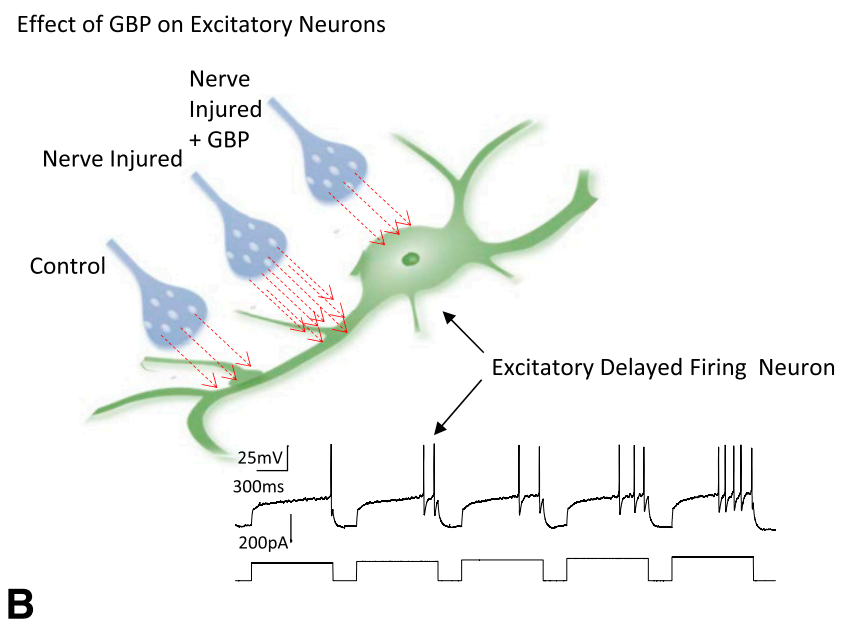

Effect of GBP on Inhibitory Neurons

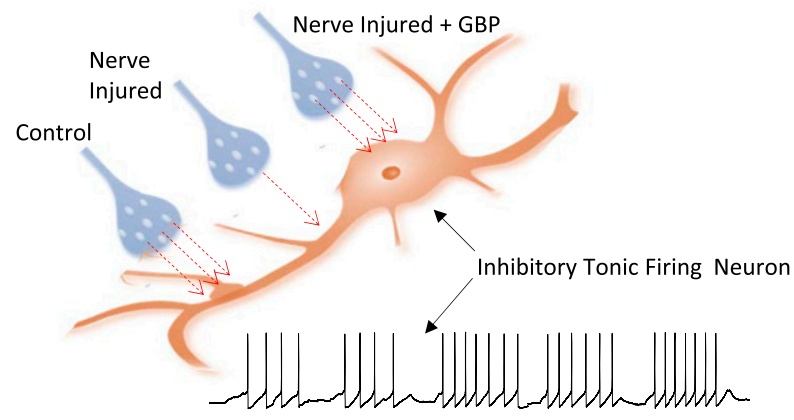

Fig. 4. (A) Diagram to illustrate increase in excitatory synaptic transmission onto excitatory dorsal horn neurons following CCI and reversal of these changes following GBP treatment. The inset shows the characteristic delay-firing pattern of excitatory neurons. Red arrows illustrate relative quantity of glutamate released onto control excitatory neurons, onto neurons in animals subject to CCI, and onto CCI neurons following treatment with GBP. The inset shows the characteristic delay-firing pattern of excitatory neurons. (B) Diagram to illustrate decrease in excitatory synaptic transmission onto inhibitory dorsal horn neurons following CCI and restoration of glutamate release following GBP treatment. The inset shows the characteristic tonic-firing pattern of inhibitory neurons. Red arrows illustrate relative quantity of glutamate released onto control-inhibitory neurons, onto neurons in animals subject to CCI, and onto CCI neurons following treatment with GBP.

cognitive impairment and the onset of depression (Autry and Monteggia, 2012; Smith, 2014).

3. Use of Botulinum Toxin. Botulinum toxin represents another means by which to control neurotransmitter release. Although it is currently a fourth-line treatment (Finnerup et al., 2015), there is increasing interest in its use in the management of neuropathic pain (Oh and Chung, 2015; Baron and Binder, 2016; Park and Park, 2017; Yaksh et al., 2017). Botulinum A cleaves the synaptic protein SNAP-25 and thereby decreases the $\mathrm{Ca}^{2+}$ responsiveness of the secretory machinery and attenuation of neurotransmitter release (Trudeau et al., 1998). Because the toxin blocks the release of both inhibitory and excitatory transmitters, its mechanism of action has been debated (Baron and Binder, 2016). Actions may include attenuation of neurogenic inflammation in the periphery. The suggestion that the substantia gelatinosa is "primarily an excitatory network" (Santos et al., 2007) in which only $25 \%$ of the neurons are inhibitory (Boyle et al., 2017) may account for the actions of botulinum toxin at the spinal level.

\section{Altered Sensory Processing and Generation of Allodynia}

Following nerve injury, attenuation of GABAergic and/or glycinergic transmission leads to aberrant processing of sensory information within the dorsal horn (Baba et al., 2003; Torsney and MacDermott, 2006; Prescott et al., 2014). In addition to changes in chloride gradient (Coull et al., 2003, 2005) and decreased excitatory drive to inhibitory neurons (Balasubramanyan et al., 2006; Lu et al., 2009; Leitner et al., 2013), this may involve a loss of GABAergic terminals (Lorenzo et al., 2014) or reduced glycine release (Imlach et al., 2016). Tactile and innocuous information is carried by $\mathrm{A} \beta$ fibers, which synapse primarily onto dorsal horn neurons in laminae III and IV (Abraira et al., 2017), whereas noxious information carried by $\mathrm{C}$ and $\mathrm{A} \delta$ fibers is transmitted to the superficial laminae I and II (Peirs and Seal, 2016) (Fig. 1C). GABAergic and glycinergic inhibition normally separates these two modalities by suppressing the activity of pre-existing excitatory synaptic circuits ( $\mathrm{Lu}$ et al., 2013). However, when this inhibition is compromised, tactile and innocuous information traveling to lamina III and IV gains access to the painprocessing centers in lamina I and II. Thus, touch is processed as pain, thereby providing a rational explanation for the generation of allodynia. This idea is supported by the observation that impediment of inhibitory transmission in the spinal cord with bicuculline and/or strychnine produces allodynia and hyperalgesia in uninjured animals (Yaksh, 1989; Sherman and Loomis, 1994; Loomis et al., 2001).

Anomalous distribution of tactile information is reinforced by increased excitatory transmission between deep and superficial laminae. This involves transient expression of the vesicular glutamate transporter vesicular glutamate transporter 3 by a discrete population of neurons that receive direct low-threshold primary afferent input (Fig. 1C). The circuit extends to nociceptive lamina I projection neurons and includes lamina II calretinin neurons (Peirs et al., 2015).

In addition to being a substrate for allodynia, injuryinduced ongoing aberrant activity in $\mathrm{A} \beta$ fibers (Devor, 2009), including large-diameter cutaneous afferents (Cummins et al., 2000), would be expected to drive persistent activation of the superficial laminae that may contribute to chronic, stimulus-independent pain.

1. Mechanosensitive Ion Channels as Therapeutic Targets. Because light touch instigates allodynia, there is interest in pharmacological manipulation of normally innocuous modalities as a means to alleviate 
aspects of human neuropathic pain (Eijkelkamp et al., 2013). Transduction of light touch by mechanoreceptors is effected by the mechanosensitive ion channel, Piezo 2 (Ranade et al., 2014), which is modulated by stomatinlike protein 3 (STOML-3) (Wetzel et al., 2007, 2017). Interference with STOML-3 function has been proposed as a novel therapeutic approach for neuropathic pain. Recently, a small molecule blocker of STOML-3 oligomerization was identified. This substance termed OB-1 by the authors was shown to attenuate mechanoreceptor sensitivity and to increase paw withdrawal threshold in mice subject to CCI (Wetzel et al., 2017).

2. Potentiation of GABA or Glycine as Therapeutic Targets. Some of the anticonvulsant agents used in pain management are thought to act, at least in part, by augmentation of GABA function (Table 1). Given the established role of GABAergic and glycinergic dysfunction in the etiology of allodynia (Yaksh, 1989; Sherman and Loomis, 1994; Loomis et al., 2001), restoration of this function represents an attractive therapeutic approach (Zeilhofer et al., 2012a, 2015). Augmentation of glycinergic function may be achieved by pharmacological manipulation of the glial and neuronal glycine transporters GlyT1 and GlyT2 or direct stimulation of glycine receptors (Zeilhofer et al., 2017).

The collapse of the chloride gradient in response to CCI-induced release of BDNF from spinal microglia has already been alluded to (Coull et al., 2003, 2005; Beggs et al., 2004; Lavertu et al., 2014). Because this reflects downregulation of the $\mathrm{K}^{+} / \mathrm{Cl}^{-}$cotransporter $\mathrm{KCC} 2$, there is considerable interest in developing pharmacological agents that will restore KCC2 function (Gagnon et al., 2013). These authors identified an arylmethylidine family of compounds and found that the analog CLP257 was KCC2 selective and that it restored impaired $\mathrm{Cl}^{-}$transport and $\mathrm{Cl}^{-}$gradients in neurons with diminished KCC2 activity. It also alleviated allodynia in a rat model of neuropathic pain with an oral efficacy equivalent to PGB, thus validating KCC2 as a therapeutic target for neuropathic pain and perhaps for other central nervous system (CNS) disorders (Gagnon et al., 2013).

It is well established that $\mathrm{GABA}_{\mathrm{A}}$ receptor function is augmented by benzodiazepines, but their use as antiallodynic agents in the clinic is limited by their sedative effects (Besson et al., 2013). It is known, however, that different subtypes of $\mathrm{GABA}_{\mathrm{A}}$ receptor localize with different cell types and terminals in the spinal dorsal horn. In particular, $\mathrm{GABA}_{\mathrm{A}}$ receptors containing the $\alpha 2$ subunit associate with $\mathrm{C}$ fibers (Paul et al., 2012), and this has led to the notion that benzodiazepines with high affinity for $\alpha 2$ may be effective in treating neuropathic pain (Besson et al., 2013; Paul et al., 2014; Ralvenius et al., 2016). One such agent, clobazam (Besson et al., 2013), which acts through an active metabolite (Ralvenius et al., 2016), is effective in relieving allodynia in the CCI model (Besson et al., 2013).
Moreover, preliminary clinical trials with this agent are showing encouraging results (Besson et al., 2015).

\section{E. Other Spinal Mechanisms of Central Sensitization}

1. Long-Term Potentiation and Memory Processes. Transmission at CNS synapses is characteristically plastic. Repeated activation of presynaptic fibers can lead to short-term potentiation (lasting for less than half an hour), early-phase long-term potentiation (LTP; lasting for up to 3 hours), and late-phase LTP, which depends on protein synthesis and can last indefinitely (Luo et al., 2014). Given that peripheral nerve injury increases activity of both primary afferent fibers and dorsal horn neurons, these processes are doubtlessly engaged and serve to reinforce central sensitization (Ji et al., 2003; Sandkuhler, 2007; Fenselau et al., 2011; Ruscheweyh et al., 2011; Luo et al., 2014). Mechanistically, spinal LTP involves presynaptic mechanisms (Luo et al., 2014) as well as opening of T-type [voltagaegated $\mathrm{Ca}_{2}{ }^{+}$channels type $\left.3\left(\mathrm{Ca}_{\mathrm{v}} 3\right)\right]$ calcium channels and activation of NMDA receptors (Ikeda et al., 2003, 2006; Zhuo, 2016b). These receptors have long been implicated in the etiology of neuropathic pain (Woolf and Thompson, 1991; Kerr et al., 1999; Latremoliere and Woolf, 2009; Salter and Pitcher, 2012; Hildebrand et al., 2016), and this may account for the effectiveness of the NMDA receptor blocker, ketamine, in the management of chronic pain (Hewitt, 2000; Niesters et al., 2014; Maher et al., 2017) and the observation that T-type calcium channel blockers mibefradil and ethosuximide can reverse neuropathic pain in an animal model (Dogrul et al., 2003). Physiological blockade of NMDA channels with $\mathrm{Mg}^{2+}$ has been shown to be effective in reducing signs of pain in animal models (Brill et al., 2002; Rondon et al., 2010), and there is some evidence that it may play a role in the treatment of human neuropathic pain (Pickering et al., 2011).

Central sensitization in the dorsal horn shares many mechanistic parallels with memory formation (Sandkuhler and Lee, 2013), including reconsolidation, a protein synthesis-dependent process by which memories become labile after reactivation and susceptible to erasure (Nader et al., 2000; Debiec et al., 2002). Thus, following lasting hyperalgesia induced by injection of capsaicin or complete Freund's adjuvant into mice hindpaw, a second capsaicin injection administered within 2 hours of the first suppressed hyperalgesia by a mechanism independent of protein synthesis (Bonin and de Koninck, 2014). It remains to be determined whether this phenomenon can be exploited therapeutically in management of neuropathic pain.

2. Role of Astrocytic Glutamate Transporter (Excitatory Amino Acid Transporter 2). Studies using various animal models have also reported that downregulation of the astrocytic excitatory amino acid transporter, excitatory amino acid transporter 2 (EAAT2), correlates with development of signs of 
neuropathic pain (Cata et al., 2006; Weng et al., 2006). Both partial sciatic nerve ligation and CCI significantly reduce expression of EAAT2 in rat dorsal horn (Sung et al., 2003), whereas spinal EAAT2 gene transfer via recombinant adenovirus significantly decreases mechanical hyperalgesia and allodynia (Maeda et al., 2008). Decreased removal of extracellular glutamate following EAAT2 downregulation may lead to activation of extrasynaptic NMDA receptors (Nie and Weng, 2009). The signal responsible for EAAT2 downregulation remains to be established. It is unlikely to be BDNF as this neurotrophin upregulates EAAT2 in other brain regions (Rodriguez-Kern et al., 2003).

Although riluzole, a positive regulator of glutamate transporters, significantly reduces thermal hyperalgesia and mechanical allodynia in CCI (Sung et al., 2003), this effect may reflect other actions of the drug such as interaction with $\mathrm{Na}^{+}$channels (Hebert et al., 1994; Munro et al., 2007).

\section{F. The Pain Matrix}

Neuronal plasticity during neuropathic pain is by no means limited to the dorsal horn and periphery (West et al., 2015; Zhuo, 2016a,b; Bannister and Dickenson, 2017). Multiple changes are observed in the pain matrix that includes the medial prefrontal cortex, nucleus accumbens, anterior cingulate cortex, insula, amygdala, periaqueductal gray, locus coeruleus, and rostroventral medulla (Schweinhardt and Bushnell, 2010; von Hehn et al., 2012; Zhang et al., 2015c; Peirs and Seal, 2016; Tan et al., 2017; Taylor et al., 2017). For example, synapses in the anterior cingulate cortex are altered after peripheral nerve injury, and LTP of glutamatergic transmission appears in the insula (Zhuo, 2016a). There is also an increase in feed-forward GABAergic inhibition in the medial prefrontal cortex (Zhang et al., 2015c) that is thought to contribute to the emotional aspects of neuropathic pain.

Brain regions that comprise the pain matrix were identified by functional neuroimaging (Apkarian et al., 2011). Interestingly, areas activated by acute pain do not correspond exactly to those activated in chronic pain (Apkarian et al., 2011; von Hehn et al., 2012). The "matrix is reloaded!"

\section{G. Changes in Descending Control Mechanisms}

In addition to altering pain perception, changes in the pain matrix can also alter control of spinal dorsal horn neurons as a result of alterations in descending control mechanisms (Porreca et al., 2002; Ossipov et al., 2010). The well-established role of serotonergic and noradrenergic pathways in controlling spinal nociceptive processing (Ossipov et al., 2010) helps to explain the effectiveness of tricyclic antidepressants and related monoamine uptake inhibitors in pain management (Dworkin et al., 2007; Kuner, 2010; Finnerup et al., 2015; Bannister and Dickenson, 2017). Descending inhibition of nociceptive processing is mediated via $\alpha_{2}$ adrenoceptors and $5 \mathrm{HT}_{7}$ receptors, whereas serotonergic activation of metabotropic $5 \mathrm{HT}_{2}$ receptors and ionotropic $5 \mathrm{HT}_{3}$ receptors facilitates transmission (Millan, 2002; Bannister et al., 2015, 2017a; Bannister and Dickenson, 2017).

Although intrathecal administration of the $\alpha_{2}$ receptor antagonist, yohimbine, hastens the onset of cold allodynia and heat sensitivity following tibial nerve transduction, the drug loses its sensitizing effect once these phenomena have fully developed. These findings have been interpreted as a loss of descending noradrenergic control once allodynia and hyperalgesia have developed (Hughes et al., 2013). Similarly, silencing of locus coeruleus neurons by adenoviral infection of $\mathrm{K}^{+}$ channels attenuates descending inhibition, but this effect disappears once neuropathy is introduced (Howorth et al., 2009).

Experiments with the antagonist, ondansetron, implicate upregulation of $5 \mathrm{HT}_{3}$ receptor function in the generation of neuropathic pain (Bannister et al., 2015). The resulting facilitation of nociceptive processing along with attenuation of the inhibitory actions of noradrenaline thus conspires to promote allodynia and hyperalgesia.

For additional information on mechanisms of central sensitization and allodynia, consult publications by Jürgen Sandkühler (Sandkuhler, 2009; Ruscheweyh et al., 2011; Sandkuhler and Gruber-Schoffnegger, 2012), Clifford Woolf (Ji and Woolf, 2001; Costigan et al., 2009b; Latremoliere and Woolf, 2009), and Allan Basbaum (Basbaum et al., 2009), as well as that by Peirs and Seal (2016). Several additional reviews address supraspinal changes associated with neuropathic pain (Zhuo, 2008, 2016b; Luo et al., 2014) and alterations in descending control mechanisms (Bannister and Dickenson, 2017).

\section{H. Role of Mesolimbic Reward Circuitry}

An emerging area in the study of neuropathic pain mechanisms relates to the ability of peripheral nerve injury to impair dopamine release in the reward circuitry associated with mesolimbic system (Taylor et al., 2015, 2017). This may relate to the changes in affect (anxiety, depression) experienced by neuropathic pain patients (Mitsi and Zachariou, 2016). It was also shown recently that peripheral nerve injury selectively increases excitability of the nucleus accumbens indirect pathway spiny projection neurons and alters their synaptic connectivity. In addition, tactile allodynia was reversed by inhibiting and exacerbated by exciting these neurons. This suggests that neurons in the nucleus accumbens not only participate in the central representation of pain, but that they may gate activity in ascending pathways associated with expression of neuropathic pain in higher centers (Ren et al., 2016). 


\section{Role of Ectopic Activity in Primary Afferent Fibers}

The initial inflammatory event at the site of nerve injury is a major trigger for the sequelae that lead to central sensitization (Watkins and Maier, 2002; Scholz and Woolf, 2007; White et al., 2007; Basbaum et al., 2009; Stemkowski and Smith, 2012b; Grace et al., 2014; Schuh et al., 2014; Ko et al., 2016) (Fig. 2A). As mentioned above, processes involved in the onset of neuropathic pain are very different from those involved in its long-term persistence and maintenance ( $\mathrm{Ji}$ and Woolf, 2001). Classic mediators of inflammation such as IL-1 $\beta$ (Binshtok et al., 2008; Stemkowski and Smith, 2012a,b; Stemkowski et al., 2015), IL-6 (Ko et al., 2016), prostaglandins (Ma and Eisenach, 2002), and tumor necrosis factor (TNF) (Leung and Cahill, 2010) interact with or modulate ion channels on primary afferent neurons to instigate ectopic activity that contributes to spontaneous, stimulus-independent pain (Pitcher and Henry, 2008; Devor, 2009; Devor et al., 2014). Indeed, it has been shown that, following a peripheral nerve injury, there is altered synaptic activity of $s u b$ stantia gelatinosa neurons with little effect on their intrinsic electrophysiological properties, suggesting that changes in the CNS are driven by activity of peripheral neurons (Balasubramanyan et al., 2006; Devor, 2006). In a simple yet elegant series of experiments, it was shown by application of lidocaine to block nerve conduction and subsequent monitoring of spontaneous baseline discharge that the hyperexcited state of dorsal horn neurons is maintained by ongoing, afferent discharges from the peripheral nerve distal to and proximal to the site of injury (Pitcher and Henry, 2008). Increased activity in afferent nerves leads to upregulation of the $\alpha 2 \delta-1$ subunit of voltage-gated $\mathrm{Ca}^{2+}$ channels (Boroujerdi et al., 2008). This in turn alters $\mathrm{Ca}^{2+}$ channel function in primary afferent terminals and increases transmitter release (see Gabapentinoids and the $\alpha 2 \delta$ Subunits of Voltage-Gated Ca2+Channels).

Increased discharge in TRPV1-expressing neurons may contribute to central sensitization more indirectly by increasing the permeability of the blood brain and blood spinal cord barrier (Beggs et al., 2010). This permits access of proinflammatory cytokines and immunocompetent cells such as T-lymphocytes and macrophages (Calvo et al., 2012).

1. Changes in Voltage-Gated $\mathrm{Na}^{+}$Channels. As mentioned, increases in various types of voltage-gated sodium channel current contribute to the increased excitability of DRG neurons seen in neuropathic pain (Cummins and Waxman, 1997; Waxman et al., 2000a,b; Abdulla and Smith, 2001a, 2002; Stemkowski and Smith, 2012b; Bourinet et al., 2014; Waxman and Zamponi, 2014). Genetic studies have confirmed the importance of voltage-gated sodium channels by showing that gain-of-function mutations in $\mathrm{Na}_{\mathrm{v}} 1.7, \mathrm{Na}_{\mathrm{v}} 1.8$, and $\mathrm{Na}_{\mathrm{v}} 1.9$ are implicated in peripheral neuropathy disorders in humans by increasing the excitability of nociceptive neurons (Dib-Hajj et al., 2013; Sexton et al., 2017; Yekkirala et al., 2017).

a. Peripheral $\mathrm{Na}^{+}$channels as drug targets. Pharmacological treatments such as carbamazepine, which are known to target $\mathrm{Na}^{+}$channels, have been used for many years to treat some types of neuropathic pain (Demant et al., 2014), particularly trigeminal neuralgia (Walsh and Smith, 1968). Several smallmolecule blockers with affinity for $\mathrm{Na}_{\mathrm{v}} 1.7,1.8$, or 1.9 have been considered. To date, the most promising compounds that are currently in phase 1 or phase 2 clinical trials target $\mathrm{Na}_{\mathrm{v}} 1.7$ [Table 2; for additional information, see review by Yekkirala et al. (2017)].

Small-molecule peptide blockers of $\mathrm{Na}_{\mathrm{v}} 1.7$ (for example, $\mu$-TRTX-Hhn $1 \mathrm{~b}$ derived from spider venom or $\mu$-SLPTX-Ssm6a from centipede venom) are also of interest (Yang et al., 2013; Liu et al., 2014). A monoclonal antibody targeting the voltage sensor paddle domain of Nav1.7 is available to allow for greater sodium channel subtype selectivity (Lee et al., 2014). Slow inactivation-specific channel modulators represent another method by which ion channels can be stabilized in their slow inactivated state to act as a brake during periods of neuronal hyperexcitability, and these have been applied to target both sodium and calcium channel currents for treatment of neuropathic pain (Hildebrand et al., 2011).

A recent review drew attention to the possible pharmacological manipulation of $\beta$ subunits of $\mathrm{Na}^{+}$ channels rather than the pore-forming $\alpha$ subunits (O'Malley and Isom, 2015). This approach may be especially attractive as three different types of $\beta$ subunits are differentially and selectively expressed in small, medium, and large DRG neurons (Zhao et al., 2011; Ho et al., 2012).

Further to its obvious role in controlling neuronal excitability, the importance of $\mathrm{Na}_{\mathrm{v}} 1.7$ in normal and pathologic pain processing may derive from its ability to directly or indirectly affect several other processes, including gene expression (Sexton et al., 2017). These authors have brought forward the possibility that upregulation of the penk (preproenkephalin) gene may contribute to the beneficial effects of $\mathrm{Na}_{\mathrm{v}} 1.7$ blockers. This is supported by the observation that the analgesic effect of a selective $\mathrm{Na}_{\mathrm{v}} 1.7$ blocker, mu-theraphotoxinPn3a (from the tarantula Pamphobeteus nigricolor), is augmented by administration with subeffective doses of opioids or with an enkephalinase inhibitor (Deuis et al., 2017).

In a more straightforward physiologic mechanism, Nav1.7 appears to be necessary for substance $P$ release from primary afferent terminals (Minett et al., 2012).

2. Changes in High Voltage-Activated $\mathrm{Ca}^{2+}$ Channels $\left(C a_{v} 1\right.$ and $\left.C a_{v} 2\right)$. Voltage-gated calcium channels are another player in the field of neuropathic pain and pain therapeutics in general (Baccei and Kocsis, 2000; 
Abdulla and Smith, 2001b; Bourinet et al., 2014; Waxman and Zamponi, 2014; Zamponi et al., 2015; Pan et al., 2016; Zamponi, 2016; Patel et al., 2017). These channels encompass high-voltage-activated (HVA) L-types $\left(\mathrm{Ca}_{\mathrm{v}} 1.1, \mathrm{Ca}_{\mathrm{v}} 1.2, \mathrm{Ca}_{\mathrm{v}} 1.3\right.$, and $\left.\mathrm{Ca}_{\mathrm{v}} 1.4\right)$ : P/Q-type $\left(\mathrm{Ca}_{\mathrm{v}} 2.1\right)$, N-type $\left(\mathrm{Ca}_{\mathrm{v}} 2.2\right)$, and R-type $\left(\mathrm{Ca}_{\mathrm{v}} 2.3\right)$, as well as T-type [low-voltage-activated (LVA)] $\mathrm{Ca}^{2+}$ channels $\left(\mathrm{Ca}_{\mathrm{v}} 3.1, \mathrm{Ca}_{\mathrm{v}} 3.2, \mathrm{Ca}_{\mathrm{v}} 3.3\right)$ (Zamponi et al., 2015; Dolphin, 2016). Influx of $\mathrm{Ca}^{2+}$ through $\mathrm{HVA}-\mathrm{Ca}^{2+}$ channels triggers neurotransmitter release from presynaptic vesicles and thereby determines neuronal network excitability. The importance of $\mathrm{HVA}-\mathrm{Ca}^{2+}$ channels in neuropathic pain is illustrated by the clinical effectiveness of the N-type $\mathrm{Ca}^{2+}$ channel blocker ziconotide (Zamponi, 2016) and, as will be discussed below, the relationship between $\mathrm{HVA}-\mathrm{Ca}^{2+}$ channel function $\alpha 2 \delta$-1 subunits and the actions of gabapentinoids (Dolphin, 2012b). (See Gabapentinoids and the $\alpha 2 \delta$ Subunits of Voltage-Gated Ca2+Channels and $\alpha 2 \delta$ Subunits and Neuropathic Pain.)

Voltage-gated $\mathrm{Ca}^{2+}$ channels (VGCC) consist of five subunits, as follows: the $\alpha 1$ pore-forming subunit and auxiliary subunits $\alpha 2-\delta, \beta$, and $\gamma$. The main subtype found in presynaptic terminals is $\mathrm{Ca}_{\mathrm{v}} 2$ (Westenbroek et al., 1998; Zamponi et al., 2015). $\mathrm{Ca}_{\mathrm{v}} 2.1$ and $\mathrm{Ca}_{\mathrm{v}} 2.2$ both contain a synaptic protein interaction site (synprint) that interacts with SNARE proteins (syntaxin and SNAP-25) (Rettig et al., 1996; Sheng et al., 1996). By this mechanism, channels can be closely associated with synaptic vesicles that govern release of neurotransmitter.

Because these channels are responsible for depolarization-induced influx of $\mathrm{Ca}^{2+}$ and triggering consequent release of neurotransmitter, blocking or genetically deleting these channels in hyperexcitable nociceptive neurons would be expected to reduce net excitability (Bourinet et al., 2014). For example, N-type VGCC knockout mice exhibit reduced signs of both inflammatory and neuropathic pain (Saegusa et al., 2001).

It is important to note, however, that there is a classic third-fourth power relationship between $\mathrm{Ca}^{2+}$ influx and neurotransmitter release (Dodge and Rahamimoff, 1967). In other words, even if one were to reduce the amount of $\mathrm{Ca}^{2+}$ entering terminals via VGCCs, there would still be sufficient VGCCs expressed to support substantial neurotransmitter release. This is supported

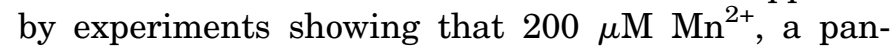
VGCC blocker, produces no change in sEPSC frequency or amplitude of spinal dorsal horn neurons, but can produce a significant reduction of the amplitude of $35 \mathrm{mM} \mathrm{K}^{+}$-evoked $\mathrm{Ca}^{2+}$ responses that reflect activation of voltage-gated $\mathrm{Ca}^{2+}$ channels following the depolarizing action of a high concentration of extracellular $\mathrm{K}^{+}$ (Biggs et al., 2014).

If suppression of $\mathrm{Ca}^{2+}$ entry via presynaptic $\mathrm{Ca}_{\mathrm{v}} 2$ channels has only very modest effects on neurotransmitter release from primary afferents, these observations raise the question of how conotoxin channel blockers actually work. It has, however, long been known that $\omega$-conotoxin GVIA reduces synaptic potentials in the spinal cord (Yu et al., 1992). In the clinical setting, it is also possible that $\mathrm{Ca}_{\mathrm{v}} 2$ channel block may have additional long-term consequences, including effects on gene expression, as has been suggested for $\mathrm{Na}_{\mathrm{v}} 1.7$ channels (Deuis et al., 2017; Sexton et al., 2017). Effects of $\mathrm{Ca}_{\mathrm{v}} 2$ block may be mediated via long-term changes in intracellular $\mathrm{Ca}^{2+}$ handling by mitochondria (D'Arco et al., 2015). It is also known that nerve injury downregulates HVA calcium channel current $\left(\mathrm{I}_{\mathrm{Ca}}\right)$ in DRG neurons (Baccei and Kocsis, 2000; Hogan et al., 2000; Abdulla and Smith, 2001b; Pan et al., 2016). If a similar or greater decrease occurs in primary afferent terminals, this downregulation in combination with channel block may be sufficient to attenuate neurotransmitter release in the dorsal horn.

a. $C a_{v} 2$ channels as therapeutic targets. In view of the inconvenient pharmacokinetics of peptide neurotoxins such as ziconotide (synthetic $\omega$-conotoxin MVIIA), which has to be administered intrathecally (McGivern, 2007), there is considerable interest in developing small-molecule blockers of $\mathrm{Ca}_{\mathrm{V}} 2$ channels (Waxman and Zamponi, 2014; Zamponi et al., 2015; Zamponi, 2016; Patel et al., 2017). Several statedependent $\mathrm{Ca}_{\mathrm{v}} 2$ blockers are currently under development, including ZC88 (Meng et al., 2008; Zhang et al., 2015b), A-1264087 (Xu et al., 2014; Zhu et al., 2014), and TROX-1 (Abbadie et al., 2010; Swensen et al., 2012; Patel et al., 2015). Oral administration of all of these drugs displays antiallodynic efficacy in rodent models of neuropathic pain (Patel et al., 2017).

N-type $\mathrm{Ca}^{2+}$ channels are also modulated by $\alpha_{2}$ adrenoceptor agonists such as clonidine (Abdulla and Smith, 1997) and opioids (Seward and Henderson, 1990; Abdulla and Smith, 1998; Altier and Zamponi, 2008). Given their limited clinical efficacy and loss of functional $\mu$-opioid receptors after nerve injury (Abdulla and Smith, 1998; Zhang et al., 1998), actions of opioids are not particularly relevant to discussion of neuropathic pain. In contrast, the $\alpha_{2}$ adrenoceptor agonist, clonidine, displays antiallodynic actions in a rodent model (Puke et al., 1991), and meta-analysis of clinical trials suggests some clinical efficacy (Giovannitti et al., 2015). These effects may be mediated by restoration of $\alpha_{2}$ adrenergic modulation of pain processing at the spinal level following peripheral nerve injury (Bannister and Dickenson, 2017) and/or by attenuation of aberrant interactions between sympathetic and sensory nerves in the periphery (McLachlan et al., 1993; Abdulla and Smith, 1997; Yen et al., 2006). N-type $\mathrm{Ca}^{2+}$ channels in DRG are also modulated by neuropeptide Y (NPY), and this effect, which is mediated via Y2 receptor, is increased after nerve injury (Abdulla and Smith, 1999). This has led to the suggestion that Y2 agonists, which suppress excitatory synaptic transmission in substantia 
gelatinosa, may play a role in the management of neuropathic pain (Moran et al., 2004; Smith et al., 2007). This idea is supported by the observation that intrathecal injection of NPY attenuates mechanical and cold hypersensitivity in the rodent (spared nerve injury) model (Intondi et al., 2008). Spinal galanin receptors may represent an additional drug target (Alier et al., 2008). Both NPY and galanin are found in inhibitory interneurons in dorsal horn (Iwagaki et al., 2013; Boyle et al., 2017; Todd, 2017).

b. $C a_{v} 1$ channels as therapeutic targets. In addition to the established role of changes in $\mathrm{N}$-type $\mathrm{Ca}^{2+}$ channels, certain lines of evidence support an additional contribution of L-type $\mathrm{Ca}^{2+}$ channels in the maintenance of neuropathic pain (Balasubramanyan and Smith, 2005; Fossat et al., 2010; Chang et al., 2015; Radwani et al., 2016). This has led to increased interest in broad-spectrum dihydropyridine-related $\mathrm{Ca}^{2+}$ channel blockers such as M4, which blocks $\mathrm{Ca}_{\mathrm{v}} 1.2$ (L-type), $\mathrm{Ca}_{\mathrm{v}} 2.2$ (N-type), and $\mathrm{Ca}_{\mathrm{v}} 3.2$ and 3.3 (T-type channels) (Gadotti et al., 2015; Zamponi et al., 2015). Possible cardiovascular actions of this type of substance may curtail their further therapeutic development,

3. Changes in LVA $\mathrm{Ca}^{2+}$ Channels $\left(\mathrm{Ca}_{v} 3\right)$. By contrast with the role of P/Q-type $\left(\mathrm{Ca}_{\mathrm{v}} 2.1\right)$ and N-type $\left(\mathrm{Ca}_{\mathrm{v}} 2.2\right)$, HVA-Ca ${ }^{2+}$ channels in neurotransmitter release, T-type, LVA, $\mathrm{Ca}^{2+}$ channels $\left(\mathrm{Ca}_{\mathrm{v}} 3.1, \mathrm{Ca}_{\mathrm{v}} 3.2\right.$, $\left.\mathrm{Ca}_{\mathrm{v}} 3.3\right)$ play an important role in setting neuronal excitability. In view of this, there is considerable interest in targeting these channels in pain management (Altier and Zamponi, 2004; Iftinca and Zamponi, 2009; Todorovic and Jevtovic-Todorovic, 2013; Snutch and Zamponi, 2017). This is especially the case as T-type $\mathrm{Ca}^{2+}$ channel currents are increased in sensory neurons following nerve injury in a model of diabetic neuropathy (Jagodic et al., 2007, 2008). Mechanistically, this may involve upregulation of the deubiquitinase, USP5, by the action of the inflammatory mediator IL- $1 \beta$. The resultant impairment of $\mathrm{Ca}_{\mathrm{v}} 3.2$ channel ubiquitination would prolong surface expression of T-type LVA Ca ${ }^{2+}$ channels and thereby promote increased excitability (Stemkowski et al., 2017).

a. $C a_{v} 3$ channels as therapeutic targets. The observation that T-type $\mathrm{Ca}^{2+}$ channel blockers mibefradil and ethosuximide acutely increase withdrawal thresholds in rats subject to nerve injury further supports the suggestion that T-type channels are involved in neuropathic pain expression. Small-molecule T-channel blockers (KYS05090S or ABT-639) also showed promise in preclinical studies (Jarvis et al., 2014; Zhang et al., 2015a; M'Dahoma et al., 2016). Unfortunately, preliminary clinical results with ABT-639 have been disappointing (Patel et al., 2015).

Cannabinoids, which are effective in some neuropathic pain cases (Moulin et al., 2014; Hauser et al., 2017), inhibit recombinant human T-type $\left(\mathrm{Ca}_{\mathrm{v}} 3.1,3.2\right)$ $\mathrm{Ca}^{2+}$ channels (Ross et al., 2008), and intrathecal injection of the cannabinoid receptor 1/cannabinoid receptor 2 (CB2) receptor agonist NMP-7 inhibits injury-induced neuropathic pain in a rodent model. This effect involves CB2 receptors and $\mathrm{Ca}_{\mathrm{v}} 3.2$ channels (Berger et al., 2014). To the best of our knowledge, NMP7 has not yet progressed to clinical trials, but its preclinical effectiveness led to the development of the derivative [N-((1-(2-(tertbutylamino)-2-oxoethyl)piperidin-4-yl)methyl)-9-pentyl-9Hcarbazole-3-carboxamide], which displays remarkable effectiveness in both inflammatory and neuropathic pain (Bladen et al., 2015).

Several additional small molecules that modulate $\mathrm{Ca}_{\mathrm{v}} 3.2$ channels either directly or via CB2 receptor activation are in early preclinical development. For further information, see review by Snutch and Zamponi (2017).

4. Changes in Hyperpolarization-Activated Cyclic Nucleotide-Gated Channels. HCN channels have emerged as a promising peripheral drug target for neuropathic as well as inflammatory pain (Chaplan et al., 2003; Emery et al., 2011, 2012; Noh et al., 2014; Young et al., 2014; Tsantoulas et al., 2016). HCN2 is expressed in about half of small somatosensory neurons, which are mainly nociceptors, and plays an important role in the control of firing frequency in response to noxious stimuli (Emery et al., 2011). Indeed, deletion of HCN2 in nociceptive neurons prevents the development of inflammatory and neuropathic pain (Emery et al., 2011).

HCN channels are upregulated after nerve injury, and it is thought that they drive spontaneous activity in the DRG (Luo et al., 2007; Emery et al., 2011, 2012; Young et al., 2014) to increase transmitter release from primary afferents (Antal et al., 2004; Papp et al., 2006).

a. HCN channels as therapeutic targets. A blocker of HCN channels, ivabradine, which is also used clinically to treat angina and heart failure, has been shown to be effective in treating signs of neuropathic pain in animal models through peripheral action on small sensory neurons and to decrease firing frequency in cultured DRG neurons from nerve-injured animals (Noh et al., 2014; Young et al., 2014). More recent work has focused on the search for selective HCN2 blockers (Sartiani et al., 2017) that may abrogate hyperexcitability of DRG neurons without affecting the HCN1 channels that are responsible for controlling cardiac rhythmicity (Tsantoulas et al., 2016).

5. Changes in $\mathrm{K}^{+}$Channels. Attenuation of various types of $\mathrm{K}^{+}$channel conductance also contributes to the increased excitability of DRG neurons that follows injury or exposure to inflammatory cytokines such as IL-1 $\beta$ (Abdulla and Smith, 2001a,b; Kim et al., 2002; Tan et al., 2006; Stemkowski et al., 2015; Cao et al., 2012; Stemkowski and Smith, 2012a; Tsantoulas et al., 2012; Waxman and Zamponi, 2014; Gonzalez et al., 2017).

Changes in $\mathrm{K}^{+}$channel currents may also contribute to pain associated with diabetic neuropathy (Cao et al., 2010). 
This prompted the suggestion that the anticonvulsant retigabine (Passmore et al., 2003) and related $\mathrm{K}_{\mathrm{v}} 7.2-\mathrm{K}_{\mathrm{v}} 7.3$ channel openers (Zhang et al., 2013; Busserolles et al., 2016), as well as facilitators of $\mathrm{Na}^{+}$activated $\mathrm{K}^{+}$channel currents (Huang et al., 2013) or two pore $\mathrm{K}^{+}$channels or $\mathrm{K}_{\mathrm{V}} 2$ or Kv9.1 channels, may be useful in pain management (Tsantoulas et al., 2012; Yekkirala et al., 2017). Unfortunately, a clinical trial with retigabine failed to meet its primary efficacy end point (Yekkirala et al., 2017). The retigabine analog $\mathrm{N}$-(6-chloro-pyridin-3-yl)-3,4-difluorobenzamide (ICA-27243) has been reported to attenuate inflammatory pain in animal models (Hayashi et al., 2014), but we are unaware of any clinical trials with this substance. Beyond neuropathic pain arising from peripheral nerve injury, it has been reported that injury to the spinal cord per se can impede $\mathrm{K}^{+}$channel function in DRG (Ritter et al., 2015), and this may contribute to mechanical allodynia. Altered $\mathrm{K}^{+}$channel function in DRG may reflect the diffusion of inflammatory mediators from the site of injury within the spinal cord (Carlton et al., 2009).

Changes in $\mathrm{K}^{+}$channel function may not always involve changes in expression or properties of poreforming $\alpha$ subunits themselves but may rather result from changes in regulatory subunits. For example, it was recently shown that $\mathrm{K}^{+}$channel modulatory subunits KChIP1, KChIP2, and DPP10 are coexpressed with $\mathrm{K}_{\mathrm{v}} 4.3$ in nonpeptidergic small neurons of the rat DRG. Spinal nerve ligation downregulated all three modulatory subunits, and their knockdown by intrathecal injection of a gene-specific antisense oligodeoxynucleotides evoked mechanical hypersensitivity. Rescue of the downregulated subunits by injection of appropriate cDNA constructs attenuated injuryinduced hypersensitivity (Kuo et al., 2017). These findings imply that targeting of regulatory subunits rather than pore-forming subunits of $\mathrm{K}^{+}$channels may lead the way to new therapeutic approaches. This is in fact analogous to targeting the $\alpha 2 \delta$-1 subunit of $\mathrm{Ca}^{2+}$ channels by gabapentin to control $\alpha$ subunit function (Dolphin, 2016) and to the suggested targeting of nonconducting $\beta$ subunits of $\mathrm{Na}^{+}$channels (O'Malley and Isom, 2015).

6. Changes in Transient Receptor Potential Channels. TRPV1 are nonselective cation channels that belong to the larger group of multifunctional TRP channels (Nilius et al., 2007). They are activated by the vanilloid, capsaicin, and by noxious heat, low $\mathrm{pH}$, osmolarity changes, and arachidonic acid metabolites (Caterina and Julius, 2001). TRPV1 sensitivity to temperature is increased following exposure to nociceptive molecules like nerve growth factor, or agents acting through $G$ protein-coupled receptors such as bradykinin, prostaglandin E2, or angiotensin acting on angiotensin type 2 receptors (AT2) (Yekkirala et al., 2017).

A recent paper addresses the role of the cold-sensing channel, TRP channel type M8 (TRPM8), in cold allodynia (Gonzalez et al., 2017). Nerve injury does not appear to directly upregulate this channel but rather decreases expression of an excitability brake potassium current $\left(\mathrm{K}_{\mathrm{v}} 1.1-1.2\right)$ in cold-sensitive DRG neurons. Cold-induced currents through an unchanged population of TRPM8 are thus more effective in promoting depolarization and increased action potential discharge.

a. Transient receptor potential type V1 channels as therapeutic targets-capsaicin and transient receptor potential channel type V1 antagonists. TRPV1 is upregulated in DRG following partial nerve injury or spinal nerve ligation (Hudson et al., 2001; Fukuoka et al., 2002), and TRPV1 antagonists have been shown to attenuate injury-induced hyperalgesia (Basso and Altier, 2017). These findings implicate TRPV1 channels in the etiology of neuropathic pain, and it is possible that other TRP channels such as TRPM8 and TRP channel type A1 also play a role (Basso and Altier, 2017). Because TRPV1 antagonists are effective in animal models, it seems paradoxical that capsaicin patches are somewhat effective in management of neuropathic pain (Finnerup et al., 2015). One explanation may be that the $\mathrm{Ca}^{2+}$ influx induced by TRPV1 activation destroys nociceptor terminals or that the receptors become desensitized and no longer respond to inflammatory mediators. Given the demonstration of interruption of pain memory in animal models by capsaicin (Bonin and de Koninck, 2014), perhaps some of its actions in the clinic reflect the presence of a reconsolidation phenomenon in human neuropathic pain.

b. Transient receptor potential type V1 channels as therapeutic targets-angiotensin receptor type 2 receptor antagonists. The observation that activation of the AT2 can enhance TRPV1 channel function has brought forward the idea that it may serve as a therapeutic target in control of neuropathic pain (Smith et al., 2013; Ink and Schatman, 2017; Yekkirala et al., 2017). The AT2 receptor antagonist EMA401 produces dosedependent antinociception in mouse neuropathic pain models and inhibits capsaicin-induced calcium fluxes in human and DRGs (Anand et al., 2013). The results of phase I and II clinical trials in patients suffering from postherpetic neuralgia are encouraging as EMA401 produces significant analgesia (Rice et al., 2014; Rice and Smith, 2015). The tolerability of EMA401 may reflect the fact that cardiovascular, renal, and vasoconstrictor actions of angiotensin are mediated by the angiotensin receptor type 1.

\section{J. Neuroimmune Interactions in Neuropathic Pain}

In addition to the obvious importance of neurons and the accepted role of microglia in the initiation of neuropathic pain (Coull et al., 2005; Lu et al., 2009; Beggs and Salter, 2012b, 2013), the role of other immunocompetent cells, such as astrocytes, endothelial cells, perivascular macrophages, infiltrating $\mathrm{T}$ cells, and 
satellite glial cells of DRG neurons, must not be overlooked (DeLeo et al., 2007; Scholz and Woolf, 2007; Costigan et al., 2009a; Beggs et al., 2010; Calvo et al., 2012; Grace et al., 2014; Vicuna et al., 2015; Dodds et al., 2016; Ji et al., 2016; Lim et al., 2017; Mikuzuki et al., 2017). This follows the recognition that immune cells express many of the receptors and transduction mechanisms that are activated by injury to neurons (Chiu et al., 2012). The idea of immune system involvement in chronic pain came about from observing classic signs of a systemic sickness response (malaise, lethargy, depression, anxiety) in chronic pain patients. This idea was later corroborated by findings showing that elevated levels of IL- $1 \beta$ in peripheral nerves could both mediate and induce hyperalgesia (Grace et al., 2014). It was also demonstrated that IL- $1 \beta$, in addition to its proinflammatory actions, can directly activate nociceptors to generate action potential firing, increased membrane availability of $\mathrm{Ca}_{\mathrm{v}} 3.2$ (T-type) channels (Stemkowski et al., 2017), and hyperalgesia (Binshtok et al., 2008; Stemkowski and Smith, 2012a; Stemkowski et al., 2015). As already mentioned, cytokines such as IL- $1 \beta$ may be responsible for increased expression of CSF-1 in primary afferent neurons (Lim et al., 2017). This in turn is released into the spinal cord, where it promotes BDNF release from microglia and increased dorsal horn excitability (Guan et al., 2016; Okubo et al., 2016) (Fig. 2A).

In addition to altering neuronal activity via the release of $\mathrm{BDNF}$, reactive microglia release cytokines and chemokines such as fractalkine and other inflammatory mediators that trigger peripheral immune cell infiltration and astrogliosis. In addition, damaged sensory neurons release CCL2 (also known as monocyte chemoattractant protein 1) as well as neuregulin 1 and fractalkine. The net effect of complex interactions between invading and resident immunocompetent cells and numerous signaling molecules is the generation of classic inflammatory mediators such as IL- $1 \beta$, IL- 6 , and IL-18, and TNF. These influence neuronal activity by facilitation of spinal LTP (Gruber-Schoffnegger et al., 2013), direct excitatory actions on neurons (Binshtok et al., 2008; Gustafson-Vickers et al., 2008; Kawasaki et al., 2008; Stemkowski and Smith, 2012a; Stemkowski et al., 2015), increased release of glutamate from primary afferents (Yan and Weng, 2013), and decreased release of GABA from dorsal horn interneurons (Zhang and Dougherty, 2011).

It is noteworthy that generation of mediators such as IL-1 $\beta$ and TNF may not be entirely maladaptive as cytokines have been implicated in functional recovery of damaged nerves (Nadeau et al., 2011) and neuroinflammation may assist in remyelination (Goldstein et al., 2016).

A further development in the area of neuroimmune interactions related to pain is the observation that bacterial infections can cause pain via pathogens interacting directly with and activating nociceptors (Chiu et al., 2013; Ji et al., 2016).

A full description of neuroimmune interactions in neuropathic pain is beyond the scope of the present review. For further information, the reader is referred to reviews by Linda Watkins and others (DeLeo et al., 2007; Milligan and Watkins, 2009; Grace et al., 2014; Dodds et al., 2016; Mifflin and Kerr, 2017). Although targeting the immune system may seem a rational basis for developing antiallodynic drugs (Leung and Cahill, 2010), to the best of our knowledge, no suitable small molecules have yet been identified (Yekkirala et al., 2017). This lack of success may be attributed, at least in part, to the notion that neuroimmune interactions trigger the onset of neuropathic pain, whereas other mechanisms, more relevant to the clinical presentation, are responsible for its long-term maintenance.

\section{K. Adenosine A3 Receptors as a Therapeutic Target}

The idea that the most effective agents in neuropathic pain management likely exert actions through multiple targets has already been alluded to. Adenosine A3 receptor agonists represent one such class of agents as they interact with several of the pathophysiological mechanisms outlined above (Janes et al., 2016). A3 receptors are found on immune cells, astrocytes (Bjorklund et al., 2008; Janes et al., 2015), microglia (Hammarberg et al., 2003), and both peripheral and central neurons (Janes et al., 2016). In addition, the A3 receptor agonist MRS5698 attenuates KCC2 downregulation and restores $\mathrm{Cl}^{-}$gradients in rodent CCI models (Ford et al., 2015), a process that may involve attenuation of BDNF signaling (Janes et al., 2016). A3 receptor activation also attenuates neuroinflammatory responses, astrocyte reactivity, and cytokine release (Janes et al., 2015, 2016). Efficacy of A3 receptor agonists such as IB-MECA and MRS5698 in relief of allodynia in rodent models of neuropathic pain has been convincingly demonstrated (Ford et al., 2015; Little et al., 2015). Because cardiovascular actions of adenosine are mediated via A1 and A2 adrenoceptors (Sawynok, 2016), A3 agonists show considerable promise as therapeutic agents (Janes et al., 2016). The results of clinical trials are thus eagerly awaited.

\section{Current Therapeutic Management of Neuropathic Pain: Focus on Gabapentinoids}

Whereas opioids are highly effective in many forms of nociceptive pain (Yekkirala et al., 2017), an equivalent panacea for the management of neuropathic pain is yet to appear (Patel et al., 2017). As mentioned above, loss of opioid effectiveness after nerve injury may reflect downregulation or attenuated signaling via $\mu$ opioid receptors (Abdulla and Smith, 1998; Zhang et al., 1998; Kohno et al., 2005). This underlines the urgent need to develop new drugs. Despite the extensive investigation 
of signaling mechanisms associated with neuropathic pain and the new data available, with the possible exception of cannabinoids (Hauser et al., 2017; Yekkirala et al., 2017), essentially no new evidence-based therapeutic approaches have gained widespread recognition since the introduction of gabapentinoids in the 1990s. As already mentioned, Table 2 lists a variety of agents or viable candidates that are currently under investigation and that have either not yet reached clinical trials or have progressed successfully to phase 1 and/or phase 2 trials.

GBP and PGB, as well as tricyclic antidepressants (such as low-dose amitriptyline) and serotoninnoradrenaline reuptake inhibitors (such as venlafaxine), thus still retain their status as first-line treatments (Finnerup et al., 2015) (Table 1). Given their therapeutic importance and the paucity of information regarding their exact mechanism of action (Dolphin, 2016), the remainder of the review will discuss the current understanding of gabapentinoid action in the light of recent advances in the understanding of the etiology of neuropathic pain. We have already commented that "the most used drugs are the least well understood."

\section{A. Gabapentinoids and the $\alpha 2 \delta$ Subunits of Voltage- Gated $\mathrm{Ca}^{2+}$ Channels}

GBP was originally used as an adjunct or monotherapy for partial and general tonic-clonic seizures, but was later approved as a treatment of postherpetic neuralgia (Taylor et al., 2007). Both PGB and GBP are used to treat various forms of neuropathic pain, including fibromyalgia (Moore et al., 2014). Some reports suggest they may be beneficial in postoperative pain (Dauri et al., 2009; Clarke et al., 2012), as well as in management of neurogenic overactive bladder (Carbone et al., 2006) and migraine (Calandre et al., 2010; Pizzolato et al., 2011; Cain et al., 2017). An enacarbil derivative of GBP with improved oral bioavailability is available (Cundy et al., 2004), and this has been approved for use in postherpetic neuralgia and restless legs syndrome.

Despite their structural similarity to GABA, neither GBP nor PGB binds to $\mathrm{GABA}_{\mathrm{A}}$ or to $\mathrm{GABA}_{\mathrm{B}}$ receptors (Lanneau et al., 2001; Moore et al., 2002; Sutton et al., 2002; Li et al., 2011). Gabapentinoids also do not affect GABA uptake, synthesis, or metabolism (Taylor et al., 2007; Taylor, 2009). Gee et al. (1996) isolated and sequenced a protein that bound GBP from porcine brain, which was identified as the $\alpha 2 \delta$-1 subunit of voltage-gated calcium channels (VGCCs). Gabapentinoids are thus referred to as $\alpha 2 \delta$ ligands. Because partial purification of $\alpha 2 \delta$ subunits increases their apparent apparent affinity for GBP (Davies et al., 2006), it has been suggested that the drug competes for binding of an endogenous ligand, which may be a small molecule such as leucine, isoleucine, or valine (Hendrich et al., 2008).

The importance of the $\alpha 2 \delta$-1 subunit for gabapentinoid action is supported by the observation that gabapentinoid binding is reduced and inhibition of allodynia is also lost in a R217A- $\alpha 2 \delta$ - 1 loss-of-function mutant mouse (Field et al., 2006). These mice do, however, exhibit allodynia following peripheral nerve injury. Structure activity studies of PGB analogs also identified a correlation between $\alpha 2 \delta$-binding affinity (labeled GBP displacement) and therapeutic effectiveness (Belliotti et al., 2005).

The $\alpha_{2} \delta$ subunits are encoded by one of four mammalian genes, CACNA2D1-CACNA2D4. Although the $\alpha_{2} \delta$ subunit is encoded by a single gene, it is expressed as two individual proteins ( $\alpha_{2}$ and $\delta$ ), which then reassemble and associate with the pore-forming $\alpha$ subunit of the VGCC (Dolphin, 2012b, 2013, 2016).

1. Isoforms and Structure of $\alpha 2 \delta$ Subunits. The four mammalian genes, CACNA2D1, 2, 3, and 4, encode the four known isoforms of the $\alpha_{2} \delta$ subunit: $\alpha_{2} \delta-1, \alpha_{2} \delta-2$, $\alpha_{2} \delta$-3, and $\alpha_{2} \delta$-4 (Dolphin, 2013, 2016). All isoforms have a similar structure (Dolphin, 2012b), and a signal sequence at the $\mathrm{N}$ terminus of the nascent polypeptide directs $\alpha 2 \delta$ into the lumen of the endoplasmic reticulum. The subunit is thus expressed extracellularly once transported to the plasma membrane. The protein sequence of all $\alpha 2 \delta$ isoforms contains a Von Willebrand Factor A (VWA) domain that plays an important role in protein-protein interactions. Such interactions may be affected by a five-residue sequence comprising the metal ion-dependent adhesion site (MIDAS) motif (Whittaker and Hynes, 2002). The nature of a short hydrophobic domain at the $\mathrm{C}$ terminus of $\alpha 2 \delta$ subunits predicts that they are glycosylphosphatidylinositol anchored (Davies et al., 2010). This means that the mature protein appears on the extracellular surface, making it potentially susceptible to extracellular modulation (Davies et al., 2010). However, recent data suggest that gabapentinoids interact with $\alpha 2 \delta$ at an intracellular site prior to its trafficking to the cell surface (Lana et al., 2016). As will be discussed below, this is supported by the observation that GBP has to gain access to the neuronal cytoplasm via the system-L neutral amino acid transporter to exert its action (Hendrich et al., 2008; Biggs et al., 2014, 2015).

Another cache domain containing the RRR (triple arginine repeat) is positioned adjacent to the VWA domain in $\alpha 2 \delta$-1. This sequence may be important for gabapentinoid binding (Field et al., 2006). The structure of $\alpha 2 \delta-1$ is illustrated schematically in Fig. 5A.

2. Tissue Distribution of $\alpha 2 \delta$ Subunits. The expression of $\alpha 2 \delta$ subunits is fairly ubiquitous (Gong et al., 2001). Whereas the $\alpha 2 \delta$-1 subunit is expressed in skeletal, cardiac, and smooth muscles as well as in the CNS, peripheral nervous system, and endocrine tissues, 
the $\alpha 2 \delta$-2 subunit is expressed predominantly in the CNS, especially the cerebellum (Dolphin, 2012b, 2013). The $\alpha 2 \delta$-3 subunit is expressed in the CNS, whereas $\alpha 2 \delta$ 4 is expressed primarily in the retina and in endocrine tissues. In neurons, the $\alpha 2 \delta$-1 transcript preferentially colocalizes with excitatory neurons, and the $\alpha 2 \delta-2$ mRNA colocalizes with GABAergic inhibitory neurons (Cole et al., 2005). This is congruent with the observation that overexpression of $\alpha 2 \delta$-1 increases excitatory synaptic transmission with minimal effect on inhibitory synaptic transmission in the spinal dorsal horn (Zhou and Luo, 2015). Gabapentin binds with greater affinity to the $\alpha 2 \delta-1$ than to the $\alpha 2 \delta$-2 subunit, with no binding affinity for $\alpha 2 \delta-3$ (Marais et al., 2001).

\section{B. $\alpha 2 \delta$ Subunits and Neuropathic Pain}

It is now well established that $\alpha 2 \delta$-1 protein expression is increased in rodent models of neuropathic pain (Luo et al., 2002; Xiao et al., 2002; Boroujerdi et al., 2008, 2011; Bauer et al., 2009). After nerve ligation in nerve-injured (but not sham-operated) rats, a 17-fold increase in the $\alpha 2 \delta$-1 protein in ipsilateral L5/L6 DRGs was observed. No increase in expression levels of other subtypes of the $\alpha 2 \delta$ subunit ( $\alpha 2 \delta-2,-3$, and -4) following nerve injury has been reported. Another spinal nerve ligation study showed that injury-induced discharges that contribute to the onset of neuropathic pain moderate the expression of $\alpha 2 \delta$ in the spinal dorsal horn (Boroujerdi et al., 2008, 2011). Local application of lidocaine blocked both injury-induced discharges and the upregulation of $\alpha 2 \delta$ in both dorsal spinal cord and dorsal root ganglia.

In mice, $\alpha 2 \delta$-1 gene deletion results in deficits in behavioral signs of mechanical and cold sensitivity and delayed mechanical hypersensitivity in response to peripheral nerve injury (Patel et al., 2013). This correlates with the observation that sensory neurons in $\alpha 2 \delta-1$ knockout mice show diminished ability to generate repetitive action potentials (Margas et al., 2016). In addition, mice that overexpress $\alpha 2 \delta$ develop mechanical allodynia similar to nerve injury models, and this has been shown to be mediated by a presynaptic mechanism involving an increase in excitatory synaptic transmission, as is the case with nerve injury (Nguyen et al., 2009; Zhou and Luo, 2014, 2015). Inhibitory transmission is unaffected. It is clear therefore that the $\alpha 2 \delta$-1 subunits of VGCCs play an important role in the onset of neuropathic pain.

\section{Physiologic Roles of $\alpha 2 \delta$ Subunits}

Mutation or dysfunction of $\alpha 2 \delta$ subunits has been associated with convulsive and neuropsychiatric disorders as well as with night blindness and cardiovascular dysfunction (Heyes et al., 2015; Dolphin, 2016). These observations relate directly to the use of gabapentinoids as anticonvulsants (Taylor et al., 2007; Offord and Isom, 2015). For the purpose of the present review, we will focus on the physiologic role of $\alpha 2 \delta$ subunits as they pertain to nociception and neuropathic pain.

1. Rapid Trafficking of $\mathrm{Ca}^{2+}$ Channel $\alpha$ Subunits to the Plasma Membrane. Upregulation of $\alpha 2 \delta$ subunits increases the expression of $\mathrm{Ca}_{\mathrm{v}} 1$ and $\mathrm{Ca}_{\mathrm{v}} 2 \alpha$ subunits at the plasma membrane as well as calcium current density (Yasuda et al., 2004; Canti et al., 2005; TranVan-Minh and Dolphin, 2010; Dolphin, 2016). The MIDAS motif in the VWA domain of $\alpha 2 \delta-1$ and $\alpha 2 \delta-2$ is responsible for both effects (Canti et al., 2005; Hoppa et al., 2012; D'Arco et al., 2015). In the case of $\mathrm{Ca}_{\mathrm{v}} 1$ channels, this involves interaction with extracellular site on the $\alpha 1$ subunit (Walsh et al., 2009). Altered surface expression of $\mathrm{Ca}^{2+}$ channels has been proposed to exert a secondary effect on mitochondrial $\mathrm{Ca}^{2+}$ buffering (D'Arco et al., 2015).

2. Slower Trafficking of $\mathrm{Ca}^{2+}$ Channel $\alpha$ Subunits to Primary Afferent Terminals. In addition to controlling trafficking of $\mathrm{Ca}^{2+}$ channel $\alpha$ subunits to the cell surface, $\alpha 2 \delta$ subunits are thought to interact with proteins involved in trafficking of membrane protein cargos (Dolphin, 2012b, 2016). In the case of primary afferent neurons, $\alpha 2 \delta$ is implicated in the relatively slow trafficking of $\alpha$ subunits of HVA-Ca ${ }^{2+}$ channels from their site of synthesis in the cell body, along primary afferent axons, to their terminals in the spinal dorsal horn (Bauer et al., 2009). It is tempting to speculate that attenuation of this slow trafficking process by gabapentinoids corresponds to reports of their slow onset of action in neuropathic pain patients (Cheshire, 2002; Stacey et al., 2008; Sharma et al., 2010), but, as discussed in Rate of Onset of Gabapentinoid Effect, we think this is unlikely to be the case.

3. Regulation of High-Voltage-Activated $\mathrm{Ca}^{2+}$ Channel Function. Because $\alpha 2 \delta$ does not affect singlechannel conductance, increases in whole-cell HVA $\mathrm{I}_{\mathrm{Ca}}$ observed following increased $\alpha 2 \delta$ expression may be a consequence of more channels being inserted into the plasma membrane (Dolphin, 2016). However, in the case of $\alpha 2 \delta-1$ effects on $\mathrm{Ca}_{\mathrm{v}} 2.2$ channels in N2a cells, the increase in current is 10 -fold, whereas the increase in protein surface expression is <twofold (Hoppa et al., 2012; Cassidy et al., 2014). This implies that $\alpha 2 \delta$ has additional effects on channel function. In rat DRG neurons, we found that $\mathrm{PGB}$ decreased the rate of inactivation of $\mathrm{HVA}_{\mathrm{Ca}}$ (mainly $\mathrm{Ca}_{\mathrm{v}} 2.2$ and $\mathrm{Ca}_{\mathrm{v}} 1.2$ ) in medium and small $\mathrm{IB}^{+}{ }^{+}$and IB4 ${ }^{-}$neurons, but not in non-nociceptive large neurons (Biggs et al., 2014). This is consistent with the the generalization that $\alpha 2 \delta-1$ may serve to increase the rate of inactivation (Dolphin, 2016). Further attempts to elucidate these mechanisms in terms of voltage dependence and rate of activation and inactivation have led to conflicting findings. This is because the effects observed depend on which $\alpha 2 \delta$ subunits $-\mathrm{Ca}_{\mathrm{v}}$ channel $\alpha$ subunit combination is studied. Effects may also be contingent on the presence of $\beta$ subunits (Dolphin, 2016). 
A Schematic structure of $\alpha 2 \delta-1$

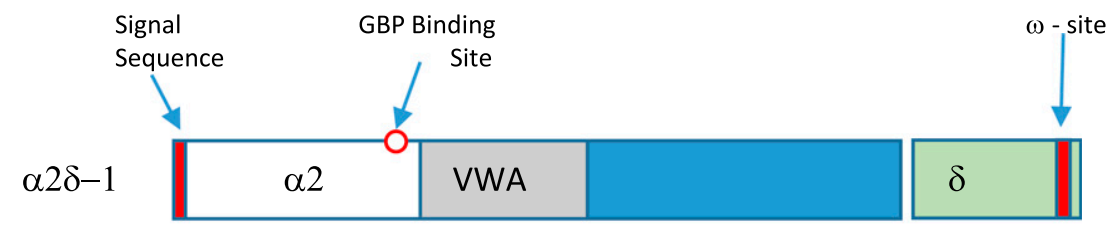

$\mathrm{N}$

C

B Slow and rapid actions of Gabapentinoids

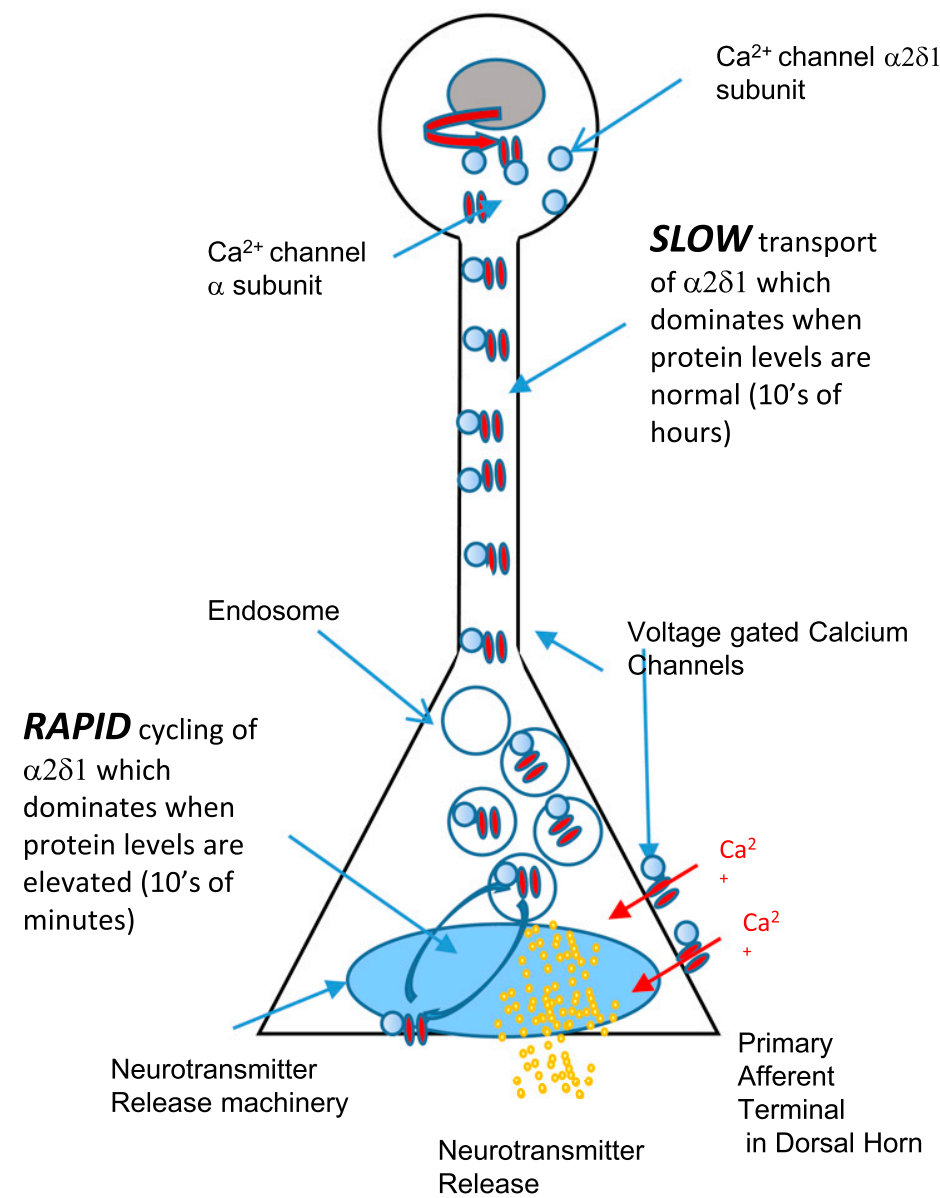

Fig. 5. (A) Diagram to illustrate the essential structural features of the $\alpha 2 \delta$-1 protein. (B) Diagram to illustrate slow and fast transport processes associated with $\alpha 2 \delta-1$. When levels of $\alpha 2 \delta 1$ are normal, its accumulation in nerve terminals is controlled by transport along primary afferent fibers from cell bodies to the dorsal horn, a distance of about $7.5 \mathrm{~mm}$ in a rat. When levels of $\alpha 2 \delta-1$ are elevated after nerve injury, rapid cycling in nerve terminals over distances of $<1 \mu \mathrm{m}$ determines level at release sites. Gabapentinoids that inhibit transport of $\alpha 2 \delta$-1 thus work slowly when $\alpha 2 \delta$ - 1 levels are normal, but rapidly when its levels are elevated in neuropathic pain.

It was shown recently, however, that the posttranslational cleavage of $\alpha 2 \delta-1$ into the disulfidelinked polypeptides $\alpha 2-1$ and $\delta$ is an essential step that permits voltage-dependent activation of plasma membrane $\mathrm{N}$-type $\mathrm{Ca}^{2+}$ channels $\left(\mathrm{Ca}_{\mathrm{V}} 2.2\right)$, and that uncleaved $\alpha 2 \delta$ inhibits native calcium currents (Kadurin et al., 2016). These authors showed that voltage-dependent activation of $\mathrm{Ca}_{\mathrm{V}} 2.2$ channels is promoted following cell surface proteolytic cleavage of $\alpha 2 \delta$, and that this effect was independent from the role of $\alpha 2 \delta$ trafficking. Trafficking of Cav2.2 channel complexes into neuronal processes was not supported by uncleaved $\alpha 2 \delta$. This mechanism may maintain immature calcium channels in an inhibited state such that proteolytic processing of $\alpha 2 \delta$ permits their voltagedependent activation. This may allow selective trafficking of mature calcium channel complexes into neuronal processes (Kadurin et al., 2016). 
4. Setting Neurotransmitter Release Probability. Experiments on hippocampal neurons have shown that, in addition to setting presynaptic $\mathrm{HVA}-\mathrm{Ca}^{2+}$ channel abundance, $\alpha 2 \delta$ subunits also directly control neurotransmitter release probability. It has been suggested that $\alpha 2 \delta$ subunits configure presynaptic $\mathrm{Ca}^{2+}$ channels to directly drive exocytosis. This process involves interaction affected via the MIDAS domain on $\alpha 2 \delta$ (Hoppa et al., 2012). It may be of special relevance to gabapentinoid action, as their ability to control $\mathrm{Ca}^{2+}$ channel abundance may not fully account for its ability to control neurotransmitter release from primary afferents (Biggs et al., 2014).

For additional information on $\alpha 2 \delta$ subunits and VGCC, see reviews by Bauer et al. (2010), Dolphin (2012b, 2013, 2016), and Zamponi et al. (2015).

\section{How Do the Gabapentinoids Work?}

1. Evidence for an Intracellular Site of Action. As already mentioned, GBP is thought to exert its actions by entering the neuronal cytosol through the system-L-neutral amino acid transporter prior to binding with $\alpha 2 \delta$-1. Structure-activity studies have revealed that PGB analogs that strongly bind $\alpha 2 \delta$, but which are not substrates for the transporter, lack therapeutic efficacy (Belliotti et al., 2005). This may, however, reflect failure of transport of the analogs into the brain. Stronger support for an intracellular site of action comes from the observation that GBP inhibition of HVA $\mathrm{I}_{\mathrm{Ca}}$ expressed in tsA-201 cells is prevented when the transporter is inhibited by 2-(-)-endoaminobicycloheptene-2-carboxylic acid (BCH). GBP effectiveness was also increased in Xenopus oocytes when the system-L-neutral amino acid transporter was coexpressed with $\mathrm{HVA}-\mathrm{Ca}^{2+}$ channels (Hendrich et al., 2008). Additional support for an intracellular site of action comes from the observation that GBP application ipsilateral to CCI alleviates allodynia and hyperalgesia, whereas contralateral application does not (Shahid et al., 2017).

One potential concern with these findings is that $\mathrm{BCH}$ binds to $\alpha 2 \delta$-1, albeit with a 10 -fold lower affinity than GBP (Gong et al., 2001). Our recent findings argue against the possibility that $\mathrm{BCH}$ prevents the effect of GBP by attenuating its binding to $\alpha 2 \delta-1$. We first established that application of GBP for 5 days reduced the excitability of spinal cord neurons maintained in organotypic culture, and that this effect was blocked by BCH (Biggs et al., 2014). We next used capsaicin to open TRPV1 channels and showed that GBP could enter the cytoplasm of primary afferent neurons via the open channel pore (Biggs et al., 2015). We used this method of GBP delivery to circumvent its entry via the transporter. GBP delivered via TRPV1 channels decreased spinal cord activity, but this effect was not blocked by $\mathrm{BCH}$. This indicates that the weak binding of $\mathrm{BCH}$ to $\alpha 2 \delta$ cannot account for its ability to attenuate GBP effects. Had this been the case, $\mathrm{BCH}$ would have attenuated the effect of GBP regardless of its route of access.

More recent work from our laboratory lends support to the idea that gabapentinoids work intracellularly (Alles et al., 2017). Part of this study involved in vivo administration of GBP and study of substantia gelatinosa neurons ex vivo from animals that had received GBP. These were nerve-injured animals and GBP effectively attenuated mechanical allodynia. Compared with controls, synaptic transmission was impaired in spinal cord slices obtained from animals that had received GBP, and liquid chromatography with mass spectrometry measurements confirmed the continued presence of the drug. Had the drug worked extracellularly to block allodynia in vivo, it would have been washed away by the time spinal cord slices were studied and no persistent effect of the drug would be seen. This supposition is supported by detailed quantitative arguments outlined in our paper (Alles et al., 2017). These observations are congruent with those of Lana et al. (2016), who showed that GBP displacement of thrombospondin 4 binding (see below) is effected at an intracellular site on $\alpha 2 \delta$-1.

2. A Role of Thrombospondins? Thrombospondins (TSP) 1-4 are endogenous ligands that bind to $\alpha 2 \delta-1$ (Eroglu et al., 2009; Lana et al., 2016; Park et al., 2016b). They are large extracellular matrix proteins that are upregulated by peripheral nerve injury (Pan et al., 2015). Because $\alpha 2 \delta$-1 has been implicated in synaptogenesis (Eroglu et al., 2009; Bauer et al., 2010), aberration of this process following nerve injury and the actions of thrombospondin 4 on $\alpha 2 \delta$-1 may contribute to central sensitization ( $\mathrm{Li}$ et al., 2014; Crosby et al., 2015; Park et al., 2016a,b). GBP disrupts the interaction between $\alpha 2 \delta$-1 and the synaptogenic domain of TSP2 and thereby disrupts synaptogenesis in vitro. It has been argued, however, that this effect may be of limited relevance to the therapeutic action of GBP, as any synaptic sprouting and remodelling associated with onset of neuropathic pain would have taken place before the initiation of therapy (Dolphin, 2016). Despite this, recent findings suggest that increased levels of TSP4 produced by nerve injury may contribute to hypersensitivity of peripheral sensory systems by decreasing $\mathrm{HVA}_{\mathrm{Ca}}$ and increasing $\mathrm{LVA} \mathrm{I}_{\mathrm{Ca}}$ in DRG neurons by interaction with $\alpha 2 \delta-1$. These effects are blocked by GBP (Pan et al., 2016).

3. Rapid and Slow Actions in the Spinal Dorsal Horn. The idea that $\alpha 2 \delta$ participates in two types of trafficking processes in primary afferent neurons has already been alluded to. This idea is supported by studies in hippocampal neurons, in which Hoppa et al. (2012) posited that $\alpha 2 \delta$ subunits function through two mechanisms: "A trafficking step from the cell soma and a local step at the presynaptic terminal allowing synapses to have increased exocytosis with decreased $\mathrm{Ca}^{2+}$ influx." We suggest that when $\alpha 2 \delta-1$ levels are 
elevated, either in neuropathic pain models or by genetic modulation (Luo et al., 2001, 2002; Bauer et al., 2009), it is rapidly and locally trafficked from the endoplasmic reticulum to the plasma membrane within primary afferent nerve terminals (Bauer et al., 2010; Alles and Smith, 2016; Alles et al., 2017). The presence of high levels of $\alpha 2 \delta$-1 in nerve terminals facilitates interaction of the $\alpha$ subunits of HVA-Ca ${ }^{2+}$ channels with the neurotransmitter release machinery. This interaction occurs via the MIDAS motif within the VWA domain of $\alpha 2 \delta$-1 (Hoppa et al., 2012).

This process is interrupted by gabapentinoids within 30 minutes of i.p. injection and accounts for the rapid antiallodynic effect seen in nerve-injured animals (Hunter et al., 1997; Field et al., 2006; Narita et al., 2012; Kumar et al., 2013; Alles and Smith, 2016; Alles et al., 2017). This idea is supported by the observation that a rapidly developing effect of $\mathrm{PGB}$ in rats subject to spared nerve injury was not associated with reduced accumulation of $\alpha 2 \delta-1$ in the superficial dorsal horn (Yang et al., 2014a). The immunohistochemical methods used in this paper would not distinguish between endoplasmic reticulum and cell surface-expressed $\alpha 2 \delta$-1.

By contrast, slowly developing actions of gabapentinoids seen in uninjured dorsal horn neurons in vitro (Moore et al., 2002; Hendrich et al., 2012; Biggs et al., 2014) may reflect interruption of trafficking of $\alpha_{2} \delta$ subunits from cell bodies to nerve terminals (Alles and Smith, 2016). The concept of actions of gabapentinoids on injured nerves and slower actions on uninjured nerves is illustrated schematically in Fig. 5B.

4. Differential Effects of Gabapentinoids on Excitatory and Inhibitory Processes in the Substantia Gelatinosa. As mentioned already, peripheral nerve injury increases excitatory synaptic transmission between primary afferent fibers and excitatory neurons in substantia gelatinosa (Balasubramanyan et al., 2006) (Fig. 4A). These neurons usually display a delayed or transient firing pattern in response to depolarizing current (Yasaka et al., 2010; Punnakkal et al., 2014). Acute treatment with GBP (Alles et al., 2017) restores synaptic transmission to the level seen in uninjured animals (Fig. 4A). As mentioned above, Fig. 4B shows that nerve injury also reduces excitatory synaptic transmission to inhibitory neurons (Balasubramanyan et al., 2006). Inhibitory neurons in substantia gelatinosae usually display a tonic firing pattern in response to depolarizing current commands (Yasaka et al., 2010). Interestingly, GBP appears to increase excitatory drive to inhibitory neurons (Biggs et al., 2014; Alles et al., 2017). The mechanism of this unexpected effect, which involves an increase in the frequency of sEPSC, remains to be elucidated.

By contrast, GABA/glycinergic inhibitory postsynaptic currents per se seem to be enhanced or unaffected by GBP (Moore et al., 2002). Taken together, these actions culminate in overall decrease in dorsal horn excitability as judged from $\mathrm{Ca}^{2+}$ responses to $35 \mathrm{mM} \mathrm{K}^{+}$(Biggs et al., 2014; Alles et al., 2017).

Figure 3B illustrates the effect of gabapentin on the electophysiological footprint produced in the substantia gelatinosa by sciatic CCI. The majority of the changes produced by gabapentin are the opposite of those seen with CCI (Fig. 3A). Thus, GBP almost entirely eliminates the electrophysiological footprint of CCI in the substantia gelatinosa (Fig. 3C).

5. Supraspinal Actions of Gabapentinoids. In addition to its spinal actions, supraspinal mechanisms clearly contribute to the therapeutic effects of gabapentinoids (Bannister et al., 2017b). This is hardly surprising given the ubiquitous distribution of $\alpha 2 \delta$ subunits throughout the nervous system (Dolphin, 2012a,b, 2013). Systemically administered GBP (100 mg/kg) inhibits descending excitatory pronociceptive serotonergic $\left(5 \mathrm{HT}_{3}\right.$-mediated) pathways from the brain to spinal cord in neuropathic rats (Suzuki et al., 2005). The effect of GBP was antagonized by a $5 \mathrm{HT}_{3}$ antagonist, which suggests that this could be a more predominant effect compared with a peripheral effect for an acute mechanism of cell-type-specific action of systemically delivered GBP. It has also been shown that GBP can increase extracellular glutamate release in the locus coeruleus via astrocyte-dependent mechanisms involving glutamate-transporter-1 (GLT-1; also known as EAAT2) to activate descending noradrenergic inhibition to reduce nociception (Suto et al., 2014).

Another study using ${ }^{8} \mathrm{~F}$-fluorodeoxyglucose-positron emission tomography supports a central contribution to the antiallodynic action of acute GBP (Lin et al., 2014). It was shown that spared nerve injury induced increases of glucose metabolism in thalamus, cerebellar vermis, and medial prefrontal cortex and that these changes were attenuated by acute GBP treatment. In a functional magnetic resonance imaging study, acute $100 \mathrm{mg} / \mathrm{kg}$ GBP was shown to evoke changes in multiple nociceptive brain regions, including the thalamus and periaqueductal gray in anesthetized naive rats (Governo et al., 2008). More recently, it was shown that PGB can reduce neuronal hyperexcitability that accompanies mechanical and heat-evoked responses in the ventral posterior thalamus of spinal nerve-ligated rats (Patel and Dickenson, 2016b). In addition, Alles et al. (2017) demonstrated that GBP can reduce neuronal hyperexcitability in the primary somatosensory cortex immediately following systemic injection in neuropathic rats, and that these effects correlate with effects on synaptic transmission in the spinal dorsal horn and antiallodynic actions of GBP.

6. Additional Sites of Gabapentinoid Action. The ubiquitous distribution of $\alpha 2 \delta$ subunits throughout the nervous system (Dolphin, 2012a,b, 2013) brings forward the possibility that they interact with downstream effectors other than the $\alpha$ subunits of voltage-gated $\mathrm{Ca}^{2+}$ channels. This would predict additional mechanisms of 
gabapentinoid effectiveness. For example, gabapentin has been reported to shift the voltage dependence of HCN4 channels to more negative potentials (Tae et al., 2017), but may increase hyperpolarization-activated cation current in hippocampal neurons (Surges et al., 2003). It has also been reported to interact with NMDA and AMPA receptors, as well as $\mathrm{K}_{\mathrm{ATP}}$ channels (Cheng and Chiou, 2006). It remains to be determined whether these actions proceed via interactions with $\alpha 2 \delta-1$ or whether other molecular processes are engaged. Some of the interactions of gabapentinoids with ion channels may reflect simple channel block.

\section{E. Doses of Gabapentinoids Used in Animal Studies and Relationship to Clinical Studies}

In early studies of GBP action and interaction with $\alpha 2 \delta$, seemingly high drug concentrations of drugs were used. For example, some of the results obtained by Hendrich et al. (2008) used $1 \mathrm{mM}$ GBP. These authors argued that the actions of GBP may reflect antagonism of positive modulators of $\alpha 2 \delta$ function, namely isoleucine and leucine, which were present at $800 \mu \mathrm{M}$ in their culture medium, as well as valine, which was present at $400 \mu \mathrm{M}$. Despite this, they were also able to observe some effects with more reasonable concentrations of GBP (100-200 $\mu \mathrm{M})$. We have routinely used $100 \mu \mathrm{M}$ gabapentin in our in vitro studies (Biggs et al., 2014, 2015; Alles and Smith, 2016; Alles et al., 2017), and this is within the range of plasma drug concentrations measured in patients: 70-120 (Johannessen et al., 2003) or 34.5-127.9 $\mu \mathrm{M}$ (Berry et al., 2003).

\section{Basic Science of Gabapentinoid Action and Observations in the Clinic}

\section{A. Inconsistency of Gabapentinoid Effectiveness}

In laboratory models of neuropathic pain, every rat or mouse that is tested responds to the antiallodynic action of gabapentinoids (Kimura et al., 2016). This differs from the clinical picture, in which as few as $35 \%$ of patients report appreciable pain relief (Moore et al., 2011). There may be many reasons for this discrepancy. One possibility may relate to decreased clinical effectiveness with time. This is frequently observed but poorly documented (Cheshire, 2007). It is not known whether it reflects tachyphylaxis or tolerance as a result of repeated administration of drug or whether the pain pathophysiology changes with time. Loss of gabapentinoid effectiveness has, however, been replicated in an animal model of poststroke pain and was also seen in animals subject to spared nerve injury (Kimura et al., 2016; Yang et al., 2016). In the first case, this was attributed to downregulation of $\alpha 2 \delta$ - 1 with time despite the persistence of pain (Yang et al., 2016). In the second case, loss of gabapentin efficacy was associated with downregulation of GLT-1 (better known as EAAT2) in locus coeruleus (Kimura et al., 2016). It had been established previously that GBP increases glutamatergic transmission within the locus coeruleus by a GLT-1/ EAAT2-dependent mechanism to stimulate descending noradrenergic inhibition of spinal nociceptive circuits (Suto et al., 2014). Interestingly, this loss of gabapentinoid effect in the spinal nerve ligation model could be restored using the histone deacetylase inhibitor and anticonvulsant agent, valproic acid (Kimura et al., 2016). This effect was attributed to increased GLT-1/ EAAT2 expression. Other histone deacetylase inhibitors such as JNJ-26481585 produce robust upregulation of $\alpha 2 \delta-1$ in mice in vivo (Capasso et al., 2015). It is therefore possible that upregulation of $\alpha 2 \delta$-1 also contributes to the restoration of GBP effectiveness by valproate described by Kimura et al. (2016). This may go along with the idea that long-term persisting neuropathic pain may be $\alpha 2 \delta$-1 independent, and that high levels of $\alpha 2 \delta-1$ in nerve terminals are required for gabapentin effectiveness (Alles and Smith, 2016; Yang et al., 2016). There is, however, a problem with the idea that if long-term neuropathic pain is truly $\alpha 2 \delta$-1 independent, why should its upregulation and its binding to GBP have any effect at all? Nevertheless, the obvious clinical implication is that loss or absence of gabapentinoid effect in the clinic may be restored or established by treatment with valproate, a clinically approved anticonvulsant agent.

\section{B. Improving Gabapeninoid Effectiveness}

Another emerging approach to pain management is to introduce drugs into the neuronal cytoplasm via the open pore of TRP channels (Binshtok et al., 2007, 2009). This may be achieved by direct activation of TRPV1 by capsaicin or indirect activation of other drug-permeable channels via Toll-like receptor 5 (TLR5) (Peirs and Seal, 2015; Xu et al., 2015). The TRPV1 channel pore is large enough to permit permeation of a quaternary derivative of lidocaine known as QX-314. This substance does not have a local anesthetic when applied extracellularly, as it is membrane impermeable. It is effective when introduced into the cytoplasm via the TRPV1 channel, and this allows selective targeting of classic $\mathrm{C}$ fiber nociceptors in nociceptive pain. Because TLR5 is expressed on medium to large A fibers, including $\mathrm{A} \beta$ mechanoreceptors in both mice and humans (Xu et al., 2015), this may allow selective pharmacological blockade of transmission in fiber types that mediate allodynia. We recently noted that GBP is able to permeate TRPV1 channels activated by capsaicin, and this led to increased effectiveness (Biggs et al., 2015). Perhaps topical application of GBP (Shahid et al., 2017) combined with a TLR5 agonist such as flagellin (Xu et al., 2015) may facilitate its access to $\alpha 2 \delta-1$ and thereby increase its effectiveness in the clinic. 


\section{Rate of Onset of Gabapentinoid Effect}

In animal models of neuropathic pain, gabapentinoids consistently produce an antiallodynic effect within 30 minutes of administration (Hunter et al., 1997; Field et al., 2006; Narita et al., 2012; Kumar et al., 2013; Alles and Smith, 2016; Alles et al., 2017). We contend this rapidity reflects gabapentin interaction with upregulated $\alpha 2 \delta-1$ and increased trafficking of VGCC from endosomes to the plasma membrane within the confine of the nerve terminal (Fig. 5B; see Rapid Trafficking of Ca2+ Channel $\alpha$ Subunits to the Plasma Membrane). Effects of gabapentinoids in animal models of anxiety and epilepsy are similarly rapid and are $\alpha 2 \delta$ 1 mediated (Vartanian et al., 2006; Lotarski et al., 2011, 2014 ). Although this could mean $\alpha 2 \delta$-1 is upregulated in these conditions, we could find no evidence to support this. There is evidence, however, that various mutations in the Cacna2d2 gene that codes for $\alpha 2 \delta$-2 exhibit an epileptic phenotype.

Gabapentinoids may thus require a pathologic situation to work in neuropathic pain, but not necessarily in epilepsy and anxiety. One possible explanation for this is that $\mathrm{Ca}^{2+}$ channels are rapidly turning over at central synapses involved in anxiety and epilepsy and are thus sensitive to GBP. By contrast, $\mathrm{Ca}^{2+}$ channel turnover in uninjured primary afferents may be relatively slow and thus insensitive to gabapentinoids. The idea that gabapentinoids target $\mathrm{Ca}^{2+}$ channel populations that are rapidly turning over has been used to explain their lack of effect on cardiac and skeletal muscle channels (Dolphin, 2016).

Despite their rapid efficacy in animal models of neuropathic pain (Hunter et al., 1997; Field et al., 2006; Narita et al., 2012; Kumar et al., 2013; Alles and Smith, 2016; Alles et al., 2017), several reports indicate that GBP effects in clinical pain management take a day or more to develop (Cheshire, 2002; Stacey et al., 2008; Sharma et al., 2010; Rauck et al., 2013).

One factor that may contribute to this discrepancy in time course is the difference in evaluating drug effects in rodents and people (Yekkirala et al., 2017). Even if a human patient exhibited an increased withdrawal threshold to von Frey filament immediately after GBP, it might take several days for them to state improvement on a pain questionnaire; despite a rapid antiallodynic effect, it may take a longer period of time for other manifestations of neuropathic pain such as causalgia and spontaneous pain to be altered. It should also be noted that it is often necessary to titrate appropriate dosage in human patients so that the absence of obvious effectiveness may reflect the failure to achieve an effective concentration of drug in plasma and cerebrospinal fluid.

We therefore think it unlikely that slowly developing action of gabapentinoids in inhibiting transport of $\mathrm{Ca}^{2+}$ channel $\alpha$ subunits from the cell body to nerve terminals in animal models in vitro (Fig. 5B; see also Rapid and Slow Actions in the Spinal Dorsal Horn) has any direct bearing on their antiallodynic action in the clinic.

\section{Animal Models of Antiallodynic Effectiveness}

The discrepancy between observations in people and in animal models may start to be addressed as more refined models for evaluating pain are developed (Mogil and Crager, 2004; Mogil, 2009). Indeed, recent review has stated that current models of animal testing are predicted to fail in modeling human pain and drug effectiveness (Yekkirala et al., 2017). Supraspinal processing of nociceptive information may be more akin to the human sensation of pain than tests of mechanical, cold, or thermal allodynia. Human pain may be better modeled and evaluated in animals by using operant models such as conditioned place aversion (King et al., 2009; Zhang et al., 2015c; Bannister et al., 2017b) or evaluation of spontaneously emitted behaviors such as facial grimacing (Langford et al., 2010) or examination of changes in social interaction (Mogil, 2009).

\section{Conclusions}

There is an urgent need to develop new pharmaceutical agents for the treatment of neuropathic pain. Extensive investigation of the etiology of neuropathic pain has identified several potential drug targets, and some promising new compounds are in development.

Results from clinical trials have in general been disappointing. Many substances identified in preclinical studies have failed in phase 1 or phase 2 trials because of lack of efficacy or the presence of doselimiting untoward effects. Experience suggests that highly specific agents that target one receptor or channel never progress to the clinic, and this may reflect the diverse etiologies of pain seen in the human population. By contrast, drugs that interact with multiple targets such as broad-spectrum dihydropyridine $\mathrm{Ca}^{2+}$ channel blockers (Gadotti et al., 2015) may be more effective. Interestingly, A3 adenosine receptor antagonists and gabapentinoids interact with clearly defined targets, A3 receptors and $\alpha 2 \delta-1$, yet consequences are wide ranging. Even carbamazepine, which has been used for many years to treat trigeminal neuralgia (Cheshire, 2007), affects both $\mathrm{Na}^{+}$channels and GABA function. Ion channel function is also affected by the noradrenaline serotonin uptake inhibitor amitriptyline (Wolff et al., 2016), which retains its status as a firstline treatment of neuropathic pain (Finnerup et al., 2015; Gilron et al., 2015).

Despite their inconsistent effectiveness, gabapentinoids remain a first-line treatment option. Because these drugs are expected to retain this status for the immediate future, therapeutic management may be improved in the light of new information regarding their mechanism of action. Might rational combinations 
of gabapentinoids with drugs such as valproate, TLR5 agonists, or TRP channel openers improve their therapeutic effectiveness?

\section{Authorship Contributions}

Wrote or contributed to the writing of the manuscript: Alles, Smith.

\section{References}

Abbadie C, McManus OB, Sun SY, Bugianesi RM, Dai G, Haedo RJ, Herrington JB, Kaczorowski GJ, Smith MM, Swensen AM, et al. (2010) Analgesic effects of a substituted N-triazole oxindole (TROX-1), a state-dependent, voltage-gated calcium channel 2 blocker. J Pharmacol Exp Ther 334:545-555.

Abdulla FA and Smith PA (1997) Ectopic alpha2-adrenoceptors couple to N-type $\mathrm{Ca} 2+$ channels in axotomized rat sensory neurons. J Neurosci 17:1633-1641.

Abdulla FA and Smith PA (1998) Axotomy reduces the effect of analgesic opioids yet increases the effect of nociceptin on dorsal root ganglion neurons. $J$ Neurosci 18: 9685-9694.

Abdulla FA and Smith PA (1999) Nerve injury increases an excitatory action of neuropeptide $\mathrm{Y}$ and $\mathrm{Y} 2$-agonists on dorsal root ganglion neurons. Neuroscience $\mathbf{8 9}$ : $43-60$.

Abdulla FA and Smith PA (2001a) Axotomy- and autotomy-induced changes in the excitability of rat dorsal root ganglion neurons. J Neurophysiol 85:630-643.

Abdulla FA and Smith PA (2001b) Axotomy- and autotomy-induced changes in $\mathrm{Ca}^{2+}$ and $\mathrm{K}^{+}$channel currents of rat dorsal root ganglion neurons. $J$ Neurophysiol 85 : 644-658.

Abdulla FA and Smith PA (2002) Changes in $\mathrm{Na}^{+}$) channel currents of rat dorsal root ganglion neurons following axotomy and axotomy-induced autotomy. J Neurophysiol 88:2518-2529.

Abraira VE, Kuehn ED, Chirila AM, Springel MW, Toliver AA, Zimmerman AL, Orefice LL, Boyle KA, Bai L, Song BJ, et al. (2017) The cellular and synaptic architecture of the mechanosensory dorsal horn. Cell 168:295-310.e19.

Alier KA, Chen Y, Sollenberg UE, Langel U, and Smith PA (2008) Selective stimulation of GalR1 and GalR2 in rat substantia gelatinosa reveals a cellular basis for the anti- and pro-nociceptive actions of galanin. Pain 137:138-146.

Alles SRA, Bandet MV, Eppler K, Noh MC, Winship IR, Baker G, Ballanyi K, and Smith PA (2017) Acute anti-allodynic action of gabapentin in dorsal horn and primary somatosensory cortex: correlation of behavioural and physiological data. Neuropharmacology 113 (Pt A):576-590.

Alles SRA and Smith PA (2016) The anti-allodynic gabapentinoids: myths, paradoxes, and acute effects. Neuroscientist 23:40-55.

Altier C and Zamponi GW (2004) Targeting Ca2+ channels to treat pain: T-type versus N-type. Trends Pharmacol Sci 25:465-470.

Altier C and Zamponi GW (2008) Signaling complexes of voltage-gated calcium channels and G protein-coupled receptors. J Recept Signal Transduct Res 28:71-81.

Alvarado S, Tajerian M, Millecamps M, Suderman M, Stone LS, and Szyf M (2013) Peripheral nerve injury is accompanied by chronic transcriptome-wide changes in the mouse prefrontal cortex. Mol Pain 9:21.

Anand U, Facer P, Yiangou Y, Sinisi M, Fox M, McCarthy T, Bountra C, Korchev YE, and Anand P (2013) Angiotensin II type 2 receptor (AT2 R) localization and antagonist-mediated inhibition of capsaicin responses and neurite outgrowth in human and rat sensory neurons. Eur J Pain 17:1012-1026.

Antal M, Papp I, Bahaerguli N, Veress G, and Vereb G (2004) Expression of hyperpolarization-activated and cyclic nucleotide-gated cation channel subunit 2 in axon terminals of peptidergic nociceptive primary sensory neurons in the superficial spinal dorsal horn of rats. Eur J Neurosci 19:1336-1342.

Apkarian AV, Hashmi JA, and Baliki MN (2011) Pain and the brain: specificity and plasticity of the brain in clinical chronic pain. Pain 152(Suppl):S49-S64

Autry AE and Monteggia LM (2012) Brain-derived neurotrophic factor and neuropsychiatric disorders. Pharmacol Rev 64:238-258.

Baba H, Ji RR, Kohno T, Moore KA, Ataka T, Wakai A, Okamoto M, and Woolf CJ (2003) Removal of GABAergic inhibition facilitates polysynaptic A fiber-mediated excitatory transmission to the superficial spinal dorsal horn. Mol Cell Neurosci 24: 818-830.

Baccei ML and Kocsis JD (2000) Voltage-gated calcium currents in axotomized adult rat cutaneous afferent neurons. $J$ Neurophysiol 83:2227-2238.

Bagal SK, Chapman ML, Marron BE, Prime R, Storer RI, and Swain NA (2014) Recent progress in sodium channel modulators for pain. Bioorg Med Chem Lett 24 3690-3699.

Bagal SK, Marron BE, Owen RM, Storer RI, and Swain NA (2015) Voltage gated sodium channels as drug discovery targets. Channels (Austin) 9:360-366.

Bailey AL and Ribeiro-da-Silva A (2006) Transient loss of terminals from nonpeptidergic nociceptive fibers in the substantia gelatinosa of spinal cord following chronic constriction injury of the sciatic nerve. Neuroscience 138:675-690.

Balasubramanyan S and Smith PA (2005) L-type calcium channels and neuropathic pain. Abstract viewer/itinerary planner. Society for Neuroscience, Washington, DC. Online Program No. 860.21.

Balasubramanyan S, Stemkowski PL, Stebbing MJ, and Smith PA (2006) Sciatic chronic constriction injury produces cell-type-specific changes in the electrophysiological properties of rat substantia gelatinosa neurons. J Neurophysiol 96: $579-590$.

Balkowiec A and Katz DM (2000) Activity-dependent release of endogenous brainderived neurotrophic factor from primary sensory neurons detected by ELISA in situ. J Neurosci 20:7417-7423.

Bannister K and Dickenson AH (2017) The plasticity of descending controls in pain: translational probing. J Physiol 595:4159-4166.
Bannister K, Lockwood S, Goncalves L, Patel R, and Dickenson AH (2017a) An investigation into the inhibitory function of serotonin in diffuse noxious inhibitory controls in the neuropathic rat. Eur J Pain 21:750-760.

Bannister K, Patel R, Goncalves L, Townson L, and Dickenson AH (2015) Diffuse noxious inhibitory controls and nerve injury: restoring an imbalance between descending monoamine inhibitions and facilitations. Pain 156:1803-1811.

Bannister K, Qu C, Navratilova E, Oyarzo J, Xie JY, King T, Dickenson AH, and Porreca F (2017b) Multiple sites and actions of gabapentin-induced relief of ongoing experimental neuropathic pain. Pain 158:2386-2395.

Bardoni R, Torsney C, Tong CK, Prandini M, and MacDermott AB (2004) Presynaptic NMDA receptors modulate glutamate release from primary sensory neurons in rat spinal cord dorsal horn. J Neurosci 24:2774-2781.

Baron R and Binder A (2016) Fighting neuropathic pain with botulinum toxin A. Lancet Neurol 15:534-535.

Basbaum AI, Bautista DM, Scherrer G, and Julius D (2009) Cellular and molecular mechanisms of pain. Cell 139:267-284.

Basso L and Altier C (2017) Transient receptor potential channels in neuropathic pain. Curr Opin Pharmacol 32:9-15.

Bauer CS, Nieto-Rostro M, Rahman W, Tran-Van-Minh A, Ferron L, Douglas L, Kadurin I, Sri Ranjan Y, Fernandez-Alacid L, Millar NS, et al. (2009) The increased trafficking of the calcium channel subunit alpha2delta-1 to presynaptic terminals in neuropathic pain is inhibited by the alpha2delta ligand pregabalin. J Neurosci 29:4076-4088.

Bauer CS, Tran-Van-Minh A, Kadurin I, and Dolphin AC (2010) A new look at calcium channel $\alpha 2 \delta$ subunits. Curr Opin Neurobiol 20:563-571.

Beggs S, Currie G, Salter MW, Fitzgerald M, and Walker SM (2012a) Priming of adult pain responses by neonatal pain experience: maintenance by central neuroimmune activity. Brain 135:404-417.

Beggs S, Liu XJ, Kwan C, and Salter MW (2010) Peripheral nerve injury and TRPV1expressing primary afferent C-fibers cause opening of the blood-brain barrier. $\mathrm{Mol}$ Pain 6:74.

Beggs S and Salter MW (2013) The known knowns of microglia-neuronal signalling in neuropathic pain. Neurosci Lett $\mathbf{5 5 7}$ (Pt A):37-42.

Beggs S, Trang T, and Salter MW (2012b) P2X4R+ microglia drive neuropathic pain. Nat Neurosci 15:1068-1073.

Beggs SA, Coull JAM, Boivin D, Boudreau D, Salter MW, and de Koninck Y (2004) Activated microglia induce tactile allodynia in the rat through a disruption of anion homeostasis in dorsal horn lamina I neurons. 2004 abstract viewer/itinerary planner. Society for Neuroscience, Washington, DC. Online Program No. 292.13.

Belliotti TR, Capiris T, Ekhato IV, Kinsora JJ, Field MJ, Heffner TG, Meltzer LT, Schwarz JB, Taylor CP, Thorpe AJ, et al. (2005) Structure-activity relationships of pregabalin and analogues that target the alpha(2)-delta protein. $J$ Med Chem 48: 2294-2307.

Berger ND, Gadotti VM, Petrov RR, Chapman K, Diaz P, and Zamponi GW (2014) NMP-7 inhibits chronic inflammatory and neuropathic pain via block of Cav3.2 Ttype calcium channels and activation of CB2 receptors. Mol Pain 10:77.

Berry DJ, Beran RG, Plunkeft MJ, Clarke LA, and Hung WT (2003) The absorption of gabapentin following high dose escalation. Seizure 12:28-36.

Besson M, Daali Y, Di Lio A, Dayer P, Zeilhofer HU, and Desmeules J (2013) Antihyperalgesic effect of the GABA(A) ligand clobazam in a neuropathic pain model in mice: a pharmacokinetic-pharmacodynamic study. Basic Clin Pharmacol Toxicol 112:192-197.

Besson M, Matthey A, Daali Y, Poncet A, Vuilleumier P, Curatolo M, Zeilhofer HU, and Desmeules J (2015) GABAergic modulation in central sensitization in humans: a randomized placebo-controlled pharmacokinetic-pharmacodynamic study comparing clobazam with clonazepam in healthy volunteers [published correction appears in Pain (2015) 156:1370]. Pain 156:397-404.

Biber K, Tsuda M, Tozaki-Saitoh H, Tsukamoto K, Toyomitsu E, Masuda T, Boddeke $\mathrm{H}$, and Inoue $\mathrm{K}$ (2011) Neuronal CCL21 up-regulates microglia P2X4 expression and initiates neuropathic pain development. EMBO J 30:1864-1873.

Biggs JE, Lu VB, Kim H, Lai A, Todd KG, Ballanyi K, Colmers WF, and Smith PA (2012) Defined medium organotypic cultures of spinal cord put 'pain in a dish', in Isolated Brain Circuits (Ballanyi K ed) pp 405-435, Humana Press, Springer, New York

Biggs JE, Lu VB, Stebbing MJ, Balasubramanyan S, and Smith PA (2010) Is BDNF sufficient for information transfer between microglia and dorsal horn neurons during the onset of central sensitization? Mol Pain 6:44.

Biggs JE, Boakye PA, Ganesan N, Stemkowski PL, Lantero A, Ballanyi K, and Smith PA (2014) Analysis of the long-term actions of gabapentin and pregabalin in dorsal root ganglia and substantia gelatinosa. $J$ Neurophysiol 112:2398-2412.

Biggs JE, Stemkowski PL, Knaus EE, Chowdhury MA, Ballanyi K, and Smith PA (2015) Suppression of network activity in dorsal horn by gabapentin permeation of TRPV1 channels: implications for drug access to cytoplasmic targets. Neurosci Lett 584:397-402.

Binshtok AM, Bean BP, and Woolf CJ (2007) Inhibition of nociceptors by TRPV1mediated entry of impermeant sodium channel blockers. Nature 449:607-610.

Binshtok AM, Gerner P, Oh SB, Puopolo M, Suzuki S, Roberson DP, Herbert T, Wang $\mathrm{CF}$, Kim D, Chung G, et al. (2009) Coapplication of lidocaine and the permanently charged sodium channel blocker QX-314 produces a long-lasting nociceptive blockade in rodents. Anesthesiology 111:127-137.

Binshtok AM, Wang H, Zimmermann K, Amaya F, Vardeh D, Shi L, Brenner GJ, Ji RR, Bean BP, Woolf CJ, et al. (2008) Nociceptors are interleukin-1beta sensors. $J$ Neurosci 28:14062-14073.

Björklund O, Shang M, Tonazzini I, Daré E, and Fredholm BB (2008) Adenosine A1 and $\mathrm{A} 3$ receptors protect astrocytes from hypoxic damage. Eur J Pharmacol 596: $6-13$

Bladen C, McDaniel SW, Gadotti VM, Petrov RR, Berger ND, Diaz P, and Zamponi GW (2015) Characterization of novel cannabinoid based T-type calcium channel blockers with analgesic effects. ACS Chem Neurosci 6:277-287.

Bonin RP and De Koninck Y (2014) A spinal analog of memory reconsolidation enables reversal of hyperalgesia. Nat Neurosci 17:1043-1045. 
Boroujerdi A, Kim HK, Lyu YS, Kim DS, Figueroa KW, Chung JM, and Luo ZD (2008) Injury discharges regulate calcium channel alpha-2-delta-1 subunit upregulation in the dorsal horn that contributes to initiation of neuropathic pain. Pain 139:358-366.

Boroujerdi A, Zeng J, Sharp K, Kim D, Steward O, and Luo ZD (2011) Calcium channel alpha-2-delta-1 protein upregulation in dorsal spinal cord mediates spinal cord injury-induced neuropathic pain states. Pain 152:649-655.

Bouhassira D and Attal N (2016) Translational neuropathic pain research: a clinical perspective. Neuroscience 338:27-35.

Bourinet E, Altier C, Hildebrand ME, Trang T, Salter MW, and Zamponi GW (2014) Calcium-permeable ion channels in pain signaling. Physiol Rev 94:81-140.

Boyle KA, Gutierrez-Mecinas M, Polgár E, Mooney N, O'Connor E, Furuta T, Watanabe M, and Todd AJ (2017) A quantitative study of neurochemically defined populations of inhibitory interneurons in the superficial dorsal horn of the mouse spinal cord. Neuroscience 363:120-133.

Braz J, Solorzano C, Wang X, and Basbaum AI (2014) Transmitting pain and itch messages: a contemporary view of the spinal cord circuits that generate gate control. Neuron 82:522-536.

Brill S, Sedgwick PM, Hamann W, and Di Vadi PP (2002) Efficacy of intravenous magnesium in neuropathic pain. Br J Anaesth 89:711-714.

Busserolles J, Tsantoulas C, Eschalier A, and López García JA (2016) Potassium channels in neuropathic pain: advances, challenges, and emerging ideas. Pain 157 (Suppl 1):S7-S14.

Cain SM, Bohnet B, LeDue J, Yung AC, Garcia E, Tyson JR, Alles SR, Han H, van den Maagdenberg AM, Kozlowski P, et al. (2017) In vivo imaging reveals that pregabalin inhibits cortical spreading depression and propagation to subcortical brain structures. Proc Natl Acad Sci USA 114:2401-2406.

Calandre EP, Garcia-Leiva JM, Rico-Villademoros F, Vilchez JS, and RodriguezLopez CM (2010) Pregabalin in the treatment of chronic migraine: an open-label study. Clin Neuropharmacol 33:35-39.

Calvo M, Dawes JM, and Bennett DL (2012) The role of the immune system in the generation of neuropathic pain. Lancet Neurol 11:629-642.

Cantí C, Nieto-Rostro M, Foucault I, Heblich F, Wratten J, Richards MW, Hendrich J, Douglas L, Page KM, Davies A, et al. (2005) The metal-ion-dependent adhesion site in the Von Willebrand factor-A domain of alpha2delta subunits is key to trafficking voltage-gated $\mathrm{Ca} 2+$ channels. Proc Natl Acad Sci USA 102 11230-11235.

Cao XH, Byun HS, Chen SR, Cai YQ, and Pan HL (2010) Reduction in voltage-gated $\mathrm{K}+$ channel activity in primary sensory neurons in painful diabetic neuropathy: role of brain-derived neurotrophic factor. J Neurochem 114:1460-1475.

Cao XH, Chen SR, Li L, and Pan HL (2012) Nerve injury increases brain-derived neurotrophic factor levels to suppress BK channel activity in primary sensory neurons. J Neurochem 121:944-953.

Capasso KE, Manners MT, Quershi RA, Tian Y, Gao R, Hu H, Barrett JE, Sacan A, and Ajit SK (2015) Effect of histone deacetylase inhibitor JNJ-26481585 in pain. $J$ Mol Neurosci 55:570-578.

Carbone A, Palleschi G, Conte A, Bova G, Iacovelli E, Bettolo CM, Pastore A and Inghilleri M (2006) Gabapentin treatment of neurogenic overactive bladder [published correction appears in Clin Neuropharmacol (2009) 32:57; Clin Neuropharmacol (2006) 29:301]. Clin Neuropharmacol 29:206-214.

Carlton SM, Du J, Tan HY, Nesic O, Hargett GL, Bopp AC, Yamani A, Lin Q, Willis WD, and Hulsebosch CE (2009) Peripheral and central sensitization in remote spinal cord regions contribute to central neuropathic pain after spinal cord injury. Pain 147:265-276.

Cassidy JS, Ferron L, Kadurin I, Pratt WS, and Dolphin AC (2014) Functional exofacially tagged $\mathrm{N}$-type calcium channels elucidate the interaction with auxiliary

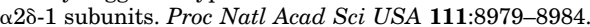

Cata JP, Weng HR, Chen JH, and Dougherty PM (2006) Altered discharges of spinal wide dynamic range neurons and down-regulation of glutamate transporter expression in rats with paclitaxel-induced hyperalgesia. Neuroscience 138:329-338.

Caterina MJ and Julius D (2001) The vanilloid receptor: a molecular gateway to the pain pathway. Annu Rev Neurosci 24:487-517.

Chang E, Chen X, Kim M, Gong N, Bhatia S, and Luo ZD (2015) Differential effects of voltage-gated calcium channel blockers on calcium channel alpha-2-delta-1 subunit protein-mediated nociception. Eur J Pain 19:639-648.

Chaplan SR, Guo HQ, Lee DH, Luo L, Liu C, Kuei C, Velumian AA, Butler MP, Brown SM, and Dubin AE (2003) Neuronal hyperpolarization-activated pacemaker channels drive neuropathic pain. J Neurosci 23:1169-1178.

Chen SR, Zhou HY, Byun HS, and Pan HL (2013) Nerve injury increases GluA2lacking AMPA receptor prevalence in spinal cords: functional significance and signaling mechanisms. J Pharmacol Exp Ther 347:765-772.

Chen W, Walwyn W, Ennes HS, Kim H, McRoberts JA, and Marvizón JC (2014) BDNF released during neuropathic pain potentiates NMDA receptors in primary afferent terminals. Eur J Neurosci 39:1439-1454.

Chen Y, Balasubramanyan S, Lai AY, Todd KG, and Smith PA (2009) Effects of sciatic nerve axotomy on excitatory synaptic transmission in rat substantia gelatinosa. J Neurophysiol 102:3203-3215.

Chen Y, Derkach VA, and Smith PA (2016) Loss of Ca(2+)-permeable AMPA receptors in synapses of tonic firing substantia gelatinosa neurons in the chronic constriction injury model of neuropathic pain. Exp Neurol 279:168-177.

Cheng JK and Chiou LC (2006) Mechanisms of the antinociceptive action of gabapentin. J Pharmacol Sci 100:471-486.

Cheshire WP Jr (2002) Defining the role for gabapentin in the treatment of trigeminal neuralgia: a retrospective study. J Pain 3:137-142.

Cheshire WP (2007) Trigeminal neuralgia: for one nerve a multitude of treatments. Expert Rev Neurother 7:1565-1579.

Chiu IM, Heesters BA, Ghasemlou N, Von Hehn CA, Zhao F, Tran J, Wainger B, Strominger A, Muralidharan S, Horswill AR, et al. (2013) Bacteria activate sensory neurons that modulate pain and inflammation. Nature 501:52-57.
Chiu IM, von Hehn CA, and Woolf CJ (2012) Neurogenic inflammation and the peripheral nervous system in host defense and immunopathology. Nat Neurosci 15: 1063-1067.

Clarke H, Bonin RP, Orser BA, Englesakis M, Wijeysundera DN, and Katz J (2012) The prevention of chronic postsurgical pain using gabapentin and pregabalin: a combined systematic review and meta-analysis. Anesth Analg 115:428-442.

Cole RL, Lechner SM, Williams ME, Prodanovich P, Bleicher L, Varney MA, and Gu G (2005) Differential distribution of voltage-gated calcium channel alpha-2 delta (alpha2delta) subunit mRNA-containing cells in the rat central nervous system and the dorsal root ganglia. J Comp Neurol 491:246-269.

Cordero-Erausquin M, Inquimbert P, Schlichter R, and Hugel S (2016) Neuronal networks and nociceptive processing in the dorsal horn of the spinal cord. Neuroscience 338:230-247.

Costigan M, Moss A, Latremoliere A, Johnston C, Verma-Gandhu M, Herbert TA, Barrett L, Brenner GJ, Vardeh D, Woolf CJ, et al. (2009a) T-cell infiltration and signaling in the adult dorsal spinal cord is a major contributor to neuropathic painlike hypersensitivity. $J$ Neurosci 29:14415-14422.

Costigan M, Scholz J, and Woolf CJ (2009b) Neuropathic pain: a maladaptive response of the nervous system to damage. Annu Rev Neurosci 32:1-32.

Coull JA, Beggs S, Boudreau D, Boivin D, Tsuda M, Inoue K, Gravel C, Salter MW, and De Koninck Y (2005) BDNF from microglia causes the shift in neuronal anion gradient underlying neuropathic pain. Nature 438:1017-1021.

Coull JA, Boudreau D, Bachand K, Prescott SA, Nault F, Sík A, De Koninck P, and De Koninck Y (2003) Trans-synaptic shift in anion gradient in spinal lamina I neurons as a mechanism of neuropathic pain. Nature 424:938-942.

Crosby ND, Zaucke F, Kras JV, Dong L, Luo ZD, and Winkelstein BA (2015) Thrombospondin-4 and excitatory synaptogenesis promote spinal sensitization after painful mechanical joint injury. Exp Neurol 264:111-120.

Cummins TR, Aglieco F, Renganathan M, Herzog RI, Dib-Hajj SD, and Waxman SG (2001) Nav1.3 sodium channels: rapid repriming and slow closed-state inactivation display quantitative differences after expression in a mammalian cell line and in spinal sensory neurons. J Neurosci 21:5952-5961.

Cummins TR, Dib-Hajj SD, Black J, and Waxman S (2000) Altered excitability of large-diameter cutaneous afferents following nerve injury: consequences for chronic pain, in Proceedings of the 9th World Congress on Pain; Vienna, Austria (Devor M, Rowbotham MC, and Wiesenfeld-Hallin Z eds) pp 119-135, IASP Press, Seattle, WA

Cummins TR and Waxman SG (1997) Downregulation of tetrodotoxin-resistant sodium currents and upregulation of a rapidly repriming tetrodotoxin-sensitive sodium current in small spinal sensory neurons after nerve injury. $J$ Neurosci 17: 3503-3514

Cundy KC, Branch R, Chernov-Rogan T, Dias T, Estrada T, Hold K, Koller K, Liu X, Mann A, Panuwat M, et al. (2004) XP13512 [(+/-)-1-([(alpha-isobutanoyloxyethoxy)carbonyl] aminomethyl)-1-cyclohexane acetic acid], a novel gabapentin prodrug. I. Design, synthesis, enzymatic conversion to gabapentin, and transport by intestinal solute transporters. J Pharmacol Exp Ther 311:315-323.

D'Arco M, Margas W, Cassidy JS, and Dolphin AC (2015) The upregulation of $\alpha 2 \delta-1$ subunit modulates activity-dependent Ca2+ signals in sensory neurons. J Neurosci 35:5891-5903.

Dalal A, Tata M, Allègre G, Gekiere F, Bons N, and Albe-Fessard D (1999) Spontaneous activity of rat dorsal horn cells in spinal segments of sciatic projection following transection of sciatic nerve or of corresponding dorsal roots. Neuroscience 94:217-228.

Daniele CA and MacDermott AB (2009) Low-threshold primary afferent drive onto GABAergic interneurons in the superficial dorsal horn of the mouse. J Neurosci 29 : 686-695.

Daou I, Beaudry H, Ase AR, Wieskopf JS, Ribeiro-da-Silva A, Mogil JS, and Séguéla $\mathrm{P}$ (2016) Optogenetic silencing of Nav1.8-positive afferents alleviates inflammatory and neuropathic pain. eNeuro 3: DOI: 10.1523/ENEURO.0140-15.2016.

Dauri M, Faria S, Gatti A, Celidonio L, Carpenedo R, and Sabato AF (2009) Gabapentin and pregabalin for the acute post-operative pain management: a systematicnarrative review of the recent clinical evidences. Curr Drug Targets 10:716-733.

Davies A, Douglas L, Hendrich J, Wratten J, Tran Van Minh A, Foucault I, Koch D, Pratt WS, Saibil HR, and Dolphin AC (2006) The calcium channel alpha2delta-2 subunit partitions with CaV2.1 into lipid rafts in cerebellum: implications for localization and function. $J$ Neurosci 26:8748-8757.

Davies A, Kadurin I, Alvarez-Laviada A, Douglas L, Nieto-Rostro M, Bauer CS, Pratt WS, and Dolphin AC (2010) The alpha2delta subunits of voltage-gated calcium channels form GPI-anchored proteins, a posttranslational modification essential for function. Proc Natl Acad Sci USA 107:1654-1659.

Debiec J, LeDoux JE, and Nader K (2002) Cellular and systems reconsolidation in the hippocampus. Neuron 36:527-538.

Decosterd I and Woolf CJ (2000) Spared nerve injury: an animal model of persistent peripheral neuropathic pain. Pain 87:149-158.

DeLeo JA, Sorkin LS, and Watkins LR (2007) Immune and Glial Regulation of Pain, IASP Press, Seattle, WA

Demant DT, Lund K, Vollert J, Maier C, Segerdahl M, Finnerup NB, Jensen TS, and Sindrup SH (2014) The effect of oxcarbazepine in peripheral neuropathic pain depends on pain phenotype: a randomised, double-blind, placebo-controlled phenotype-stratified study. Pain 155:2263-2273.

Deuis JR, Dekan Z, Wingerd JS, Smith JJ, Munasinghe NR, Bhola RF, Imlach WL, Herzig V, Armstrong DA, Rosengren KJ, et al. (2017) Pharmacological characterisation of the highly NaV1.7 selective spider venom peptide Pn3a. Sci Rep 7:40883.

Devor M (2006) Centralization, central sensitization and neuropathic pain: focus on "sciatic chronic constriction injury produces cell-type-specific changes in the electrophysiological properties of rat substantia gelatinosa neurons." $J$ Neurophysiol 96:522-523.

Devor M (2009) Ectopic discharge in Abeta afferents as a source of neuropathic pain. Exp Brain Res 196:115-128. 
Devor M, Vaso A, Adahan HM, and Vyshka G (2014) PNS origin of phantom limb sensation and pain: reply to letter to the editor regarding Foell et al., peripheral origin of phantom limb pain: is it all resolved? Pain 155:2207-2208.

Devor M and Wall PD (1978) Reorganisation of spinal cord sensory map after peripheral nerve injury. Nature 276:75-76.

Devor M, Wall PD, and Catalan N (1992) Systemic lidocaine silences ectopic neuroma and DRG discharge without blocking nerve conduction. Pain 48:261-268.

Dib-Hajj SD, Yang Y, Black JA, and Waxman SG (2013) The Na(V)1.7 sodium channel: from molecule to man. Nat Rev Neurosci 14:49-62.

Dickie AC, McCormick B, Lukito V, Wilson KL, and Torsney C (2017) Inflammatory pain reduces $\mathrm{C}$ fiber activity-dependent slowing in a sex-dependent manner, amplifying nociceptive input to the spinal cord. $J$ Neurosci 37:6488-6502.

Dodds KN, Beckett EA, Evans SF, Grace PM, Watkins LR, and Hutchinson MR (2016) Glial contributions to visceral pain: implications for disease etiology and the female predominance of persistent pain. Transl Psychiatry 6:e888.

Dodge FA Jr and Rahamimoff R (1967) Co-operative action a calcium ions in transmitter release at the neuromuscular junction. J Physiol 193:419-432.

Dogrul A, Gardell LR, Ossipov MH, Tulunay FC, Lai J, and Porreca F (2003) Reversal of experimental neuropathic pain by T-type calcium channel blockers. Pain 105: 159-168.

Dolphin AC (2012a) Calcium Channel Alpha2delta Subunits in Epilepsy and as Targets for Antiepileptic Drugs (Noebels JL, Avoli M, Rogawski MA, Olsen RW, and Delgado-Escueta AV eds) National Center for Biotechnology Information (US), Bethesda, MD.

Dolphin AC (2012b) Calcium channel auxiliary $\alpha 2 \delta$ and $\beta$ subunits: trafficking and one step beyond. Nat Rev Neurosci 13:542-555.

Dolphin AC (2013) The $\alpha 2 \delta$ subunits of voltage-gated calcium channels. Biochim Biophys Acta 1828:1541-1549.

Dolphin AC (2016) Voltage-gated calcium channels and their auxiliary subunits: physiology and pathophysiology and pharmacology. J Physiol 594:5369-5390.

Du X, Hao H, Yang Y, Huang S, Wang C, Gigout S, Ramli R, Li X, Jaworska E, Edwards I, et al. (2017) Local GABAergic signaling within sensory ganglia controls peripheral nociceptive transmission. J Clin Invest 127:1741-1756.

Dworkin RH, O'Connor AB, Backonja M, Farrar JT, Finnerup NB, Jensen TS, Kalso EA, Loeser JD, Miaskowski C, Nurmikko TJ, et al. (2007) Pharmacologic management of neuropathic pain: evidence-based recommendations. Pain 132 $237-251$.

Eijkelkamp N, Linley JE, Torres JM, Bee L, Dickenson AH, Gringhuis M, Minett MS, Hong GS, Lee E, Oh U, et al. (2013) A role for Piezo2 in EPAC1-dependent mechanical allodynia. Nat Commun 4:1682.

Emery EC, Young GT, Berrocoso EM, Chen L, and McNaughton PA (2011) HCN2 ion channels play a central role in inflammatory and neuropathic pain. Science $\mathbf{3 3 3}$ : 1462-1466.

Emery EC, Young GT, and McNaughton PA (2012) HCN2 ion channels: an emerging role as the pacemakers of pain. Trends Pharmacol Sci 33:456-463.

Eroglu C, Allen NJ, Susman MW, O'Rourke NA, Park CY, Ozkan E, Chakraborty C, Mulinyawe SB, Annis DS, Huberman AD, et al. (2009) Gabapentin receptor alpha2delta-1 is a neuronal thrombospondin receptor responsible for excitatory CNS synaptogenesis. Cell 139:380-392.

Fang X, Djouhri L, Black JA, Dib-Hajj SD, Waxman SG, and Lawson SN (2002) The presence and role of the tetrodotoxin-resistant sodium channel $\mathrm{Na}(\mathrm{v}) 1.9(\mathrm{NaN})$ in nociceptive primary afferent neurons. J Neurosci 22:7425-7433.

Fang X, Djouhri L, McMullan S, Berry C, Waxman SG, Okuse K, and Lawson SN (2006) Intense isolectin-B4 binding in rat dorsal root ganglion neurons distinguishes C-fiber nociceptors with broad action potentials and high Nav1.9 expression. J Neurosci 26:7281-7292.

Fenselau H, Heinke B, and Sandkühler J (2011) Heterosynaptic long-term potentiation at GABAergic synapses of spinal lamina I neurons. J Neurosci 31: 17383-17391.

Field MJ, Cox PJ, Stott E, Melrose H, Offord J, Su TZ, Bramwell S, Corradini L, England S, Winks J, et al. (2006) Identification of the alpha2-delta-1 subunit of voltage-dependent calcium channels as a molecular target for pain mediating the analgesic actions of pregabalin. Proc Natl Acad Sci USA 103:17537-17542.

Finnerup NB, Attal N, Haroutounian S, McNicol E, Baron R, Dworkin RH, Gilron I, Haanpää M, Hansson P, Jensen TS, et al. (2015) Pharmacotherapy for neuropathic pain in adults: a systematic review and meta-analysis. Lancet Neurol 14:162-173.

Ford A, Castonguay A, Cottet M, Little JW, Chen Z, Symons-Liguori AM, Doyle T, Egan TM, Vanderah TW, De Konnick Y, et al. (2015) Engagement of the GABA to KCC2 signaling pathway contributes to the analgesic effects of A3AR agonists in neuropathic pain. $J$ Neurosci 35:6057-6067.

Fossat P, Dobremez E, Bouali-Benazzouz R, Favereaux A, Bertrand SS, Kilk K Léger C, Cazalets JR, Langel U, Landry M, et al. (2010) Knockdown of L calcium channel subtypes: differential effects in neuropathic pain. $J$ Neurosci 30 1073-1085.

Fukuoka T, Tokunaga A, Tachibana T, Dai Y, Yamanaka H, and Noguchi K (2002) VR1, but not P2X(3), increases in the spared L4 DRG in rats with L5 spinal nerve ligation. Pain 99:111-120.

Gadotti VM, Bladen C, Zhang FX, Chen L, Gündüz MG, Șimșek R, Şafak C, and Zamponi GW (2015) Analgesic effect of a broad-spectrum dihydropyridine inhibitor of voltage-gated calcium channels. Pflugers Arch 467:2485-2493.

Gagnon M, Bergeron MJ, Lavertu G, Castonguay A, Tripathy S, Bonin RP, PerezSanchez J, Boudreau D, Wang B, Dumas L, et al. (2013) Chloride extrusion enhancers as novel therapeutics for neurological diseases. Nat Med 19:1524-1528.

Gee NS, Brown JP, Dissanayake VU, Offord J, Thurlow R, and Woodruff GN (1996) The novel anticonvulsant drug, gabapentin (Neurontin), binds to the alpha2delta subunit of a calcium channel. J Biol Chem 271:5768-5776.

Gilron I, Baron R, and Jensen T (2015) Neuropathic pain: principles of diagnosis and treatment. Mayo Clin Proc 90:532-545.

Gilron I, Watson CP, Cahill CM, and Moulin DE (2006) Neuropathic pain: a practical guide for the clinician. CMAJ 175:265-275.
Giovannitti JA Jr, Thoms SM, and Crawford JJ (2015) Alpha-2 adrenergic receptor agonists: a review of current clinical applications. Anesth Prog 62:31-39.

Gold MS and Gebhart GF (2010) Nociceptor sensitization in pain pathogenesis. Nat Med 16:1248-1257.

Goldstein EZ, Church JS, Hesp ZC, Popovich PG, and McTigue DM (2016) A silver lining of neuroinflammation: beneficial effects on myelination. Exp Neurol $\mathbf{2 8 3}$ (Pt B):550-559.

Gong HC, Hang J, Kohler W, Li L, and Su TZ (2001) Tissue-specific expression and gabapentin-binding properties of calcium channel alpha2delta subunit subtypes. $J$ Membr Biol 184:35-43.

González A, Ugarte G, Restrepo C, Herrera G, Piña R, Gómez-Sánchez JA, Pertusa M, Orio P, and Madrid R (2017) Role of the excitability brake potassium current IKD in cold allodynia induced by chronic peripheral nerve injury. $J$ Neurosci 37 : $3109-3126$

Governo RJ, Morris PG, Marsden CA, and Chapman V (2008) Gabapentin evoked changes in functional activity in nociceptive regions in the brain of the anaesthetized rat: an fMRI study. Br J Pharmacol 153:1558-1567.

Govrin-Lippmann R and Devor M (1978) Ongoing activity in severed nerves: source and variation with time. Brain Res 159:406-410.

Grace PM, Hutchinson MR, Maier SF, and Watkins LR (2014) Pathological pain and the neuroimmune interface. Nat Rev Immunol 14:217-231.

Gruber-Schoffnegger D, Drdla-Schutting R, Hönigsperger C, Wunderbaldinger G, Gassner M, and Sandkühler J (2013) Induction of thermal hyperalgesia and synaptic long-term potentiation in the spinal cord lamina I by TNF- $\alpha$ and IL-1 $\beta$ is mediated by glial cells. $J$ Neurosci 33:6540-6551.

Grudt TJ and Perl ER (2002) Correlations between neuronal morphology and electrophysiological features in the rodent superficial dorsal horn. J Physiol 540: 189-207.

Guan Z, Kuhn JA, Wang X, Colquitt B, Solorzano C, Vaman S, Guan AK, EvansReinsch Z, Braz J, Devor M, et al. (2016) Injured sensory neuron-derived CSF1 induces microglial proliferation and DAP12-dependent pain. Nat Neurosci 19: 94-101.

Gustafson-Vickers SL, Lu VB, Lai AY, Todd KG, Ballanyi K, and Smith PA (2008) Long-term actions of interleukin-1beta on delay and tonic firing neurons in rat superficial dorsal horn and their relevance to central sensitization. Mol Pain 4:63.

Hammarberg C, Schulte G, and Fredholm BB (2003) Evidence for functional adenosine A3 receptors in microglia cells. $J$ Neurochem 86:1051-1054.

Hastie BA, Riley JL III, Kaplan L, Herrera DG, Campbell CM, Virtusio K, Mogil JS, Wallace MR, and Fillingim RB (2012) Ethnicity interacts with the OPRM1 gene in experimental pain sensitivity. Pain 153:1610-1619.

Häuser W, Petzke F, and Fitzcharles MA (2017) Efficacy, tolerability and safety of cannabis-based medicines for chronic pain management - an overview of systematic reviews. Eur J Pain [published ahead of print].

Hayashi H, Iwata M, Tsuchimori N, and Matsumoto T (2014) Activation of peripheral KCNQ channels attenuates inflammatory pain. Mol Pain 10:15.

Hebert T, Drapeau P, Pradier L, and Dunn RJ (1994) Block of the rat brain IIA sodium channel alpha subunit by the neuroprotective drug riluzole. Mol Pharmacol 45:1055-1060.

Hendrich J, Bauer CS, and Dolphin AC (2012) Chronic pregabalin inhibits synaptic transmission between rat dorsal root ganglion and dorsal horn neurons in culture. Channels (Austin) 6:124-132.

Hendrich J, Van Minh AT, Heblich F, Nieto-Rostro M, Watschinger K, Striessnig J, Wratten J, Davies A, and Dolphin AC (2008) Pharmacological disruption of calcium channel trafficking by the alpha2delta ligand gabapentin. Proc Natl Acad Sci USA 105:3628-3633.

Hewitt DJ (2000) The use of NMDA-receptor antagonists in the treatment of chronic pain. Clin J Pain 16(Suppl):S73-S79.

Heyes S, Pratt WS, Rees E, Dahimene S, Ferron L, Owen MJ, and Dolphin AC (2015) Genetic disruption of voltage-gated calcium channels in psychiatric and neurological disorders. Prog Neurobiol 134:36-54

Hildebrand ME, Smith PL, Bladen C, Eduljee C, Xie JY, Chen L, Fee-Maki M, Doering CJ, Mezeyova J, Zhu Y, et al. (2011) A novel slow-inactivationspecific ion channel modulator attenuates neuropathic pain. Pain 152: $833-843$

Hildebrand ME, Xu J, Dedek A, Li Y, Sengar AS, Beggs S, Lombroso PJ, and Salter MW (2016) Potentiation of synaptic GluN2B NMDAR currents by fyn kinase is gated through BDNF-mediated disinhibition in spinal pain processing. Cell Reports 17:2753-2765.

Ho C, Zhao J, Malinowski S, Chahine M, and O'Leary ME (2012) Differential expression of sodium channel $\beta$ subunits in dorsal root ganglion sensory neurons. $J$ Biol Chem 287:15044-15053.

Hogan QH, McCallum JB, Sarantopoulos C, Aason M, Mynlieff M, Kwok WM, and Bosnjak ZJ (2000) Painful neuropathy decreases membrane calcium current in mammalian primary afferent neurons. Pain 86:43-53.

Hogan QH and Poroli M (2008) Hyperpolarization-activated current (I(h)) contributes to excitability of primary sensory neurons in rats. Brain Res 1207:102-110.

Hogan QH, Sprick C, Guo Y, Mueller S, Bienengraeber M, Pan B, and Wu HE (2014) Divergent effects of painful nerve injury on mitochondrial $\mathrm{Ca}(2+)$ buffering in axotomized and adjacent sensory neurons. Brain Res 1589:112-125.

Hoppa MB, Lana B, Margas W, Dolphin AC, and Ryan TA (2012) $\alpha 2 \delta$ expression sets presynaptic calcium channel abundance and release probability. Nature 486: $122-125$

Howorth PW, Thornton SR, O'Brien V, Smith WD, Nikiforova N, Teschemacher AG and Pickering AE (2009) Retrograde viral vector-mediated inhibition of pontospinal noradrenergic neurons causes hyperalgesia in rats. $J$ Neurosci 29 12855-12864.

Huang F, Wang X, Ostertag EM, Nuwal T, Huang B, Jan YN, Basbaum AI, and Jan LY (2013) TMEM16C facilitates $\mathrm{Na}(+)$-activated $\mathrm{K}+$ currents in rat sensory neurons and regulates pain processing. Nat Neurosci 16:1284-1290. 
Hudson LJ, Bevan S, Wotherspoon G, Gentry C, Fox A, and Winter J (2001) VR1 protein expression increases in undamaged DRG neurons after partial nerve injury. Eur J Neurosci 13:2105-2114.

Hughes DI, Scott DT, Todd AJ, and Riddell JS (2003) Lack of evidence for sprouting of Abeta afferents into the superficial laminas of the spinal cord dorsal horn after nerve section. $J$ Neurosci 23:9491-9499.

Hughes SW, Hickey L, Hulse RP, Lumb BM, and Pickering AE (2013) Endogenous analgesic action of the pontospinal noradrenergic system spatially restricts and temporally delays the progression of neuropathic pain following tibial nerve injury. Pain 154:1680-1690.

Hunter JC, Gogas KR, Hedley LR, Jacobson LO, Kassotakis L, Thompson J, and Fontana DJ (1997) The effect of novel anti-epileptic drugs in rat experimental models of acute and chronic pain. Eur J Pharmacol 324:153-160.

Iadarola JM and Caudle RM (1997) Good pain, bad pain. Science 278:239-240.

Iftinca MC and Zamponi GW (2009) Regulation of neuronal T-type calcium channels. Trends Pharmacol Sci 30:32-40.

Ikeda H, Heinke B, Ruscheweyh R, and Sandkühler J (2003) Synaptic plasticity in spinal lamina I projection neurons that mediate hyperalgesia. Science 299 1237-1240.

Ikeda H, Stark J, Fischer H, Wagner M, Drdla R, Jäger T, and Sandkühler J (2006) Synaptic amplifier of inflammatory pain in the spinal dorsal horn. Science 312: 1659-1662.

Imlach WL, Bhola RF, Mohammadi SA, and Christie MJ (2016) Glycinergic dysfunction in a subpopulation of dorsal horn interneurons in a rat model of neuropathic pain. Sci Rep 6:37104.

Intondi AB, Dahlgren MN, Eilers MA, and Taylor BK (2008) Intrathecal neuropeptide Y reduces behavioral and molecular markers of inflammatory or neuropathic pain. Pain 137:352-365.

Iwagaki N, Garzillo F, Polgár E, Riddell JS, and Todd AJ (2013) Neurochemical characterisation of lamina II inhibitory interneurons that express GFP in the PrP GFP mouse. Mol Pain 9:56

Jagodic MM, Pathirathna S, Joksovic PM, Lee W, Nelson MT, Naik AK, Su P, Jevtovic-Todorovic V, and Todorovic SM (2008) Upregulation of the T-type calcium current in small rat sensory neurons after chronic constrictive injury of the sciatic nerve. J Neurophysiol 99:3151-3156.

Jagodic MM, Pathirathna S, Nelson MT, Mancuso S, Joksovic PM, Rosenberg ER, Bayliss DA, Jevtovic-Todorovic V, and Todorovic SM (2007) Cell-specific alterations of T-type calcium current in painful diabetic neuropathy enhance excitability of sensory neurons. $J$ Neurosci 27:3305-3316.

Janes K, Symons-Liguori AM, Jacobson KA, and Salvemini D (2016) Identification of A3 adenosine receptor agonists as novel non-narcotic analgesics. Br J Pharmacol 173:1253-1267.

Janes K, Wahlman C, Little JW, Doyle T, Tosh DK, Jacobson KA, and Salvemini D (2015) Spinal neuroimmune activation is independent of T-cell infiltration and attenuated by $\mathrm{A} 3$ adenosine receptor agonists in a model of oxaliplatin-induced peripheral neuropathy. Brain Behav Immun 44:91-99.

Jarvis MF, Scott VE, McGaraughty S, Chu KL, Xu J, Niforatos W, Milicic I, Joshi S, Zhang Q, and Xia Z (2014) A peripherally acting, selective T-type calcium channe blocker, ABT-639, effectively reduces nociceptive and neuropathic pain in rats. Biochem Pharmacol 89:536-544.

Jensen TS, Baron R, Haanpää M, Kalso E, Loeser JD, Rice AS, and Treede RD (2011) A new definition of neuropathic pain. Pain 152:2204-2205.

Ji RR, Chamessian A, and Zhang YQ (2016) Pain regulation by non-neuronal cells and inflammation. Science 354:572-577.

Ji RR, Kohno T, Moore KA, and Woolf CJ (2003) Central sensitization and LTP: do pain and memory share similar mechanisms? Trends Neurosci 26:696-705.

Ji RR and Woolf CJ (2001) Neuronal plasticity and signal transduction in nociceptive neurons: implications for the initiation and maintenance of pathological pain. Neurobiol Dis 8:1-10.

Johannessen SI, Battino D, Berry DJ, Bialer M, Krämer G, Tomson T, and Patsalos PN (2003) Therapeutic drug monitoring of the newer antiepileptic drugs. Ther Drug Monit 25:347-363.

Kadurin I, Ferron L, Rothwell SW, Meyer JO, Douglas LR, Bauer CS, Lana B, Margas W, Alexopoulos O, Nieto-Rostro M, et al. (2016) Proteolytic maturation of $\alpha 2 \delta$ represents a checkpoint for activation and neuronal trafficking of latent calcium channels. ELife 5: DOI: $10.7554 / \mathrm{eLife} .21143$.

Kawasaki Y, Zhang L, Cheng JK, and Ji RR (2008) Cytokine mechanisms of central sensitization: distinct and overlapping role of interleukin-1beta, interleukin-6, and tumor necrosis factor-alpha in regulating synaptic and neuronal activity in the superficial spinal cord. J Neurosci 28:5189-5194.

Keller AF, Coull JA, Chery N, Poisbeau P, and De Koninck Y (2001) Region-specific developmental specialization of GABA-glycine cosynapses in laminas I-II of the rat spinal dorsal horn. $J$ Neurosci 21:7871-7880

Keppel Hesselink JM and Schatman ME (2017) EMA401: an old antagonist of the AT2R for a new indication in neuropathic pain. J Pain Res 10:439-443.

Kerr BJ, Bradbury EJ, Bennett DL, Trivedi PM, Dassan P, French J, Shelton DB, McMahon SB, and Thompson SW (1999) Brain-derived neurotrophic factor modulates nociceptive sensory inputs and NMDA-evoked responses in the rat spinal cord. $J$ Neurosci 19:5138-5148.

Kim DS, Choi JO, Rim HD, and Cho HJ (2002) Downregulation of voltage-gated potassium channel alpha gene expression in dorsal root ganglia following chronic constriction injury of the rat sciatic nerve. Brain Res Mol Brain Res 105:146-152.

Kim KJ, Yoon YW, and Chung JM (1997) Comparison of three rodent neuropathic pain models. Exp Brain Res 113:200-206.

Kimura M, Eisenach JC, and Hayashida K (2016) Gabapentin loses efficacy over time after nerve injury in rats: role of glutamate transporter- 1 in the locus coeruleus. Pain 157:2024-2032.

King T, Vera-Portocarrero L, Gutierrez T, Vanderah TW, Dussor G, Lai J, Fields HL, and Porreca F (2009) Unmasking the tonic-aversive state in neuropathic pain. Nat Neurosci 12:1364-1366
Ko JS, Eddinger KA, Angert M, Chernov AV, Dolkas J, Strongin AY, Yaksh TL, and Shubayev VI (2016) Spinal activity of interleukin 6 mediates myelin basic protein-induced allodynia. Brain Behav Immun 56:378-389.

Kohno T, Ji RR, Ito N, Allchorne AJ, Befort K, Karchewski LA, and Woolf CJ (2005) Peripheral axonal injury results in reduced mu opioid receptor pre- and postsynaptic action in the spinal cord. Pain 117:77-87.

Kremer M, Salvat E, Muller A, Yalcin I, and Barrot M (2016) Antidepressants and gabapentinoids in neuropathic pain: mechanistic insights. Neuroscience 338: 183-206.

Kumar N, Cherkas PS, Varathan V, Miyamoto M, Chiang CY, Dostrovsky JO, Sessle BJ, and Coderre TJ (2013) Systemic pregabalin attenuates facial hypersensitivity and noxious stimulus-evoked release of glutamate in medullary dorsal horn in a rodent model of trigeminal neuropathic pain. Neurochem Int 62:831-835.

Kuner R (2010) Central mechanisms of pathological pain. Nat Med 16:1258-1266.

Kuo YL, Cheng JK, Hou WH, Chang YC, Du PH, Jian JJ, Rau RH, Yang JH, Lien CC, and Tsaur ML (2017) K+ channel modulatory subunits KChIP and DPP participate in Kv4-mediated mechanical pain control. J Neurosci 37:4391-4404.

Lana B, Page KM, Kadurin I, Ho S, Nieto-Rostro M, and Dolphin AC (2016) Thrombospondin-4 reduces binding affinity of $[(3) \mathrm{H}]$-gabapentin to calciumchannel $\alpha 2 \delta$-1-subunit but does not interact with $\alpha 2 \delta-1$ on the cell-surface when co-expressed. Sci Rep 6:24531.

Langford DJ, Bailey AL, Chanda ML, Clarke SE, Drummond TE, Echols S, Glick S, Ingrao J, Klassen-Ross T, Lacroix-Fralish ML, et al. (2010) Coding of facial expressions of pain in the laboratory mouse. Nat Methods 7:447-449.

Lanneau C, Green A, Hirst WD, Wise A, Brown JT, Donnier E, Charles KJ, Wood M, Davies CH, and Pangalos MN (2001) Gabapentin is not a GABAB receptor agonist. Neuropharmacology 41:965-975.

Latremoliere A and Woolf CJ (2009) Central sensitization: a generator of pain hypersensitivity by central neural plasticity. J Pain 10:895-926.

Lavertu G, Côté SL, and De Koninck Y (2014) Enhancing K-Cl co-transport restores normal spinothalamic sensory coding in a neuropathic pain model. Brain 137: $724-738$.

Lee JH, Park CK, Chen G, Han Q, Xie RG, Liu T, Ji RR, and Lee SY (2014) A monoclonal antibody that targets a NaV1.7 channel voltage sensor for pain and itch relief. Cell 157:1393-1404.

Leitner J, Westerholz S, Heinke B, Forsthuber L, Wunderbaldinger G, Jäger T, Gruber-Schoffnegger D, Braun K, and Sandkühler J (2013) Impaired excitatory drive to spinal GABAergic neurons of neuropathic mice. PLoS One 8:e73370.

Leung L and Cahill CM (2010) TNF-alpha and neuropathic pain-a review. J Neuroinflammation 7:27.

Li KW, Yu YP, Zhou C, Kim DS, Lin B, Sharp K, Steward O, and Luo ZD (2014) Calcium channel $\alpha 2 \delta 1$ proteins mediate trigeminal neuropathic pain states associated with aberrant excitatory synaptogenesis. J Biol Chem 289:7025-7037.

Li Z, Taylor CP, Weber M, Piechan J, Prior F, Bian F, Cui M, Hoffman D, and Donevan S (2011) Pregabalin is a potent and selective ligand for $\alpha(2) \delta-1$ and $\alpha(2) \delta-2$ calcium channel subunits. Eur J Pharmacol 667:80-90.

Lim H, Lee H, Noh K, and Lee SJ (2017) IKK/NF-kB-dependent satellite glia activation induces spinal cord microglia activation and neuropathic pain after nerve injury. Pain 158:1666-1677.

Lin HC, Huang YH, Chao TH, Lin WY, Sun WZ, and Yen CT (2014) Gabapentin reverses central hypersensitivity and suppresses medial prefrontal cortical glucose metabolism in rats with neuropathic pain. Mol Pain 10:63.

Little JW, Ford A, Symons-Liguori AM, Chen Z, Janes K, Doyle T, Xie J, Luongo L, Tosh DK, Maione S, et al. (2015) Endogenous adenosine A3 receptor activation selectively alleviates persistent pain states. Brain 138:28-35.

Liu Y, Tang J, Zhang Y, Xun X, Tang D, Peng D, Yi J, Liu Z, and Shi X (2014) Synthesis and analgesic effects of $\mu$-TRTX-Hhn1b on models of inflammatory and neuropathic pain. Toxins (Basel) 6:2363-2378

Loomis CW, Khandwala H, Osmond G, and Hefferan MP (2001) Coadministration of intrathecal strychnine and bicuculline effects synergistic allodynia in the rat: an isobolographic analysis. $J$ Pharmacol Exp Ther 296:756-761.

Lorenzo LE, Magnussen C, Bailey AL, St Louis M, De Koninck Y, and Ribeiro-daSilva A (2014) Spatial and temporal pattern of changes in the number of GAD65immunoreactive inhibitory terminals in the rat superficial dorsal horn following peripheral nerve injury. Mol Pain 10:57.

Lotarski S, Hain H, Peterson J, Galvin S, Strenkowski B, Donevan S, and Offord J (2014) Anticonvulsant activity of pregabalin in the maximal electroshock-induced seizure assay in $\alpha 2 \delta 1$ (R217A) and $\alpha 2 \delta 2$ (R279A) mouse mutants. Epilepsy Res 108 833-842.

Lotarski SM, Donevan S, El-Kattan A, Osgood S, Poe J, Taylor CP, and Offord J (2011) Anxiolytic-like activity of pregabalin in the Vogel conflict test in $\alpha 2 \delta-1$ (R217A) and $\alpha 2 \delta-2$ (R279A) mouse mutants. J Pharmacol Exp Ther 338:615-621. Lu VB, Ballanyi K, Colmers WF, and Smith PA (2007) Neuron type-specific effects of brain-derived neurotrophic factor in rat superficial dorsal horn and their relevance to 'central sensitization.' J Physiol 584:543-563.

Lu VB, Biggs JE, Stebbing MJ, Balasubramanyan S, Todd KG, Lai AY, Colmers WF Dawbarn D, Ballanyi K, and Smith PA (2009) BDNF drives the changes in excitatory synaptic transmission in the rat superficial dorsal horn that follow sciatic nerve injury. $J$ Physiol 587:1013-1032.

Lu VB, Moran TD, Balasubramanyan S, Alier KA, Dryden WF, Colmers WF, and Smith PA (2006) Substantia Gelatinosa neurons in defined-medium organotypic slice culture are similar to those in acute slices from young adult rats. Pain 121:261-275.

Lu Y, Dong H, Gao Y, Gong Y, Ren Y, Gu N, Zhou S, Xia N, Sun YY, Ji RR, et al. (2013) A feed-forward spinal cord glycinergic neural circuit gates mechanical allodynia. J Clin Invest 123:4050-4062.

Lu Y and Perl ER (2003) A specific inhibitory pathway between substantia gelatinosa neurons receiving direct C-fiber input. $J$ Neurosci 23:8752-8758.

$\mathrm{Lu} \mathrm{Y}$ and Perl ER (2005) Modular organization of excitatory circuits between neurons of the spinal superficial dorsal horn (laminae I and II). J Neurosci 25:3900-3907. 
Luo C, Kuner T, and Kuner R (2014) Synaptic plasticity in pathological pain. Trends Neurosci 37:343-355.

Luo L, Chang L, Brown SM, Ao H, Lee DH, Higuera ES, Dubin AE, and Chaplan SR (2007) Role of peripheral hyperpolarization-activated cyclic nucleotide-modulated channel pacemaker channels in acute and chronic pain models in the rat. Neuroscience 144:1477-1485.

Luo ZD, Calcutt NA, Higuera ES, Valder CR, Song YH, Svensson CI, and Myers RR (2002) Injury type-specific calcium channel alpha 2 delta-1 subunit up-regulation in rat neuropathic pain models correlates with antiallodynic effects of gabapentin. $J$ Pharmacol Exp Ther 303:1199-1205.

Luo ZD, Chaplan SR, Higuera ES, Sorkin LS, Stauderman KA, Williams ME, and Yaksh TL (2001) Upregulation of dorsal root ganglion (alpha)2(delta) calcium channel subunit and its correlation with allodynia in spinal nerve-injured rats. $J$ Neurosci 21:1868-1875.

Luongo L, Starowicz K, Maione S, and Di Marzo V (2017) Allodynia lowering induced by cannabinoids and endocannabinoids (ALICE). Pharmacol Res 119:272-277.

M'Dahoma S, Gadotti VM, Zhang FX, Park B, Nam JH, Onnis V, Balboni G, Lee JY, and Zamponi GW (2016) Effect of the T-type channel blocker KYS-05090S in mouse models of acute and neuropathic pain. Pflugers Arch 468:193-199.

Ma W and Eisenach JC (2002) Morphological and pharmacological evidence for the role of peripheral prostaglandins in the pathogenesis of neuropathic pain. Eur $J$ Neurosci 15:1037-1047.

Maeda S, Kawamoto A, Yatani Y, Shirakawa H, Nakagawa T, and Kaneko S (2008) Gene transfer of GLT-1, a glial glutamate transporter, into the spinal cord by recombinant adenovirus attenuates inflammatory and neuropathic pain in rats. Mol Pain 4:65.

Magnussen C, Hung SP, and Ribeiro-da-Silva A (2015) Novel expression pattern of neuropeptide $\mathrm{Y}$ immunoreactivity in the peripheral nervous system in a rat model of neuropathic pain. Mol Pain 11:31.

Maher DP, Chen L, and Mao J (2017) Intravenous ketamine infusions for neuropathic pain management: a promising therapy in need of optimization. Anesth Analg 124:661-674.

Malcangio M and Lessmann V (2003) A common thread for pain and memory synapses? Brain-derived neurotrophic factor and trkB receptors. Trends Pharmacol Sci 24:116-121.

Marais E, Klugbauer N, and Hofmann F (2001) Calcium channel alpha(2)delta subunits-structure and gabapentin binding. Mol Pharmacol 59:1243-1248.

Margas W, Ferron L, Nieto-Rostro M, Schwartz A, and Dolphin AC (2016) Effect of knockout of $\alpha 2 \delta-1$ on action potentials in mouse sensory neurons. Philos Trans $R$ Soc Lond B Biol Sci 371: DOI: 10.1098/rstb.2015.0430.

Masuda T, Ozono Y, Mikuriya S, Kohro Y, Tozaki-Saitoh H, Iwatsuki K, Uneyama H, Ichikawa R, Salter MW, Tsuda M, et al. (2016) Dorsal horn neurons release extracellular ATP in a VNUT-dependent manner that underlies neuropathic pain. Nat Commun 7:12529.

McGivern JG (2007) Ziconotide: a review of its pharmacology and use in the treatment of pain. Neuropsychiatr Dis Treat 3:69-85.

McLachlan EM and Hu P (1998) Axonal sprouts containing calcitonin gene-related peptide and substance $\mathrm{P}$ form pericellular baskets around large diameter neurons after sciatic nerve transection in the rat. Neuroscience 84:961-965.

McLachlan EM, Jänig W, Devor M, and Michaelis M (1993) Peripheral nerve injury triggers noradrenergic sprouting within dorsal root ganglia. Nature 363:543-546.

Melchior M, Poisbeau P, Gaumond I, and Marchand S (2016) Insights into the mechanisms and the emergence of sex-differences in pain. Neuroscience 338:63-80.

Meng G, Wu N, Zhang C, Su RB, Lu XQ, Liu Y, Yun LH, Zheng JQ, and Li J (2008) Analgesic activity of ZC88, a novel N-type voltage-dependent calcium channel blocker, and its modulation of morphine analgesia, tolerance and dependence. Eur $J$ Pharmacol 586:130-138.

Mifflin KA, Frieser E, Benson C, Baker G, and Kerr BJ (2017) Voluntary wheel running differentially affects disease outcomes in male and female mice with experimental autoimmune encephalomyelitis. J Neuroimmunol 305:135-144.

Mifflin KA and Kerr BJ (2013) Sex-related differences in acute and chronic pain: a bench to bedside perspective. Can J Anaesth 60:221-226.

Mifflin KA and Kerr BJ (2017) Pain in autoimmune disorders. J Neurosci Res 95: 1282-1294.

Mikuzuki L, Saito H, Katagiri A, Okada S, Sugawara S, Kubo A, Ohara K, Lee J, Toyofuku A, and Iwata K (2017) Phenotypic change in trigeminal ganglion neurons associated with satellite cell activation via extracellular signal-regulated kinase phosphorylation is involved in lingual neuropathic pain. Eur J Neurosci 46 $2190-2202$.

Millan MJ (2002) Descending control of pain. Prog Neurobiol 66:355-474.

Milligan ED and Watkins LR (2009) Pathological and protective roles of glia in chronic pain. Nat Rev Neurosci 10:23-36.

Milligan ED, Zapata V, Chacur M, Schoeniger D, Biedenkapp J, O’Connor KA, Verge GM, Chapman G, Green P, Foster AC, et al. (2004) Evidence that exogenous and endogenous fractalkine can induce spinal nociceptive facilitation in rats. Eur $J$ Neurosci 20:2294-2302.

Minett MS, Nassar MA, Clark AK, Passmore G, Dickenson AH, Wang F, Malcangio M, and Wood JN (2012) Distinct Nav1.7-dependent pain sensations require different sets of sensory and sympathetic neurons. Nat Commun 3:791.

Mitsi V and Zachariou V (2016) Modulation of pain, nociception, and analgesia by the brain reward center. Neuroscience 338:81-92

Mogil JS (2009) Animal models of pain: progress and challenges. Nat Rev Neurosci 10:283-294.

Mogil JS (2012a) Pain genetics: past, present and future. Trends Genet 28:258-266

Mogil JS (2012b) Sex differences in pain and pain inhibition: multiple explanations of a controversial phenomenon. Nat Rev Neurosci 13:859-866.

Mogil JS (2017) Laboratory environmental factors and pain behavior: the relevance of unknown unknowns to reproducibility and translation. Lab Anim (NY) 46:136-141.

Mogil JS and Crager SE (2004) What should we be measuring in behavioral studies of chronic pain in animals? Pain 112:12-15
Molliver DC, Wright DE, Leitner ML, Parsadanian AS, Doster K, Wen D, Yan Q, and Snider WD (1997) IB4-binding DRG neurons switch from NGF to GDNF dependence in early postnatal life. Neuron 19:849-861.

Montalbano A, Baj G, Papadia D, Tongiorgi E, and Sciancalepore M (2013) Blockade of BDNF signaling turns chemically-induced long-term potentiation into long-term depression. Hippocampus 23:879-889.

Moore KA, Baba H, and Woolf CJ (2002) Gabapentin-actions on adult superficial dorsal horn neurons. Neuropharmacology 43:1077-1081.

Moore RA, Derry S, Aldington D, Cole P, and Wiffen PJ (2015) Amitriptyline for neuropathic pain in adults. Cochrane Database Syst Rev 7: DOI: 10.1002/14651858. CD008242.pub3.

Moore RA, Wiffen PJ, Derry S, and McQuay HJ (2011) Gabapentin for chronic neuropathic pain and fibromyalgia in adults. Cochrane Database Syst Rev 3: DOI: 10.1002/14651858.CD007938.pub2

Moore RA, Wiffen PJ, Derry S, Toelle T, and Rice AS (2014) Gabapentin for chronic neuropathic pain and fibromyalgia in adults. Cochrane Database Syst Rev 4: DOI 10.1002/14651858.CD007938.pub3.

Moran TD, Colmers WF, and Smith PA (2004) Opioid-like actions of neuropeptide Y in rat substantia gelatinosa: Y1 suppression of inhibition and Y2 suppression of excitation. J Neurophysiol 92:3266-3275.

Moulin D, Boulanger A, Clark AJ, Clarke H, Dao T, Finley GA, Furlan A, Gilron I, Gordon A, Morley-Forster PK, et al.; Canadian Pain Society (2014) Pharmacological management of chronic neuropathic pain: revised consensus statement from the Canadian Pain Society. Pain Res Manag 19:328-335.

Munro G, Erichsen HK and Mirza NR (2007) Pharmacological comparison of anticonvulsant drugs in animal models of persistent pain and anxiety. Neuropharmacology 53:609-618.

Nadeau S, Filali M, Zhang J, Kerr BJ, Rivest S, Soulet D, Iwakura Y, de Rivero Vaccari JP, Keane RW, and Lacroix S (2011) Functional recovery after peripheral nerve injury is dependent on the pro-inflammatory cytokines IL-1 $\beta$ and TNF: implications for neuropathic pain. J Neurosci 31:12533-12542.

Nader K, Schafe GE, and LeDoux JE (2000) The labile nature of consolidation theory. Nat Rev Neurosci 1:216-219.

Narita N, Kumar N, Cherkas PS, Chiang CY, Dostrovsky JO, Coderre TJ, and Sessle BJ (2012) Systemic pregabalin attenuates sensorimotor responses and medullary glutamate release in inflammatory tooth pain model. Neuroscience 218:359-366.

Nguyen D, Deng P, Matthews EA, Kim DS, Feng G, Dickenson AH, Xu ZC, and Luo ZD (2009) Enhanced pre-synaptic glutamate release in deep-dorsal horn contributes to calcium channel alpha-2-delta-1 protein-mediated spinal sensitization and behavioral hypersensitivity. Mol Pain 5:6.

Nie H and Weng HR (2009) Glutamate transporters prevent excessive activation of NMDA receptors and extrasynaptic glutamate spillover in the spinal dorsal horn. $J$ Neurophysiol 101:2041-2051.

Niesters M, Martini C, and Dahan A (2014) Ketamine for chronic pain: risks and benefits. Br J Clin Pharmacol 77:357-367.

Nilius B, Owsianik G, Voets T, and Peters JA (2007) Transient receptor potential cation channels in disease. Physiol Rev 87:165-217.

Noh S, Kumar N, Bukhanova N, Chen Y, Stemkowsi PL, and Smith PA (2014) The heart-rate-reducing agent, ivabradine, reduces mechanical allodynia in a rodent model of neuropathic pain. Eur J Pain 18:1139-1147.

O'Malley HA and Isom LL (2015) Sodium channel $\beta$ subunits: emerging targets in channelopathies. Annu Rev Physiol 77:481-504.

Offord $J$ and Isom LL (2015) Drugging the undruggable: gabapentin, pregabalin and the calcium channel $\alpha 2 \delta$ subunit. Crit Rev Biochem Mol Biol 51:246-256.

Oh HM and Chung ME (2015) Botulinum toxin for neuropathic pain: a review of the literature. Toxins (Basel) 7:3127-3154.

Okubo M, Yamanaka H, Kobayashi K, Dai Y, Kanda H, Yagi H, and Noguchi K (2016) Macrophage-colony stimulating factor derived from injured primary afferent induces proliferation of spinal microglia and neuropathic pain in rats. PLoS One 11 $\mathrm{e} 0153375$.

Ossipov MH, Dussor GO, and Porreca F (2010) Central modulation of pain. J Clin Invest 120:3779-3787.

Pan B, Guo Y, Wu HE, Park J, Trinh VN, Luo ZD, and Hogan QH (2016) Thrombospondin-4 divergently regulates voltage-gated $\mathrm{Ca} 2+$ channel subtypes in sensory neurons after nerve injury. Pain 157:2068-2080.

Pan B, Yu H, Park J, Yu YP, Luo ZD, and Hogan QH (2015) Painful nerve injury upregulates thrombospondin-4 expression in dorsal root ganglia. J Neurosci Res 93:443-453.

Papp I, Szucs P, Holló K, Erdélyi F, Szabó G, and Antal M (2006) Hyperpolarizationactivated and cyclic nucleotide-gated cation channel subunit 2 ion channels modulate synaptic transmission from nociceptive primary afferents containing substance $\mathrm{P}$ to secondary sensory neurons in laminae I-IIo of the rodent spinal dorsal horn. Eur J Neurosci 24:1341-1352.

Park J and Park HJ (2017) Botulinum toxin for the treatment of neuropathic pain. Toxins (Basel) 9:E260 DOI: 10.3390/toxins9090260.

Park J, Trinh VN, Sears-Kraxberger I, Li KW, Steward O, and Luo ZD (2016a) Synaptic ultrastructure changes in trigeminocervical complex posttrigeminal nerve injury. J Comp Neurol 524:309-322.

Park J, Yu YP, Zhou CY, Li KW, Wang D, Chang E, Kim DS, Vo B, Zhang X, Gong N, et al. (2016b) Central mechanisms mediating thrombospondin-4-induced pain states. J Biol Chem 291:13335-13348.

Passmore GM, Selyanko AA, Mistry M, Al-Qatari M, Marsh SJ, Matthews EA, Dickenson AH, Brown TA, Burbidge SA, Main M, et al. (2003) KCNQ/M currents in sensory neurons: significance for pain therapy. J Neurosci 23:7227-7236.

Patel R, Bauer CS, Nieto-Rostro M, Margas W, Ferron L, Chaggar K, Crews K, Ramirez JD, Bennett DLH, Schwartz A, et al. (2013) $\alpha 2 \delta-1$ gene deletion affects somatosensory neuron function and delays mechanical hypersensitivity in response to peripheral nerve damage. $J$ Neurosci 33:16412-16426.

Patel R and Dickenson AH (2016a) Mechanisms of the gabapentinoids and $\alpha 2 \delta$-1 calcium channel subunit in neuropathic pain. Pharmacol Res Perspect 4:e00205. 
Patel R and Dickenson AH (2016b) Neuronal hyperexcitability in the ventral posterior thalamus of neuropathic rats: modality selective effects of pregabalin. $J$ Neurophysiol 116:159-170.

Patel R, Montagut-Bordas C, and Dickenson AH (2017) Calcium channel modulation as a target in chronic pain control. Br J Pharmacol [published ahead of print].

Patel R, Rutten K, Valdor M, Schiene K, Wigge S, Schunk S, Damann N, Christoph T, and Dickenson AH (2015) Electrophysiological characterization of activation statedependent $\mathrm{Ca}(\mathrm{v}) 2$ channel antagonist TROX-1 in spinal nerve injured rats. $\mathrm{Neu}$ roscience 297:47-57.

Paul J, Yévenes GE, Benke D, Di Lio A, Ralvenius WT, Witschi R, Scheurer L, Cook JM, Rudolph U, Fritschy JM, et al. (2014) Antihyperalgesia by $\alpha 2$-GABAA receptors occurs via a genuine spinal action and does not involve supraspinal sites. Neuropsychopharmacology 39:477-487.

Paul J, Zeilhofer HU, and Fritschy JM (2012) Selective distribution of GABA(A) receptor subtypes in mouse spinal dorsal horn neurons and primary afferents. $J$ Comp Neurol 520:3895-3911.

Peirs C and Seal RP (2015) Targeting Toll-like receptors to treat chronic pain. Nat Med 21:1251-1252.

Peirs C and Seal RP (2016) Neural circuits for pain: recent advances and current views. Science 354:578-584.

Peirs C, Williams SP, Zhao X, Walsh CE, Gedeon JY, Cagle NE, Goldring AC, Hioki H, Liu Z, Marell PS, et al. (2015) Dorsal horn circuits for persistent mechanical pain. Neuron 87:797-812.

Pickering G, Morel V, Simen E, Cardot JM, Moustafa F, Delage N, Picard P, Eschalier S, Boulliau S, and Dubray C (2011) Oral magnesium treatment in patients with neuropathic pain: a randomized clinical trial. Magnes Res 24:28-35.

Pitcher GM and Henry JL (2008) Governing role of primary afferent drive in increased excitation of spinal nociceptive neurons in a model of sciatic neuropathy. Exp Neurol 214:219-228.

Pizzolato R, Villani V, Prosperini L, Ciuffoli A, and Sette G (2011) Efficacy and tolerability of pregabalin as preventive treatment for migraine: a 3-month follow-up study. J Headache Pain 12:521-525.

Porreca F, Ossipov MH, and Gebhart GF (2002) Chronic pain and medullary descending facilitation. Trends Neurosci 25:319-325.

Prescott SA, Ma Q, and De Koninck Y (2014) Normal and abnormal coding of somatosensory stimuli causing pain. Nat Neurosci 17:183-191.

Prescott SA, Sejnowski TJ, and De Koninck Y (2006) Reduction of anion reversal potential subverts the inhibitory control of firing rate in spinal lamina I neurons: towards a biophysical basis for neuropathic pain. Mol Pain 2:32.

Puke MJ, Xu XJ, and Wiesenfeld-Hallin Z (1991) Intrathecal administration of clonidine suppresses autotomy, a behavioral sign of chronic pain in rats after sciatic nerve section. Neurosci Lett 133:199-202.

Punnakkal P, von Schoultz C, Haenraets K, Wildner H, and Zeilhofer HU (2014) Morphological, biophysical and synaptic properties of glutamatergic neurons of the mouse spinal dorsal horn. J Physiol 592:759-776.

Radwani H, Lopez-Gonzalez MJ, Cattaert D, Roca-Lapirot O, Dobremez E, BoualiBenazzouz R, Eiriksdottir E, Langel U, Favereaux A, Errami M, et al. (2016) Cav1.2 and Cav1.3 L-type calcium channels independently control short- and longterm sensitization to pain. J Physiol 594:6607-6626.

Ralvenius WT, Acuña MA, Benke D, Matthey A, Daali Y, Rudolph U, Desmeules J, Zeilhofer HU, and Besson M (2016) The clobazam metabolite N-desmethyl clobazam is an $\alpha 2$ preferring benzodiazepine with an improved therapeutic window for antihyperalgesia. Neuropharmacology 109:366-375.

Ranade SS, Woo SH, Dubin AE, Moshourab RA, Wetzel C, Petrus M, Mathur J, Bégay V, Coste B, Mainquist J, et al. (2014) Piezo2 is the major transducer of mechanical forces for touch sensation in mice. Nature 516:121-125.

Rauck RL, Irving GA, Wallace MS, Vanhove GF, and Sweeney M (2013) Once-daily gastroretentive gabapentin for postherpetic neuralgia: integrated efficacy, time to onset of pain relief and safety analyses of data from two phase 3, multicenter randomized, double-blind, placebo-controlled studies. J Pain Symptom Manage 46: 219-228.

Reichardt LF (2006) Neurotrophin-regulated signalling pathways. Philos Trans $R$ Soc Lond B Biol Sci 361:1545-1564.

Ren W, Centeno MV, Berger S, Wu Y, Na X, Liu X, Kondapalli J, Apkarian AV, Martina M, and Surmeier DJ (2016) The indirect pathway of the nucleus accumbens shell amplifies neuropathic pain. Nat Neurosci 19:220-222.

Rettig J, Sheng ZH, Kim DK, Hodson CD, Snutch TP, and Catterall WA (1996) Isoform-specific interaction of the alpha1A subunits of brain $\mathrm{Ca} 2+$ channels with the presynaptic proteins syntaxin and SNAP-25. Proc Natl Acad Sci USA 93: $7363-7368$.

Rexed B (1952) The cytoarchitectonic organization of the spinal cord in the cat. $J$ Comp Neurol 96:414-495.

Rice AS and Smith MT (2015) Angiotensin II type 2-receptor: new clinically validated target in the treatment of neuropathic pain. Clin Pharmacol Ther 97:128-130.

Rice ASC, Dworkin RH, McCarthy TD, Anand P, Bountra C, McCloud PI, Hill J, Cutter G, Kitson G, Desem N, et al.; EMA401-003 Study Group (2014) EMA401, an orally administered highly selective angiotensin II type 2 receptor antagonist, as a novel treatment for postherpetic neuralgia: a randomised, double-blind, placebocontrolled phase 2 clinical trial. Lancet 383:1637-1647.

Ritter DM, Zemel BM, Hala TJ, O'Leary ME, Lepore AC, and Covarrubias M (2015) Dysregulation of Kv3.4 channels in dorsal root ganglia following spinal cord injury. J Neurosci 35:1260-1273.

Rodriguez-Kern A, Gegelashvili M, Schousboe A, Zhang J, Sung L, and Gegelashvili G (2003) Beta-amyloid and brain-derived neurotrophic factor, BDNF, up-regulate the expression of glutamate transporter GLT-1/EAAT2 via different signaling pathways utilizing transcription factor NF-kappaB. Neurochem Int 43:363-370.

Rondón LJ, Privat AM, Daulhac L, Davin N, Mazur A, Fialip J, Eschalier A, and Courteix C (2010) Magnesium attenuates chronic hypersensitivity and spinal cord NMDA receptor phosphorylation in a rat model of diabetic neuropathic pain. $J$ Physiol 588:4205-4215.
Ross HR, Napier I, and Connor M (2008) Inhibition of recombinant human T-type calcium channels by Delta9-tetrahydrocannabinol and cannabidiol. $J$ Biol Chem 283:16124-16134.

Ruscheweyh R, Wilder-Smith O, Drdla R, Liu XG, and Sandkühler J (2011) Longterm potentiation in spinal nociceptive pathways as a novel target for pain therapy. Mol Pain 7:20.

Saegusa H, Kurihara T, Zong S, Kazuno A, Matsuda Y, Nonaka T, Han W, Toriyama $\mathrm{H}$, and Tanabe $\mathrm{T}$ (2001) Suppression of inflammatory and neuropathic pain symptoms in mice lacking the N-type Ca2+ channel. EMBO J 20:2349-2356.

Sah DW, Ossipo MH, and Porreca F (2003) Neurotrophic factors as novel therapeutics for neuropathic pain. Nat Rev Drug Discov 2:460-472.

Salter MW and Pitcher GM (2012) Dysregulated Src upregulation of NMDA receptor activity: a common link in chronic pain and schizophrenia. FEBS $J$ 279:2-11.

Salter MW (2014) Deepening understanding of the neural substrates of chronic pain. Brain 137:651-653.

Sandkühler J (2007) Understanding LTP in pain pathways. Mol Pain 3:9.

Sandkühler J (2009) Models and mechanisms of hyperalgesia and allodynia. Physiol Rev 89:707-758.

Sandkühler J and Gruber-Schoffnegger D (2012) Hyperalgesia by synaptic long-term potentiation (LTP): an update. Curr Opin Pharmacol 12:18-27.

Sandkühler J and Lee J (2013) How to erase memory traces of pain and fear. Trends Neurosci 36:343-352.

Santos SF, Rebelo S, Derkach VA, and Safronov BV (2007) Excitatory interneurons dominate sensory processing in the spinal substantia gelatinosa of rat. $J$ Physiol $\mathbf{5 8 1}: 241-254$

Sartiani L, Mannaioni G, Masi A, Novella Romanelli M, and Cerbai E (2017) The hyperpolarization-activated cyclic nucleotide-gated channels: from biophysics to pharmacology of a unique family of ion channels. Pharmacol Rev 69:354-395.

Sawynok J (2016) Adenosine receptor targets for pain. Neuroscience 338:1-18.

Schmidt BL, Hamamoto DT, Simone DA, and Wilcox GL (2010) Mechanism of cancer pain. Mol Interv 10:164-178.

Scholz J and Woolf CJ (2007) The neuropathic pain triad: neurons, immune cells and glia. Nat Neurosci 10:1361-1368.

Schuh CD, Pierre S, Weigert A, Weichand B, Altenrath K, Schreiber Y, Ferreiros N, Zhang DD, Suo J, Treutlein EM, et al. (2014) Prostacyclin mediates neuropathic pain through interleukin 1 $\beta$-expressing resident macrophages. Pain 155:545-555. Schweinhardt P and Bushnell MC (2010) Pain imaging in health and disease-how far have we come? J Clin Invest 120:3788-3797.

Seward EP and Henderson G (1990) Characterization of two components of the N-like, high-threshold-activated calcium channel current in differentiated SH-SY5Y cells. Pflugers Arch 417:223-230.

Sexton JE, Cox JJ, Zhao J, and Wood JN (2017) The genetics of pain: implications for therapeutics. Annu Rev Pharmacol Toxicol [published ahead of print].

Shahid M, Subhan F, Ahmad N, Ali G, Akbar S, Fawad K, and Sewell RD (2017) Topical gabapentin gel alleviates allodynia and hyperalgesia in the chronic sciatic nerve constriction injury neuropathic pain model. Eur J Pain 21:668-680.

Sharma U, Griesing T, Emir B, and Young JP Jr (2010) Time to onset of neuropathic pain reduction: a retrospective analysis of data from nine controlled trials of pregabalin for painful diabetic peripheral neuropathy and postherpetic neuralgia. Am J Ther 17:577-585

Sheng ZH, Rettig J, Cook T, and Catterall WA (1996) Calcium-dependent interaction of N-type calcium channels with the synaptic core complex. Nature 379:451-454.

Sherman SE and Loomis CW (1994) Morphine insensitive allodynia is produced by intrathecal strychnine in the lightly anesthetized rat. Pain 56:17-29.

Smith MT, Wyse BD, and Edwards SR (2013) Small molecule angiotensin II type 2 receptor $\left(\mathrm{AT}_{2} \mathrm{R}\right)$ antagonists as novel analgesics for neuropathic pain: comparative pharmacokinetics, radioligand binding, and efficacy in rats. Pain Med 14 692-705.

Smith PA (2014) BDNF: no gain without pain? Neuroscience 283:107-123.

Smith PA, Moran TD, Abdulla F, Tumber KK, and Taylor BK (2007) Spinal mechanisms of NPY analgesia. Peptides 28:464-474.

Snutch TP and Zamponi GW (2017) Recent advances in the development of T-type calcium channel blockers for pain intervention. $\mathrm{Br} J$ Pharmacol [published ahead of print].

Sorge RE, Mapplebeck JC, Rosen S, Beggs S, Taves S, Alexander JK, Martin LJ, Austin JS, Sotocinal SG, Chen D, et al. (2015) Different immune cells mediate mechanical pain hypersensitivity in male and female mice. Nat Neurosci 18: 1081-1083

Sorge RE and Totsch SK (2017) Sex differences in pain. J Neurosci Res 95:1271-1281.

Stacey BR, Barrett JA, Whalen E, Phillips KF, and Rowbotham MC (2008) Pregabalin for postherpetic neuralgia: placebo-controlled trial of fixed and flexible dosing regimens on allodynia and time to onset of pain relief. J Pain 9:1006-1017.

Stebbing MJ, Balasubramanyan S, and Smith PA (2016) Calbindin-D-28K like immunoreactivity in superficial dorsal horn neurons and effects of sciatic chronic constriction injury. Neuroscience 324:330-343.

Stemkowski PL, Garcia-Caballero A, Gadotti VM, M’Dahoma S, Chen L, Souza IA, and Zamponi GW (2017) Identification of interleukin-1 beta as a key mediator in the upregulation of Cav3.2-USP5 interactions in the pain pathway. Mol Pain 13: DOI: $10.1177 / 1744806917724698$.

Stemkowski PL, Noh MC, Chen Y, and Smith PA (2015) Increased excitability of medium-sized dorsal root ganglion neurons by prolonged interleukin-1 $\beta$ exposure is $\mathrm{K}(+)$ channel dependent and reversible. J Physiol 593:3739-3755.

Stemkowski PL and Smith PA (2012a) Long-term IL-1 $\beta$ exposure causes subpopulation-dependent alterations in rat dorsal root ganglion neuron excitability. J Neurophysiol 107:1586-1597.

Stemkowski PL and Smith PA (2012b) Sensory neurons, ion channels, inflammation and the onset of neuropathic pain. Can J Neurol Sci 39:416-435.

Stemkowski PL and Smith PA (2013) An overview of animal models of neuropathic pain, in Neuropathic Pain, Causes, Management and Understanding (Toth C and Moulin DE eds) pp 33-50, Cambridge University Press, Cambridge, UK. 
Stone LS and Szyf M (2013) The emerging field of pain epigenetics. Pain 154:1-2.

Stucky CL and Lewin GR (1999) Isolectin B(4)-positive and -negative nociceptors are functionally distinct. $J$ Neurosci 19:6497-6505.

Sung B, Lim G, and Mao J (2003) Altered expression and uptake activity of spinal glutamate transporters after nerve injury contribute to the pathogenesis of neuropathic pain in rats. $J$ Neurosci 23:2899-2910.

Surges R, Freiman TM, and Feuerstein TJ (2003) Gabapentin increases the hyperpolarization-activated cation current $\mathrm{Ih}$ in rat CA1 pyramidal cells. Epilepsia 44:150-156.

Suto T, Severino AL, Eisenach JC, and Hayashida K (2014) Gabapentin increases extracellular glutamatergic level in the locus coeruleus via astroglial glutamate transporter-dependent mechanisms. Neuropharmacology 81:95-100.

Sutton KG, Martin DJ, Pinnock RD, Lee K, and Scott RH (2002) Gabapentin inhibits high-threshold calcium channel currents in cultured rat dorsal root ganglion neurones. Br J Pharmacol 135:257-265.

Suzuki R, Rahman W, Rygh LJ, Webber M, Hunt SP, and Dickenson AH (2005) Spinal-supraspinal serotonergic circuits regulating neuropathic pain and its treatment with gabapentin. Pain 117:292-303.

Swensen AM, Herrington J, Bugianesi RM, Dai G, Haedo RJ, Ratliff KS, Smith MM, Warren VA, Arneric SP, Eduljee C, et al. (2012) Characterization of the substituted N-triazole oxindole TROX-1, a small-molecule, state-dependent inhibitor of $\mathrm{Ca}(\mathrm{V}) 2$ calcium channels. Mol Pharmacol 81:488-497.

Tae HS, Smith KM, Phillips AM, Boyle KA, Li M, Forster IC, Hatch RJ, Richardson R, Hughes DI, Graham BA, et al. (2017) Gabapentin modulates HCN4 channel voltage-dependence. Front Pharmacol 8:554.

Tajerian M, Alvarado S, Millecamps M, Vachon P, Crosby C, Bushnell MC, Szyf M, and Stone LS (2013) Peripheral nerve injury is associated with chronic, reversible changes in global DNA methylation in the mouse prefrontal cortex. PLoS One 8:e55259.

Tajerian M, Leu D, Zou Y, Sahbaie P, Li W, Khan H, Hsu V, Kingery W, Huang TT, Becerra L, et al. (2014) Brain neuroplastic changes accompany anxiety and memory deficits in a model of complex regional pain syndrome. Anesthesiology 121 852-865.

Tan LL, Pelzer P, Heinl C, Tang W, Gangadharan V, Flor H, Sprengel R, Kuner T, and Kuner R (2017) A pathway from midcingulate cortex to posterior insula gates nociceptive hypersensitivity. Nat Neurosci 20:1591-1601.

Tan ZY, Donnelly DF, and LaMotte RH (2006) Effects of a chronic compression of the dorsal root ganglion on voltage-gated $\mathrm{Na}+$ and $\mathrm{K}+$ currents in cutaneous afferent neurons. J Neurophysiol 95:1115-1123.

Taylor AM, Castonguay A, Taylor AJ, Murphy NP, Ghogha A, Cook C, Xue L, Olmstead MC, De Koninck Y, Evans CJ, et al. (2015) Microglia disrupt mesolimbic reward circuitry in chronic pain. J Neurosci 35:8442-8450.

Taylor AM, Mehrabani S, Liu S, Taylor AJ, and Cahill CM (2017) Topography of microglial activation in sensory- and affect-related brain regions in chronic pain. $J$ Neurosci Res 95:1330-1335.

Taylor CP (2009) Mechanisms of analgesia by gabapentin and pregabalin-calcium channel alpha2-delta [Cavalpha2-delta] ligands. Pain 142:13-16.

Taylor CP, Angelotti T, and Fauman E (2007) Pharmacology and mechanism of action of pregabalin: the calcium channel alpha2-delta (alpha2-delta) subunit as a target for antiepileptic drug discovery. Epilepsy Res 73:137-150.

Todd AJ (2010) Neuronal circuitry for pain processing in the dorsal horn. Nat Rev Neurosci 11:823-836.

Todd AJ (2017) Identifying functional populations among the interneurons in laminae I-III of the spinal dorsal horn. Mol Pain 13: DOI: 10.1177/1744806917693003.

Todorovic SM and Jevtovic-Todorovic V (2013) Neuropathic pain: role for presynaptic T-type channels in nociceptive signaling. Pflugers Arch 465:921-927.

Tong CK and MacDermott AB (2006) Both Ca2+-permeable and -impermeable AMPA receptors contribute to primary synaptic drive onto rat dorsal horn neurons. $J$ Physiol 575:133-144.

Torrance N, Ferguson JA, Afolabi E, Bennett MI, Serpell MG, Dunn KM, and Smith BH (2013) Neuropathic pain in the community: more under-treated than refractory? Pain 154:690-699.

Torrance N, Smith BH, Bennett MI, and Lee AJ (2006) The epidemiology of chronic pain of predominantly neuropathic origin: results from a general population survey. J Pain 7:281-289.

Torsney C (2011) Inflammatory pain unmasks heterosynaptic facilitation in lamina I neurokinin 1 receptor-expressing neurons in rat spinal cord. $J$ Neurosci 31: $5158-5168$

Torsney C and MacDermott AB (2006) Disinhibition opens the gate to pathological pain signaling in superficial neurokinin 1 receptor-expressing neurons in rat spinal cord. J Neurosci 26:1833-1843.

Toyomitsu E, Tsuda M, Yamashita T, Tozaki-Saitoh H, Tanaka Y, and Inoue K (2012) CCL2 promotes P2X4 receptor trafficking to the cell surface of microglia. Purinergic Signal 8:301-310

Tozaki-Saitoh H, Tsuda M, Miyata H, Ueda K, Kohsaka S, and Inoue K (2008) P2Y12 receptors in spinal microglia are required for neuropathic pain after peripheral nerve injury. J Neurosci 28:4949-4956.

Tran-Van-Minh A and Dolphin AC (2010) The alpha2delta ligand gabapentin inhibits the Rab11-dependent recycling of the calcium channel subunit alpha2delta-2. $J$ Neurosci 30:12856-12867.

Trang T, Beggs S, and Salter MW (2011) Brain-derived neurotrophic factor from microglia: a molecular substrate for neuropathic pain. Neuron Glia Biol 7:99-108.

Trang T, Beggs S, and Salter MW (2012) ATP receptors gate microglia signaling in neuropathic pain. Exp Neurol 234:354-361.

Trang T, Beggs S, Wan X, and Salter MW (2009) P2X4-receptor-mediated synthesis and release of brain-derived neurotrophic factor in microglia is dependent on calcium and p38-mitogen-activated protein kinase activation. $J$ Neurosci 29 $3518-3528$.

Treede R-D, Jensen TS, Campbell JN, Cruccu G, Dostrovsky JO, Griffin JW, Hansson P, Hughes R, Nurmikko T, and Serra J (2008) Neuropathic pain: redefinition and a grading system for clinical and research purposes. Neurology 70:1630-1635.
Trudeau LE, Fang Y, and Haydon PG (1998) Modulation of an early step in the secretory machinery in hippocampal nerve terminals. Proc Natl Acad Sci USA 95: $7163-7168$

Tsantoulas C, Mooney ER, and McNaughton PA (2016) HCN2 ion channels: basic science opens up possibilities for therapeutic intervention in neuropathic pain. Biochem J 473:2717-2736.

Tsantoulas C, Zhu L, Shaifta Y, Grist J, Ward JPT, Raouf R, Michael GJ, and McMahon SB (2012) Sensory neuron downregulation of the Kv9.1 potassium channel subunit mediates neuropathic pain following nerve injury. J Neurosci 32 : 17502-17513.

Vartanian MG, Radulovic LL, Kinsora JJ, Serpa KA, Vergnes M, Bertram E, and Taylor CP (2006) Activity profile of pregabalin in rodent models of epilepsy and ataxia. Epilepsy Res 68:189-205.

Vaso A, Adahan HM, Gjika A, Zahaj S, Zhurda T, Vyshka G, and Devor M (2014) Peripheral nervous system origin of phantom limb pain. Pain 155:1384-1391.

Ventéo S, Laffray S, Wetzel C, Rivat C, Scamps F, Méchaly I, Bauchet L, Raoul C, Bourinet E, Lewin GR, et al. (2016) Fxyd2 regulates Aס- and C-fiber mechanosensitivity and is required for the maintenance of neuropathic pain. Sci Rep 6:36407.

Vicuna L, Strochlic DE, Latremoliere A, Bali KK, Simonetti M, Husainie D, Prokosch S, Riva P, Griffin RS, and Njoo C, et al. (2015) The serine protease inhibitor serpinA3N attenuates neuropathic pain by inhibiting $\mathrm{T}$ cell-derived leukocyte elastase. Nat Med 21:518-523.

von Hehn CA, Baron R, and Woolf CJ (2012) Deconstructing the neuropathic pain phenotype to reveal neural mechanisms. Neuron 73:638-652.

Wall PD and Devor M (1983) Sensory afferent impulses originate from dorsal root ganglia as well as from the periphery in normal and nerve injured rats. Pain 17: 321-339.

Wall PD, Devor M, Inbal R, Scadding JW, Schonfeld D, Seltzer Z, and Tomkiewicz MM (1979) Autotomy following peripheral nerve lesions: experimental anaesthesia dolorosa. Pain 7:103-111.

Walsh CP, Davies A, Butcher AJ, Dolphin AC, and Kitmitto A (2009) Threedimensional structure of CaV3.1: comparison with the cardiac L-type voltage-gated calcium channel monomer architecture. J Biol Chem 284:22310-22321.

Walsh TJ and Smith JL (1968) Tegretol-a new treatment for tic douloureux. Headache 8:62-64.

Wang X, Ratnam J, Zou B, England PM, and Basbaum AI (2009) TrkB signaling is required for both the induction and maintenance of tissue and nerve injury-induced persistent pain. $J$ Neurosci 29:5508-5515.

Watkins LR and Maier SF (2002) Beyond neurons: evidence that immune and glial cells contribute to pathological pain states. Physiol Rev 82:981-1011.

Waxman SG, Cummins TR, Dib-Hajj SD, and Black JA (2000a) Voltage-gated sodium channels and the molecular pathogenesis of pain: a review. J Rehabil Res Dev 37: $517-528$.

Waxman SG, Dib-Hajj S, Cummins TR, and Black JA (1999) Sodium channels and pain. Proc Natl Acad Sci USA 96:7635-7639.

Waxman SG, Dib-Hajj S, Cummins TR, and Black JA (2000b) Sodium channels and their genes: dynamic expression in the normal nervous system, dysregulation in disease states (1). Brain Res 886:5-14.

Waxman SG and Zamponi GW (2014) Regulating excitability of peripheral afferents: emerging ion channel targets. Nat Neurosci 17:153-163.

Weng HR, Chen JH, and Cata JP (2006) Inhibition of glutamate uptake in the spinal cord induces hyperalgesia and increased responses of spinal dorsal horn neurons to peripheral afferent stimulation. Neuroscience 138:1351-1360.

West SJ, Bannister K, Dickenson AH, and Bennett DL (2015) Circuitry and plasticity of the dorsal horn-toward a better understanding of neuropathic pain. Neuroscience 300:254-275.

Westenbroek RE, Hoskins L, and Catterall WA (1998) Localization of Ca2+ channel subtypes on rat spinal motor neurons, interneurons, and nerve terminals. $J \mathrm{Neu}$ rosci 18:6319-6330

Wetzel C, Hu J, Riethmacher D, Benckendorff A, Harder L, Eilers A, Moshourab R, Kozlenkov A, Labuz D, Caspani O, et al. (2007) A stomatin-domain protein essential for touch sensation in the mouse. Nature 445:206-209.

Wetzel C, Pifferi S, Picci C, Gök C, Hoffmann D, Bali KK, Lampe A, Lapatsina L, Fleischer R, Smith ES, et al. (2017) Small-molecule inhibition of STOML3 oligomerization reverses pathological mechanical hypersensitivity. Nat Neurosci 20: 209-218.

White FA, Jung H, and Miller RJ (2007) Chemokines and the pathophysiology of neuropathic pain. Proc Natl Acad Sci USA 104:20151-20158.

Whittaker CA and Hynes RO (2002) Distribution and evolution of von Willebrand/ integrin A domains: widely dispersed domains with roles in cell adhesion and elsewhere. Mol Biol Cell 13:3369-3387.

Wolff M, Czorlich P, Nagaraj C, Schnöbel-Ehehalt R, Li Y, Kwapiszewska G, Olschewski H, Heschl S, and Olschewski A (2016) Amitriptyline and carbamazepine utilize voltage-gated ion channel suppression to impair excitability of sensory dorsal horn neurons in thin tissue slice: an in vitro study. Neurosci Res 109:16-27.

Woolf CJ (1983) Evidence for a central component of post-injury pain hypersensitivity. Nature 306:686-688

Woolf CJ and Mannion RJ (1999) Neuropathic pain: aetiology, symptoms, mechanisms, and management. Lancet 353:1959-1964.

Woolf CJ and Thompson SW (1991) The induction and maintenance of central sensitization is dependent on N-methyl-D-aspartic acid receptor activation; implications for the treatment of post-injury pain hypersensitivity states. Pain 44 293-299

Xiao HS, Huang QH, Zhang FX, Bao L, Lu YJ, Guo C, Yang L, Huang WJ, Fu G, Xu $\mathrm{SH}$, et al. (2002) Identification of gene expression profile of dorsal root ganglion in the rat peripheral axotomy model of neuropathic pain. Proc Natl Acad Sci USA 99 $8360-8365$.

Xiao W, Boroujerdi A, Bennett GJ, and Luo ZD (2007) Chemotherapy-evoked painful peripheral neuropathy: analgesic effects of gabapentin and effects on expression of the alpha-2-delta type-1 calcium channel subunit. Neuroscience 144:714-720. 
Xu J, Chu KL, Zhu CZ, Niforatos W, Swensen A, Searle X, Lee L, Jarvis MF, and McGaraughty S (2014) A mixed Ca2+ channel blocker, A-1264087, utilizes peripheral and spinal mechanisms to inhibit spinal nociceptive transmission in a rat model of neuropathic pain. $J$ Neurophysiol 111:394-404.

Xu ZZ, Kim YH, Bang S, Zhang Y, Berta T, Wang F, Oh SB, and Ji RR (2015) Inhibition of mechanical allodynia in neuropathic pain by TLR5-mediated A-fiber blockade. Nat Med 21:1326-1331.

Yaksh TL (1989) Behavioral and autonomic correlates of the tactile evoked allodynia produced by spinal glycine inhibition: effects of modulatory receptor systems and excitatory amino acid antagonists. Pain 37:111-123.

Yaksh TL, Fisher C, Hockman T, and Wiese A (2017) Current and future issues in the development of spinal agents for the management of pain. Curr Neuropharmacol 15:232-259.

Yan X and Weng HR (2013) Endogenous interleukin-1 $\beta$ in neuropathic rats enhances glutamate release from the primary afferents in the spinal dorsal horn through coupling with presynaptic N-methyl-D-aspartic acid receptors. $J$ Biol Chem 288: 30544-30557.

Yang F, Whang J, Derry WT, Vardeh D, and Scholz J (2014a) Analgesic treatment with pregabalin does not prevent persistent pain after peripheral nerve injury in the rat. Pain 155:356-366.

Yang Q, Wu Z, Hadden JK, Odem MA, Zuo Y, Crook RJ, Frost JA, and Walters ET (2014b) Persistent pain after spinal cord injury is maintained by primary afferent activity. J Neurosci 34:10765-10769.

Yang S, Xiao Y, Kang D, Liu J, Li Y, Undheim EA, Klint JK, Rong M, Lai R, and King GF (2013) Discovery of a selective NaV1.7 inhibitor from centipede venom with analgesic efficacy exceeding morphine in rodent pain models. Proc Natl Acad Sci USA 110:17534-17539.

Yang Y, Yang F, Yang F, Li CL, Wang Y, Li Z, Lu YF, Yu YQ, Fu H, He T, et al. (2016) Gabapentinoid insensitivity after repeated administration is associated with downregulation of the $\alpha(2) \delta-1$ subunit in rats with central post-stroke pain hypersensitivity. Neurosci Bull 32:41-50.

Yasaka T, Tiong SY, Hughes DI, Riddell JS, and Todd AJ (2010) Populations of inhibitory and excitatory interneurons in lamina II of the adult rat spinal dorsal horn revealed by a combined electrophysiological and anatomical approach. Pain 151:475-488.

Yasuda T, Chen L, Barr W, McRory JE, Lewis RJ, Adams DJ, and Zamponi GW (2004) Auxiliary subunit regulation of high-voltage activated calcium channels expressed in mammalian cells. Eur $J$ Neurosci 20:1-13.

Yekkirala AS, Roberson DP, Bean BP, and Woolf CJ (2017) Breaking barriers to novel analgesic drug development. Nat Rev Drug Discov 16:545-564.

Yen LD, Bennett GJ, and Ribeiro-da-Silva A (2006) Sympathetic sprouting and changes in nociceptive sensory innervation in the glabrous skin of the rat hind paw following partial peripheral nerve injury. J Comp Neurol 495:679-690.

Yilmaz E and Gold MS (2016) Paclitaxel-induced increase in NCX activity in subpopulations of nociceptive afferents: a protective mechanism against chemotherapy-induced peripheral neuropathy? Cell Calcium 60:25-31.

Yilmaz E, Watkins SC, and Gold MS (2017) Paclitaxel-induced increase in mitochondrial volume mediates dysregulation of intracellular $\mathrm{Ca} 2+$ in putative nociceptive glabrous skin neurons from the rat. Cell Calcium 62:16-28.

Young GT, Emery EC, Mooney ER, Tsantoulas C, and McNaughton PA (2014) In flammatory and neuropathic pain are rapidly suppressed by peripheral block of hyperpolarisation-activated cyclic nucleotide-gated ion channels. Pain 155: 1708-1719.

Yu C, Lin PX, Fitzgerald S, and Nelson P (1992) Heterogeneous calcium currents and transmitter release in cultured mouse spinal cord and dorsal root ganglion neurons. J Neurophysiol 67:561-575.

Yu XH, Ribeiro-da-Silva A, and De Koninck Y (2005) Morphology and neurokinin 1 receptor expression of spinothalamic lamina I neurons in the rat spinal cord [published correction appears in $J$ Comp Neurol (2005) 493:475]. J Comp Neurol 491:56-68.

Zakrzewska JM, Palmer J, Morisset V, Giblin GM, Obermann M, Ettlin DA, Cruccu G, Bendtsen L, Estacion M, Derjean D, et al.; Study Investigators (2017) Safety and efficacy of a Nav1.7 selective sodium channel blocker in patients with trigeminal neuralgia: a double-blind, placebo-controlled, randomised withdrawal phase 2a trial. Lancet Neurol 16:291-300.

Zamponi GW (2016) Targeting voltage-gated calcium channels in neurological and psychiatric diseases. Nat Rev Drug Discov 15:19-34

Zamponi GW, Striessnig J, Koschak A, and Dolphin AC (2015) The physiology, pathology, and pharmacology of voltage-gated calcium channels and their future therapeutic potential. Pharmacol Rev 67:821-870.

Zeilhofer HU, Acuña MA, Gingras J, and Yévenes GE (2017) Glycine receptors and glycine transporters: targets for novel analgesics? Cell Mol Life Sci [published ahead of print].

Zeilhofer HU, Benke D, and Yevenes GE (2012a) Chronic pain states: pharmacological strategies to restore diminished inhibitory spinal pain control. Annu Rev Pharmacol Toxicol 52:111-133.

Zeilhofer HU, Ralvenius WT, and Acuña MA (2015) Restoring the spinal pain gate: GABA(A) receptors as targets for novel analgesics. Adv Pharmacol 73:71-96.

Zeilhofer HU, Wildner H, and Yévenes GE (2012b) Fast synaptic inhibition in spinal sensory processing and pain control. Physiol Rev 92:193-235.

Zhang F, Mi Y, Qi JL, Li JW, Si M, Guan BC, Du XN, An HL, and Zhang HL (2013) Modulation of $\mathrm{K}(\mathrm{v}) 7$ potassium channels by a novel opener pyrazolo[1,5-a]pyrimidin-7(4H)-one compound QO-58. Br J Pharmacol 168:1030-1042.

Zhang $\mathrm{H}$ and Dougherty PM (2011) Acute inhibition of signalling phenotype of spinal GABAergic neurons by tumour necrosis factor-alpha. J Physiol 589:4511-4526.

Zhang Q, Xia Z, Joshi S, Scott VE, and Jarvis MF (2015a) Optimization of ADME properties for sulfonamides leading to the discovery of a T-type calcium channel blocker, ABT-639. ACS Med Chem Lett 6:641-644.

Zhang S, Yang L, Zhang K, Liu X, Dai W, Zhang C, Yong Z, Li J, and Zheng J (2015b) ZC88, a novel N-type calcium channel blocker from 4-amino-piperidine derivatives state-dependent inhibits Cav2.2 calcium channels. Brain Res 1605:12-21.

Zhang X, Bao L, Shi TJ, Ju G, Elde R, and Hökfelt T (1998) Down-regulation of mu-opioid receptors in rat and monkey dorsal root ganglion neurons and spinal cord after peripheral axotomy. Neuroscience 82:223-240.

Zhang Z, Gadotti VM, Chen L, Souza IA, Stemkowski PL, and Zamponi GW (2015c) Role of prelimbic GABAergic circuits in sensory and emotional aspects of neuropathic pain. Cell Reports 12:752-759.

Zhao J, O'Leary ME, and Chahine M (2011) Regulation of Nav1.6 and Nav1.8 peripheral nerve $\mathrm{Na}+$ channels by auxiliary $\beta$-subunits. $J$ Neurophysiol 106:608-619.

Zhou C and Luo ZD (2014) Electrophysiological characterization of spinal neuron sensitization by elevated calcium channel alpha-2-delta-1 subunit protein. Eur $J$ Pain 18:649-658.

Zhou C and Luo ZD (2015) Nerve injury-induced calcium channel alpha-2-delta-1 protein dysregulation leads to increased pre-synaptic excitatory input into deep dorsal horn neurons and neuropathic allodynia. Eur J Pain 19:1267-1276.

Zhu CZ, Vortherms TA, Zhang M, Xu J, Swensen AM, Niforatos W, Neelands T, Milicic I, Lewis LG, Zhong C, et al. (2014) Mechanistic insights into the analgesic efficacy of A-1264087, a novel neuronal $\mathrm{Ca}(2+)$ channel blocker that reduces nociception in rat preclinical pain models. J Pain 15:387.e1-387.e14.

Zhuo M (2008) Cortical excitation and chronic pain. Trends Neurosci 31:199-207.

Zhuo M (2016a) Contribution of synaptic plasticity in the insular cortex to chronic pain. Neuroscience 338:220-229.

Zhuo M (2016b) Neural mechanisms underlying anxiety-chronic pain interactions. Trends Neurosci 39:136-145.

Zorina-Lichtenwalter K, Meloto CB, Khoury S, and Diatchenko L (2016) Genetic predictors of human chronic pain conditions. Neuroscience 338:36-62. 